\title{
Development of a Synthetic Pathway Toward a Bowl-Shaped C 27H12 Polycyclic Aromatic Hydrocarbon
}

\author{
Yang-Sheng Sun \\ West Virginia University
}

Follow this and additional works at: https://researchrepository.wvu.edu/etd

\section{Recommended Citation}

Sun, Yang-Sheng, "Development of a Synthetic Pathway Toward a Bowl-Shaped C 27H12 Polycyclic Aromatic Hydrocarbon" (2013). Graduate Theses, Dissertations, and Problem Reports. 5004.

https://researchrepository.wvu.edu/etd/5004

This Thesis is protected by copyright and/or related rights. It has been brought to you by the The Research Repository @ WVU with permission from the rights-holder(s). You are free to use this Thesis in any way that is permitted by the copyright and related rights legislation that applies to your use. For other uses you must obtain permission from the rights-holder(s) directly, unless additional rights are indicated by a Creative Commons license in the record and/ or on the work itself. This Thesis has been accepted for inclusion in WVU Graduate Theses, Dissertations, and Problem Reports collection by an authorized administrator of The Research Repository @ WVU. For more information, please contact researchrepository@mail.wvu.edu. 


\title{
Development of a Synthetic Pathway Toward a Bowl-Shaped $\mathrm{C}_{27} \mathrm{H}_{12}$ Polycyclic Aromatic Hydrocarbon
}

\author{
Yang-Sheng Sun
}

Thesis submitted to the Eberly College of Arts and Sciences at West Virginia University in partial fulfillment of the requirements

for the degree of

\author{
Master of Science \\ in \\ Chemistry
}

Kung K. Wang, Ph. D., Chair

Jeffrey L. Petersen, Ph.D.

Björn C. Söderberg, Ph. D.

Department of Chemistry

Morgantown, West Virginia

2013

Keywords: Enyne-Allene, Schmittel Cyclization, Buckybowl Copyright 2013 Yang-Sheng Sun 


\section{ABSTRACT \\ Development of a Synthetic Pathway Toward a Bowl-Shaped $\mathrm{C}_{27} \mathrm{H}_{12}$ Polycyclic Aromatic Hydrocarbon}

\section{Yang-Sheng Sun}

Bowl-shaped and basket-shaped polycyclic aromatic hydrocarbons (PAHs) have attracted considerable attention in recent years. They are challenging targets for total synthesis due to the presence of substantial strain energy in the curved structures. A solution-phase synthesis of a bowl-shaped polycyclic aromatic hydrocarbon $\mathrm{C}_{27} \mathrm{H}_{12}$ was explored. The use of the casecade radical cyclization reactions of a benzannulated enyne-allene is a key feature of this synthetic pathway. The mild reaction conditions provide efficient and flexible designs for bowlshaped and basked-shaped PAHs and their precursors. Our proposed synthesis strategy for the bowl-shaped $\mathrm{C}_{27} \mathrm{H}_{12}$ involves an initial synthesis of a benzannulated enediynyl propargylic alcohols followed by the cascade cyclization reactions of the resulting enyne-allenes. The use of the palladium-catalyzed intramoleular arylation reactions is proposed as a key step leading to the final products. Specifically, transformation of 1-indanone to a key intermediate, 2-methoxy-2-(2methoxyethyl)-1-indanone, was extensively investigated, and the conditions for forming 1-(2ethynylphenyl)-2-(2,6-dichlorophenyl)ethyne via the Sonogashira reaction were established. Condensation between the 1-indanone and the ethynyl derivatives produced the benzannulated enediynyl propargylic alcohol. Chlorinated PAHs as potential precursors leading to the bowlshpaed $\mathrm{C}_{27} \mathrm{H}_{12}$ hydrocarbon have been successfully synthesized. 


\title{
DEDICATED TO
}

\author{
My Parents \\ Jin-que Fang and Si-yan Sun
}




\section{ACKNOWLEDGEMENTS}

I would like to express my sincere gratitude to my advisor Dr. Kung Wang for his guidance, encouragement, and continuous support. He has inspired and advised me to grow intellectually and technically in organic research areas. He has never ceased to teach and inspire me to be a better scientist and person. I am very proud and grateful to be his student. I am grateful to my advisory committee, Dr. Jeffrey L. Petersen and Dr. Björn C. Söderberg for their advice, patience, and kindness.

My special thanks go to Dr. Novruz Akhmedov for his help and support in NMR and Mass Spectroscopy. I acknowledge the financial support of the Department of Chemistry at West Virginia University.

I would also like to thank my group members, past and present, for their support and friendship. Particularly I am indebted to Mr. Chi-Yuan Tseng for his help and valuable discussions in the lab.

I thank my parents and my wife, Hui-Ju Hung, and my daughter Christine for their everlasting love and encouragement. Without their unconditional support, I could not come this far. 


\section{TABLE OF CONTENTS}

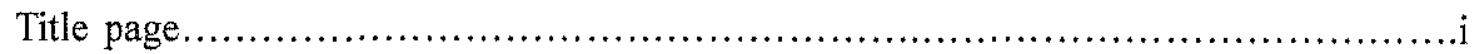

Abstract............................................................................

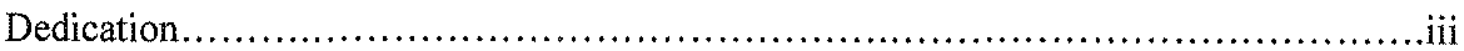

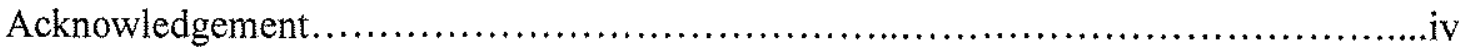

Table of Contents................................................................

List of Schemes............................................................ vi

List of Figures...............................................................

List of Tables................................................................ vii

List of $1 \mathrm{H}$ and $13 \mathrm{C}$ NMR Spectra.............................................

\section{Chapter 1 PRELUDE..............................................................................1}

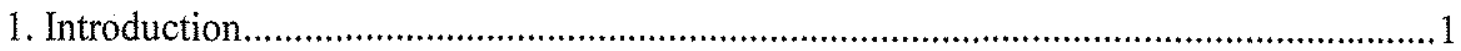

2. Literature survey for the synthsis of buckybowls .................................................4

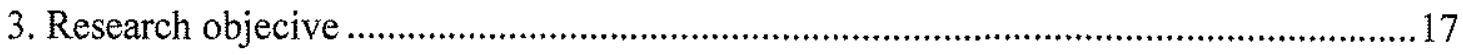

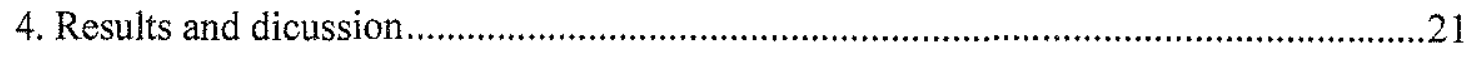

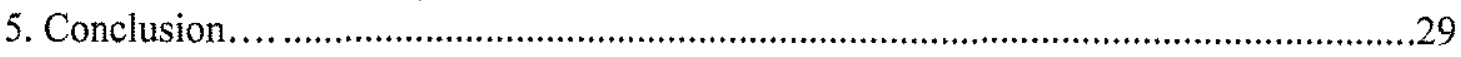

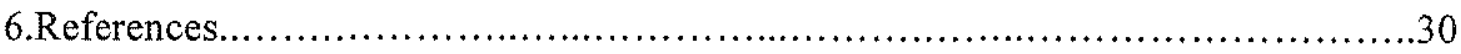

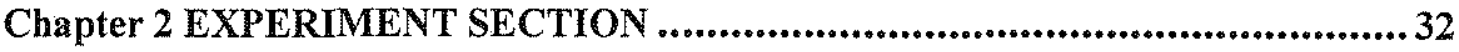

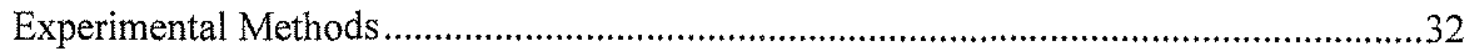

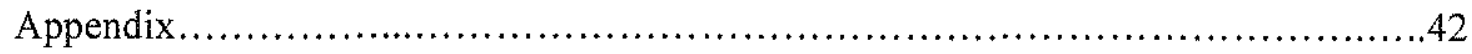

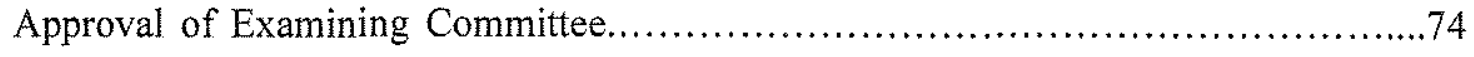




\section{LIST OF SCHEMES}

Scheme 1 Synthesis pathways of corannulene by Barth and Lawton....................

Scheme 2 Corannulene prepared by FVP pathways.....................................

Scheme 3 Other fullerene fragments prepared by FVP ..............................5

Scheme 4 Larger fragments prepared by FVP..............................................6

Scheme 5 Synthesis of dimethylcorannulene by the Siegel group $\ldots \ldots \ldots \ldots \ldots \ldots \ldots \ldots . .7$

Scheme 6 Improved synthetic procedures by Rabideau's group..............................7

Scheme 7 Palladium-catalyzed formation of buckybowls.............................8

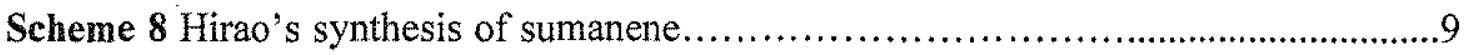

Scheme 9 Sakurai's synthesis of chiral sumanene .....................................................10

Scheme 10 Schmittel cyclization reaction......................................10

Scheme 11 Twisted polycyclic compounds synthesized via benzannulated enyene-

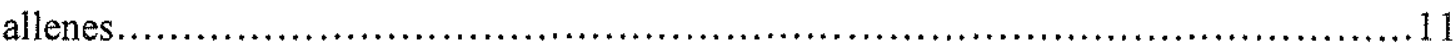

Scheme 12 An alternative synthetic pathway for twisted polycyclic aromatic hydrocarbons.

Scheme 13 Synthesis of buckybowls 1.52 and 1.55 via benzannulated enyne-allenes.....12

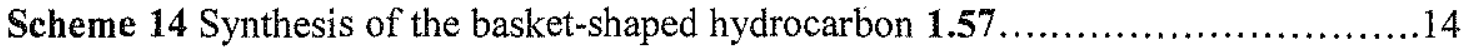

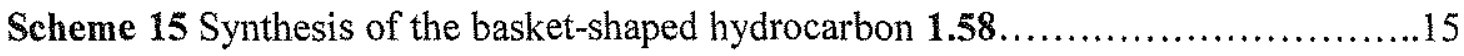

Scheme 16 Synthesis of PAH 1.56.......................................... 18

Scheme 17 Alternative synthetic pathway to the bowl-shaped PAHs $1.67 \ldots \ldots \ldots \ldots . . .19$

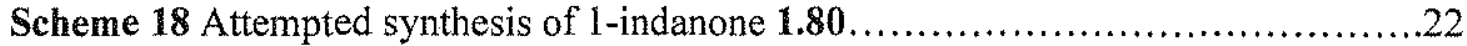

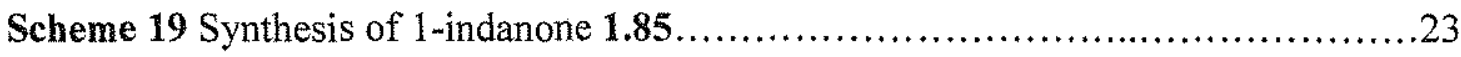

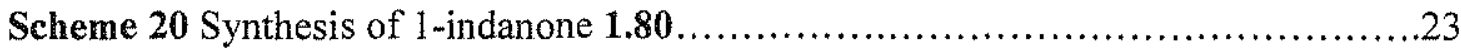

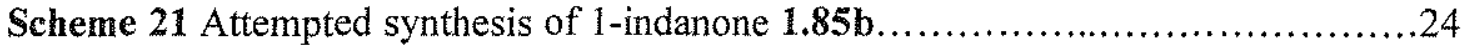

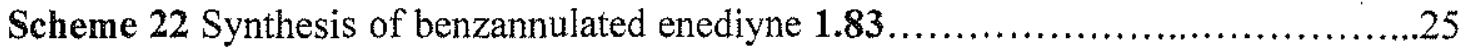

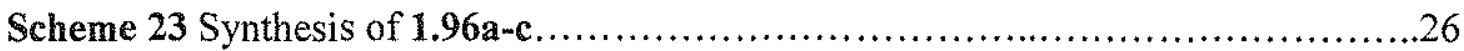

Scheme 24 Synthesis of compound 1.97 ............................................................27

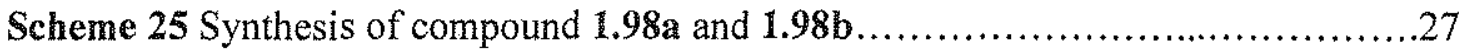

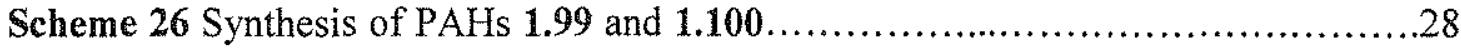




\section{LIST OF FIGURES}

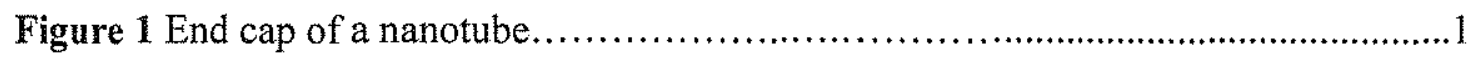

Figure 2 Fullerene fragments potential ligands in asymmetric catalysis..................2

Figure 3 Solution phase synthesis of fullerene fragments.............................

Figure 4 POAV pyramidalization angles $\left(\theta_{\sigma \pi}-90\right)$ of PAHs.......................

Figure 5 Fullerene fragments prepared from benzannulated enyne-allenes...............13

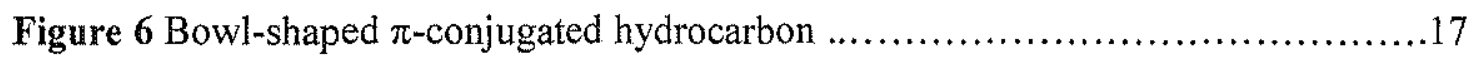

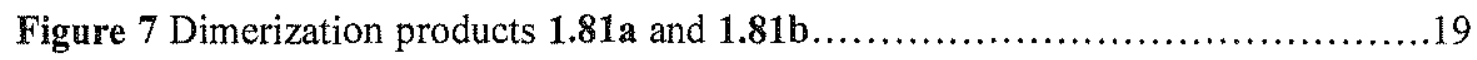

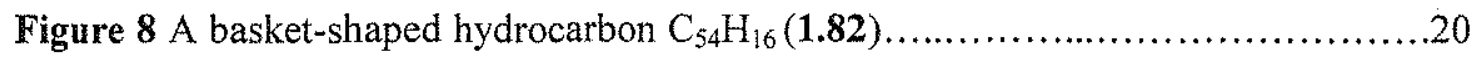

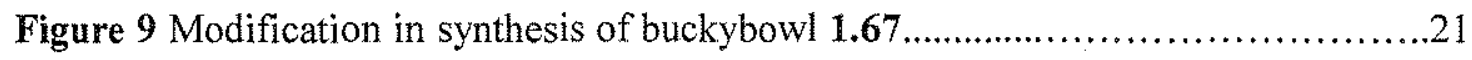

\section{LIST OF TABLES}

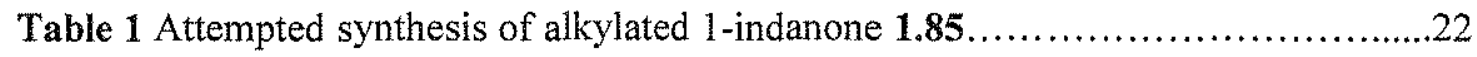

\section{LIST OF ${ }^{1} \mathrm{H}$ AND ${ }^{13} \mathrm{C}$ NMR SPECTRA}

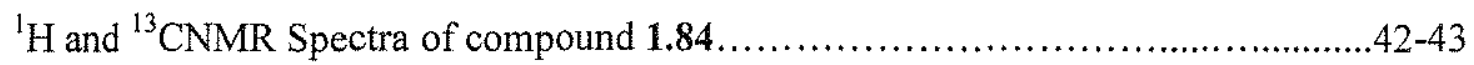

${ }^{1} \mathrm{H}$ and ${ }^{13} \mathrm{CNMR}$ Spectra of compound 1.85 ...................................44-45

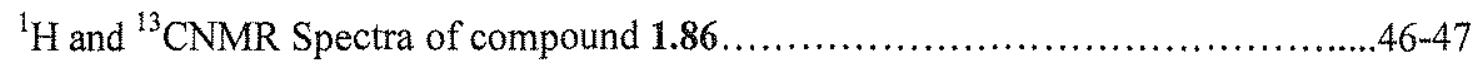

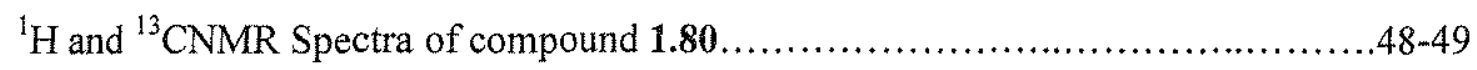

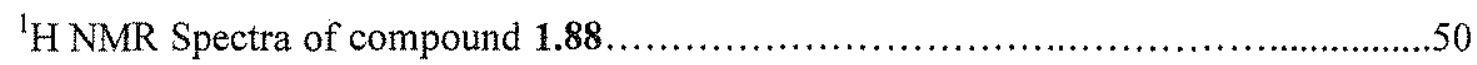

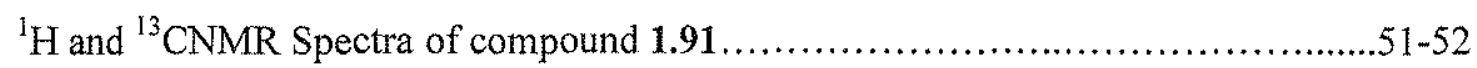

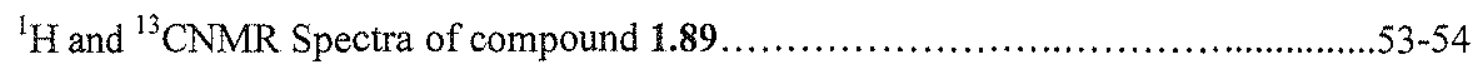

${ }^{1} \mathrm{H}$ and ${ }^{13} \mathrm{CNMR}$ Spectra of compound 1.92 ........................................55-56

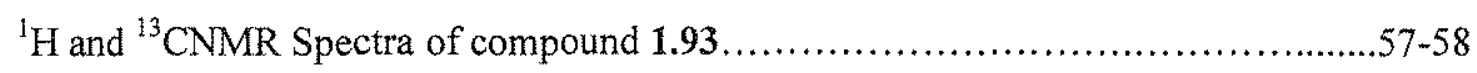

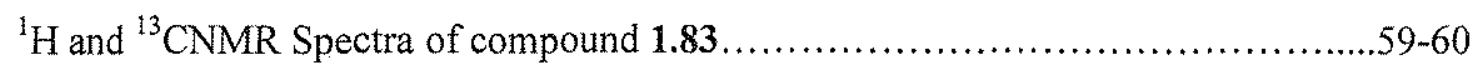

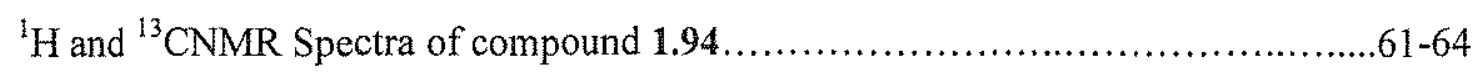

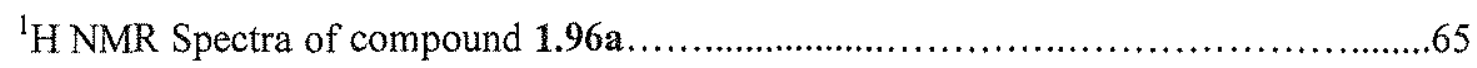




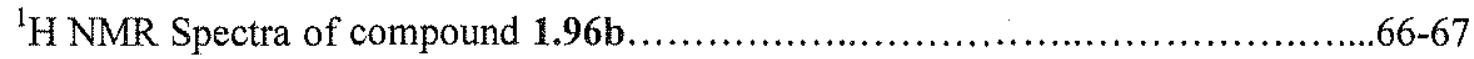

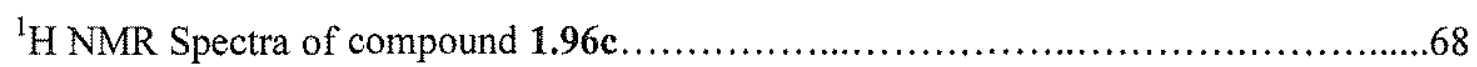

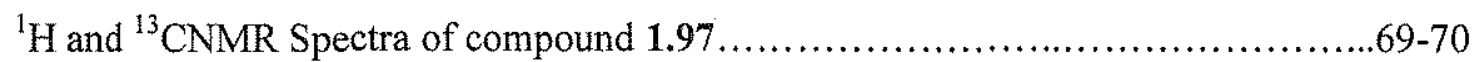

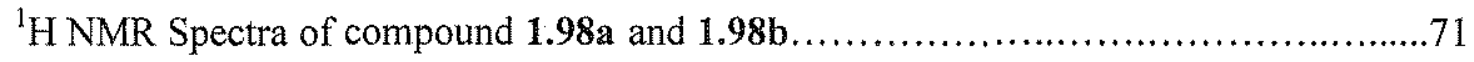

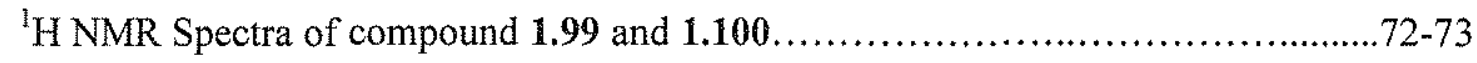




\section{Chapter 1}

\section{Development of a Synthetic Pathway Toward a Bowl-Shaped $\mathrm{C}_{27} \mathrm{H}_{12}$ Polycyclic Aromatic Hydrocarbon}

\section{Introduction}

Fullerenes are referred to as molecules that are completely comprised of carbon atoms. With the discovery of buckminsterfullerene, $\mathrm{C}_{60}$, in 1985, researches involving fullerenes and other related compounds have been intensely explored. ${ }^{1-3}$ Along with this enormous attraction toward fullerenes, polycyclic aromatic hydrocarbons (PAHs) containing the bowl-shaped or basket-shaped fragments have also received significant attention from scientists. ${ }^{4}$ These compounds, also known as buckybowls or buckybaskets, present an opportunity toward further research regarding carbon nanotubes, in that the fullerene fragments would serve as the end caps of nanotubes (Figure 1). ${ }^{5,6}$

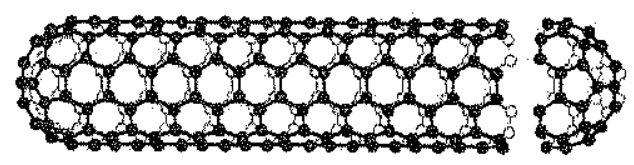

Figure 1. End cap of a nanotube

Several buckybowls that have been synthesized and investigated are shown below (Figure 2). The smallest fullerene fragment showing a significant curvature is $\mathrm{C}_{20} \mathrm{H}_{10}$, which is also known as corannulene. It was first synthesized in 1966, two decades prior to the discovery of $\mathrm{C}_{60} \cdot{ }^{7,8}$ More recently, corannulene has produced in large quantities via flash vaccum pyrolysis (FVP) developed in the early 1990s. In addition, various other buckybowls have since been prepared by both FVP and solution-phase methods. Specific types of these polycyclic aromatic hydrocarbons are presented as follows: sumanene $\left(\mathrm{C}_{21} \mathrm{H}_{12}\right)$, acecorannulene $\left(\mathrm{C}_{22} \mathrm{H}_{10}\right)$, tetrabenzopyracylene $\left(\mathrm{C}_{26} \mathrm{H}_{12}\right)$, and $[5,5]$ circulene $\left(\mathrm{C}_{30} \mathrm{H}_{12}\right)$. The carbon frameworks of these 
buckybowls can be mapped onto the surface of $\mathrm{C}_{60}$, and research on buckybowl derivatives are being actively pursued today.

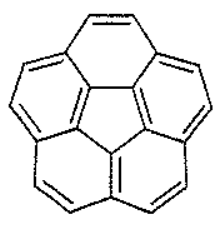

$\mathrm{C}_{20} \mathrm{H}_{10}$ corannulene

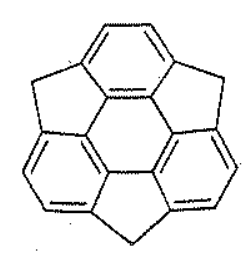

$\mathrm{C}_{21} \mathrm{H}_{12}$ sumanene

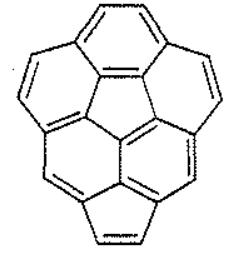

$\mathrm{C}_{22} \mathrm{H}_{10}$ acecorannulene

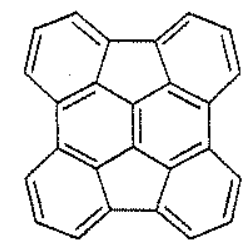

$\mathrm{C}_{26} \mathrm{H}_{12}$

tetrabenzopyracylene

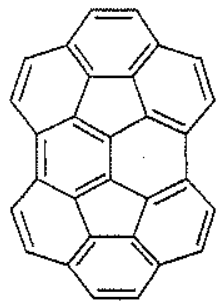

$\mathrm{C}_{30} \mathrm{H}_{12}$

$[5,5]$ circulene

Figure 2. Fullerene fragments

Since curved buckybowls have strain energy caused by pyramidalization of interior $\mathrm{sp}^{2}$ hybridized carbon atoms, successful methods for buckybowls synthesis must be able to overcome the high degree of the strain energy. Even though there are the thousands of literature related to buckybowls today, only few approaches can be utilized for their production. Flash vacuum pyrolysis (FVP) and solution-phase synthesis are the two major methods for the preparation of these curved PAHs. The FVP method has found success in the construction of a large number of fullerene fragments. However, several drawbacks are present for FVP method. First, the fullerene fragments with a delicate functional group may not survive under high temperature $\left(900^{\circ} \mathrm{C}\right.$ or higher). Second, the yields of the highly strained PAHs are usually very low $(<5 \%)$, and unwanted thermal rearrangement products can occur., ${ }^{4,9}$

To overcome these shortcomings, milder solution phase methods have been actively pursued. Several efficient nonpyrolytic methods were developed, including the transition metal (Ti-V, Ni, Pd)-catalyzed intramolecular reductive coupling of aryl, benzyl, or benzylidene 
halides. ${ }^{10-14}$ In addition, our group first reported the synthesis of several bowl-shaped and basketshaped fullerene fragments via benzannulated enyne-allenes. ${ }^{15}, 16$ With the milder reaction conditions, it is possible for scale-up production and a wide range of functional groups can be tolerated (Figure 3).

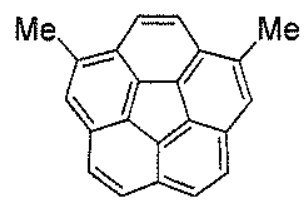

1.1

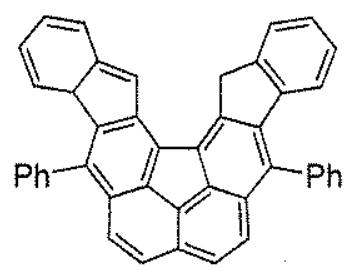

1.5

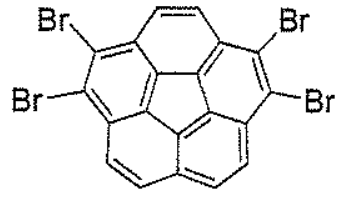

1.2

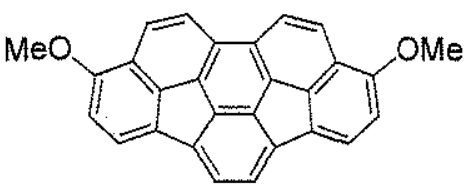

1.6

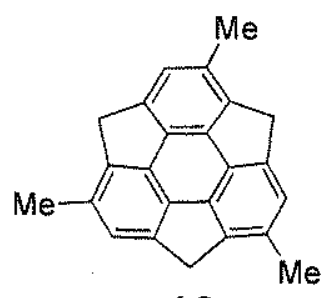

1.3

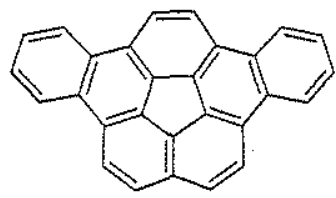

1.4

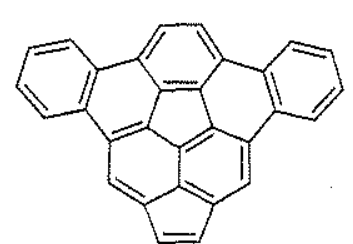

1.7

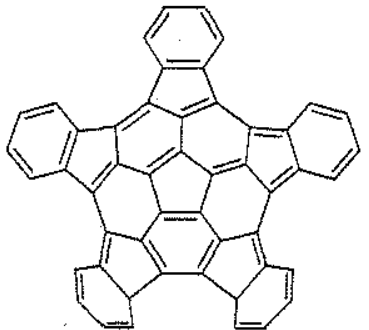

1.8

Figure 3. Solution phase synthesis of fullerene fragments 


\section{Literature survey for the synthesis of buckybowls}

The first solution-phase synthesis of the smallest buckybowl, corannulene, was first reported Barth and Lawton in 1966 (Scheme 1) ${ }^{7,17}$ This pioneer synthesis also demonstrated that even though curved buckybowls have high degree of strain energy, they can be synthesized by mild solution phase reactions. Even though synthetic route was lengthy with 17 steps, it did open the gate for further research in this area.

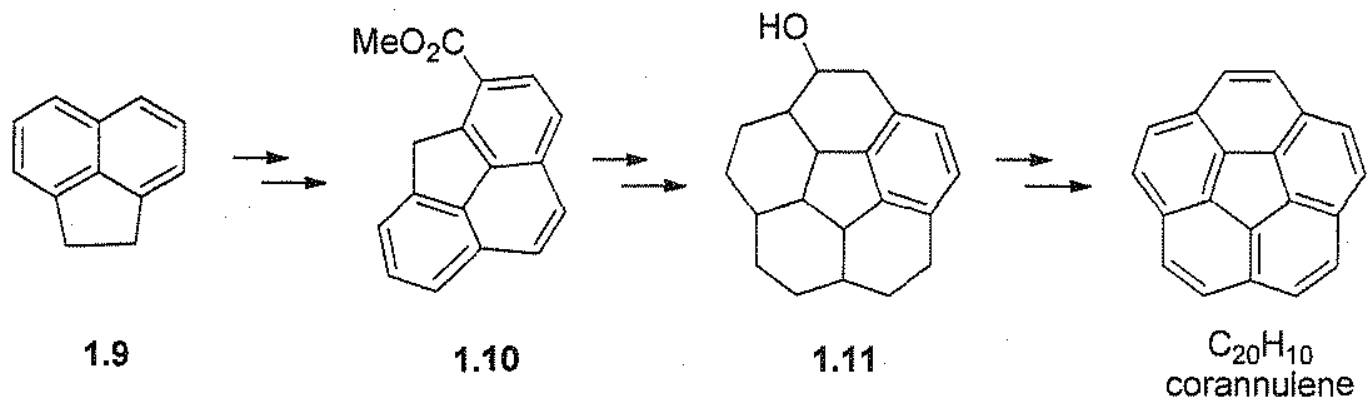

Scheme 1. Synthesis pathways of corannulene by Barth and Lawton

In the early 1990s, several examples of corannulene synthesis in moderate yields by FVP were reported. Scott's group first used diethynylfluoranthene $\mathbf{1 . 1 2}$ for the synthesis of corannulene by FVP (Scheme 2). ${ }^{18}$ An improvement to $35-40 \%$ overall yield was achieved by using bis(1-chlorovinyl)fluoranthene $\mathbf{1 . 1 3}$ to avoid polymerization of 1.12 at elevated temperatures. ${ }^{19}$

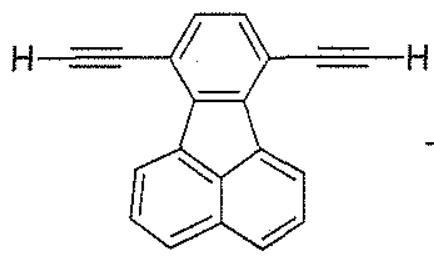

1.12

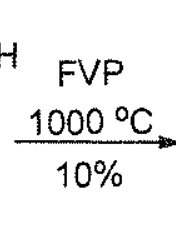

corannulene<smiles>C=C(Cl)c1ccc(C(=C)Cl)c2c1-c1cccc3cccc-2c13</smiles>

1.13

Scheme 2. Corannulene prepared by FVP pathways 
After the successful synthesis of corannulene by the FVP method, several other fullerene fragments have also been prepared from various precursors. For example, acecorannulene, tetrabenzopyracylene, and $[5,5]$ circulene were all obtained in reasonable yields by using the FVP method (Scheme 3). ${ }^{20-23}$

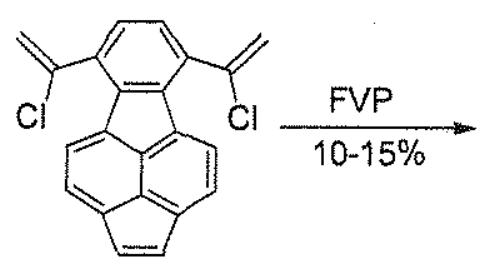

1.14

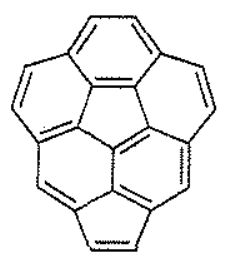

$\mathrm{C}_{22} \mathrm{H}_{10}$ acecorannulene

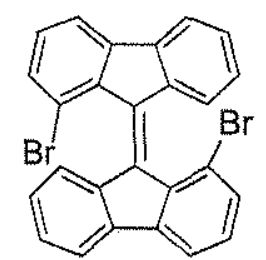

1.15

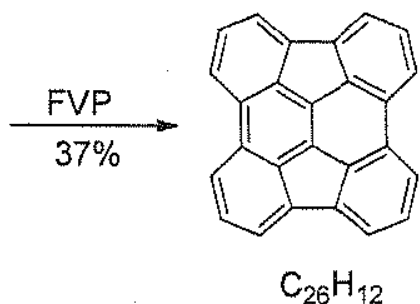

tetrabenzopyracylene

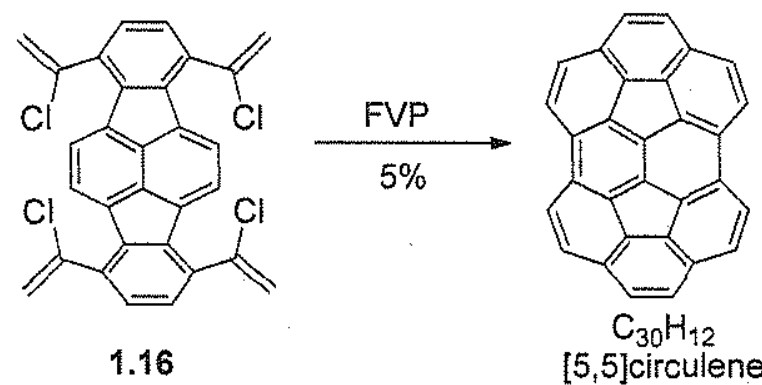

Scheme 3. Other fullerene fragments prepared by FVP

In addition, pyrolysis of precursors 1.17 and 1.19 produced semibuckyminsterfullerenes 1.18 and 1.20 , respectively (Scheme 4). ${ }^{22,}{ }^{23}$ These successful examples show that enough thermal energy can be delivered to the molecules to cross the high energy barriers during intramolecular ring closures. 


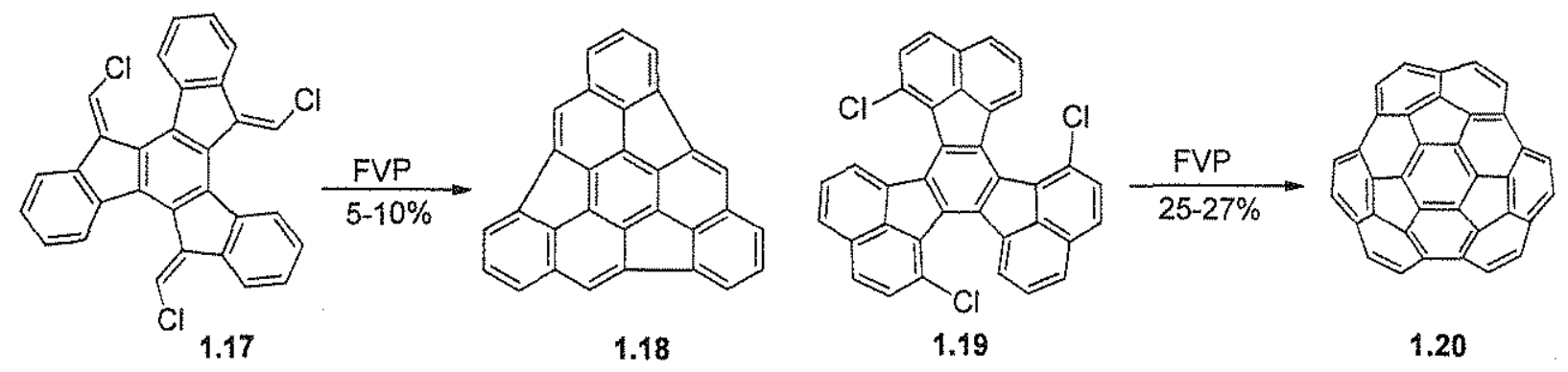

Scheme 4. Larger fragments prepared by FVP

While a number of fullerene fragments have been successfully prepared by the FVP method, several drawbacks limit the scope of the method. One major disadvantage with several of the FVP procedures is the low yields of the products, especially for higher molecular weight buckybowls. Other limitations include lack of functional group tolerance, difficulty in scaling up, byproducts caused by high temperature, and thermal rearrangement of molecular framework.

The report of the solution phase synthesis of corannulene did not attract a lot of attention for many years because of the length of the procedure and extremely low overall yield $(<1 \%)$. Until the discovery of $\mathrm{C}_{60}$ at 1985 , corannulene was known as the only bowl-shaped polynuclear aromatic hydrocarbon. Siegel and co-workers published the first example of a corannulene derivative prepared entirely by a solution-phase synthesis in 1996 (Scheme 5). ${ }^{24}$ Tetrabromide 1.22 was first treated with a reductive coupling reagent $\left(\mathrm{TiCl}_{3} / \mathrm{LiAlH}_{4}\right)$ and the resulting 1.23 then oxidized by DDQ to promote dehydrogenation for aromatization to form 1.24 in acceptable yield. 


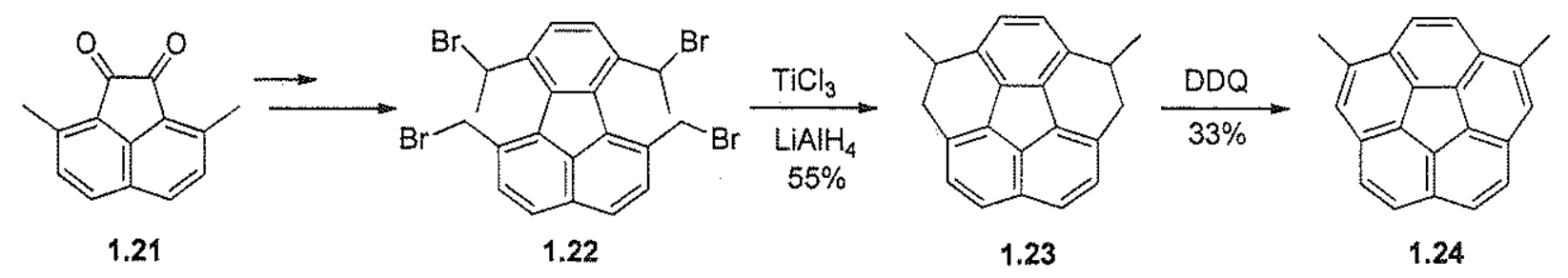

Scheme 5. Synthesis of dimethylcorannulene by the Siegel group

Rabideau's group successfully employed a similar strategy using 1.26 in conjunction with low-valent vanadium and obtained $70-75 \%$ yield of corannulene in a single step (Scheme 6$).{ }^{11}$ Further improvement using a simple and inexpensive way to prepare tetrabromocorannulene 1.27. in excellent yield (83\%) was reported later by the same group. ${ }^{25-27}$

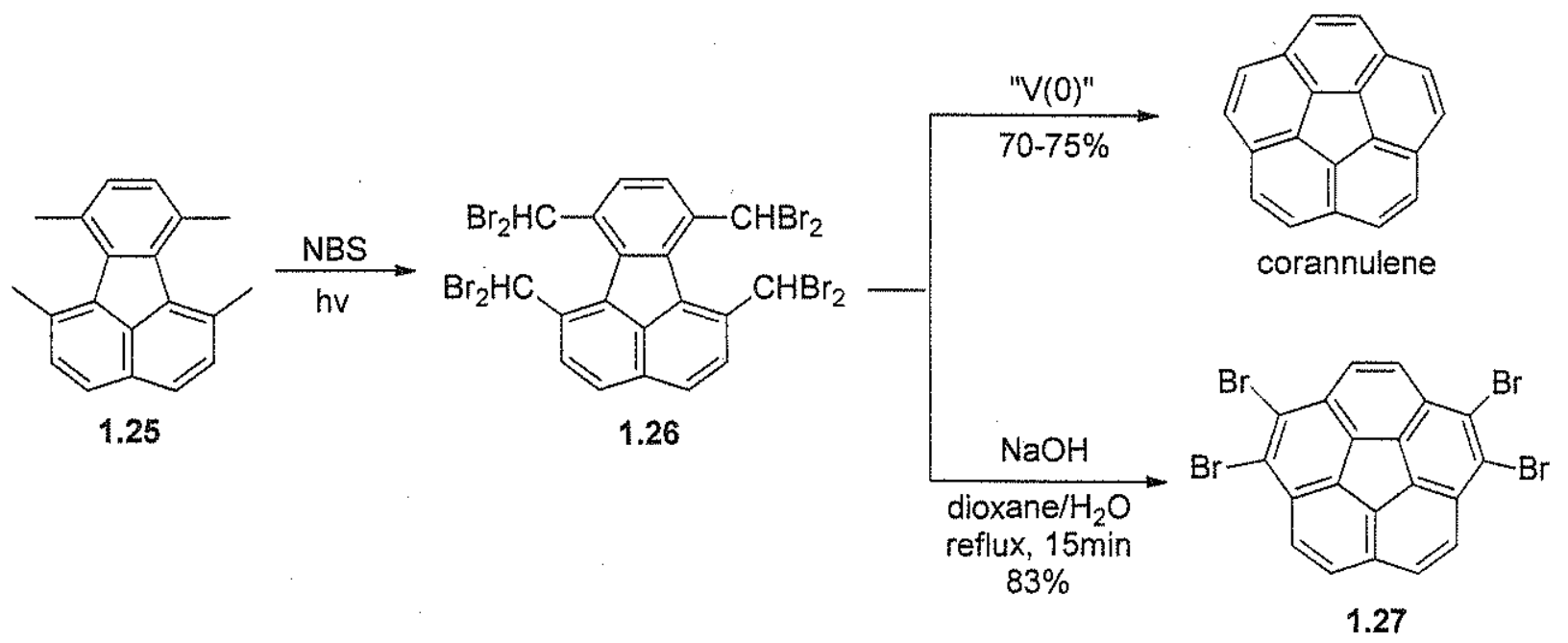

Scheme 6. Improved synthetic procedures by Rabideau's group

Several groups reported the synthesis of strained bowl-shaped fullerne fragments by emplying palladium-catalyzed intramolecular arylation reactions (Scheme7). These PAHs were generated by various palladium catalysts, bases, and reaction conditions. For example, Scott's group found that intramolecular arylation of dibromide 1.28 produced dibenzocorannulene 1.4 in $60 \%$ yield after $72 \mathrm{~h}$ at $150{ }^{\circ} \mathrm{C}$ using $\mathrm{Pd}\left(\mathrm{PPh}_{3}\right)_{2} \mathrm{Br}_{2}$ as the catalyst in the presence of $1,8-$ 
diazabicyclooundec-7-ene (DBU) in DMF. In addition, other groups reported that PAHs $\mathbf{1 . 6}$ and 1.7 were prepared using $\mathrm{Pd}\left(\mathrm{PCy}_{3}\right)_{2} \mathrm{Cl}_{2}$ with $\mathrm{DBU}$ in DMAc. Moreover, the Scott's group prepared pentaindenocorannulene 1.8 via microwave-assisted arylation from the corresponding halogenated corannulenes in $45 \mathrm{~min}$.

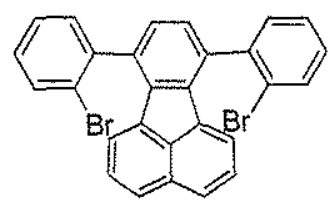

1.28

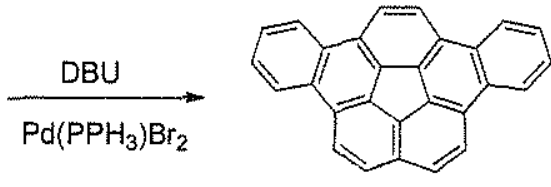

1.4

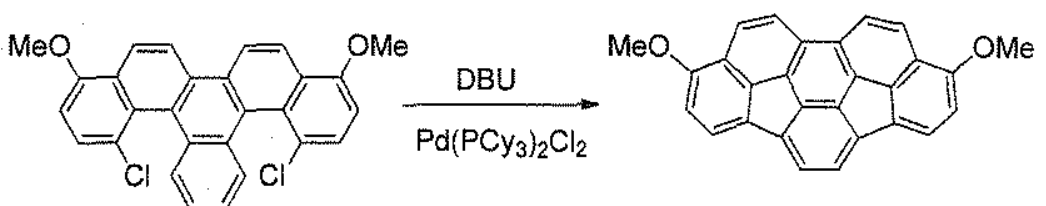

1.29

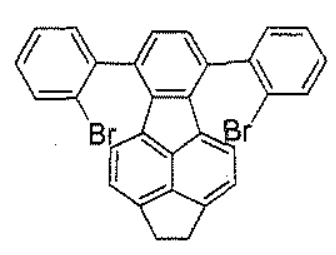

1.30

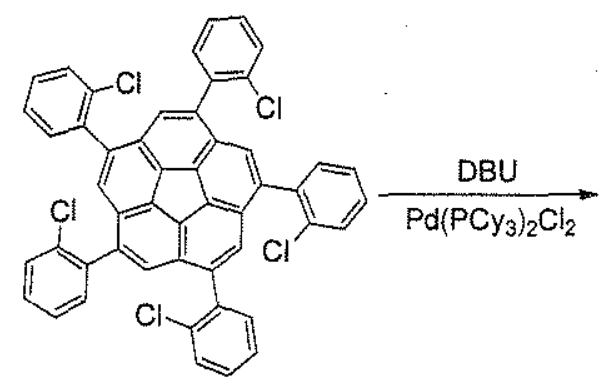

1.31
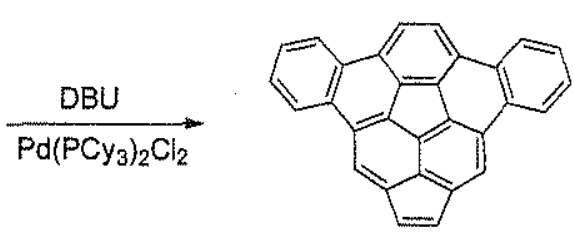

1.7

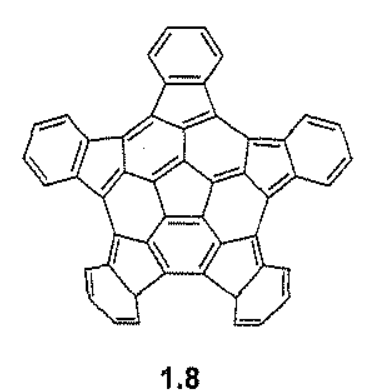

1.8

Scheme 7. Palladium-catalyzed formation of buckybowls

Sumanene $\left(\mathrm{C}_{21} \mathrm{H}_{12}\right)$ possesses a $\mathrm{C}_{3 \mathrm{v}}$ symmetry and represents the fundamental structure motif of buckminsterfullerene. The FVP method is yet unknown for obtaining this structure. In 2003, Hirao et al. provided a successful synthetic method to prepare sumanene in solution under mild conditions. ${ }^{28}$ Similar to other synthetic strategy for corannulene, they first constructed the three- 
dimensional framework using tetrahedral $\mathrm{sp}^{3}$ carbons and later aromatized the structure oxidatively to obtain the designed product. Norborandiene 1.32 was first treated with $\mathrm{Bu}_{3} \mathrm{SnCl}$ to form trimer products $s y n-1.33 \mathrm{a}$ and anti-1.33b (ratio 1:3) in a total yield of $47 \%$ (Scheme 8). Syn-1.33a was then reacted with a Ru-catalyst to afford 1.34 in $30 \%$ yield via a ring-opening and ring-closing metathesis reaction sequence. By oxidization of 1.34 with $\mathrm{DDQ}$, sumanene can be obtained in $70 \%$ yield. $^{28}$
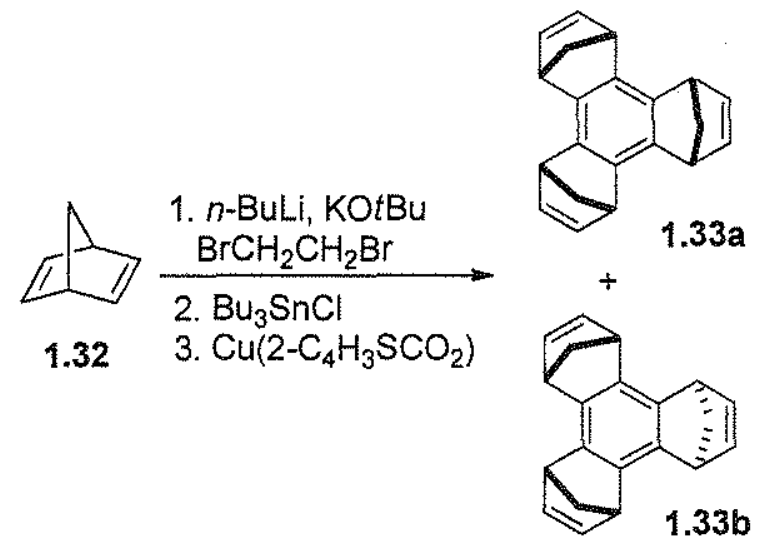

$(1.33 a: 1.33 b=1: 3)$
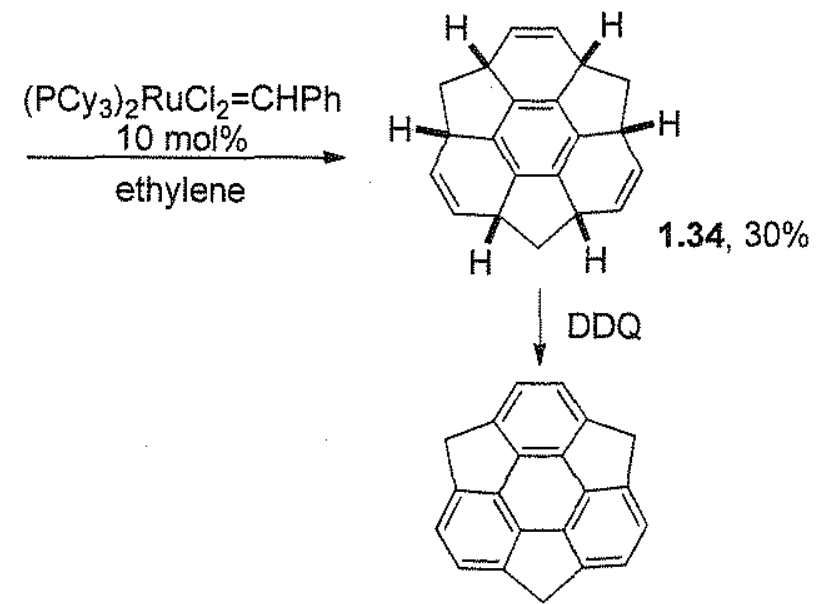

sumanene, $70 \%$

Scheme 8. Hirao's synthesis of sumanene

The first asymmetric synthesis of a chiral trimethylsumanene 1.38 in a non-pyrolytic pathway was reported by the Sakurai's group in 2008. A similar synthetic course was utilized via a syn-selective trimerization of an enantiopure halonorbornene 1.35, ring-opening/closing olefin metathesis reactions, and DDQ oxidation at low temperature (Scheme 9) ${ }^{29}$ 


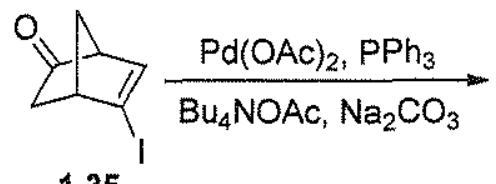

1.35
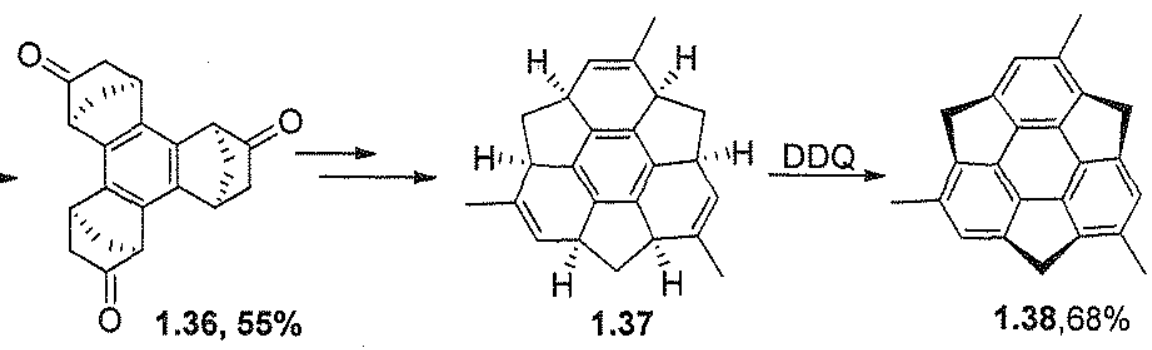

$1.38,68 \%$

Scheme 9. Sakurai's synthesis of chiral sumanene

Our group has developed successful pathways to synthesize curved PAHs via benzannulated enyne-allenes. The key reaction of our synthetic schemes involves a biradicalforming $\mathrm{C} 2-\mathrm{C} 6$ cyclization (Schmittel cyclization) reaction of the benzannulated enyne-allenes, such as 1.39 , to form the corresponding biradicals, such as 1.40 , followed by an intramolecular radical-radical coupling to form the Diels-Alder adducts as depicted in $\mathbf{1 . 4 1}$. Benzofluorene 1.42 was obtained after a prototropic rearrangement (Scheme 10$).^{30,31}$

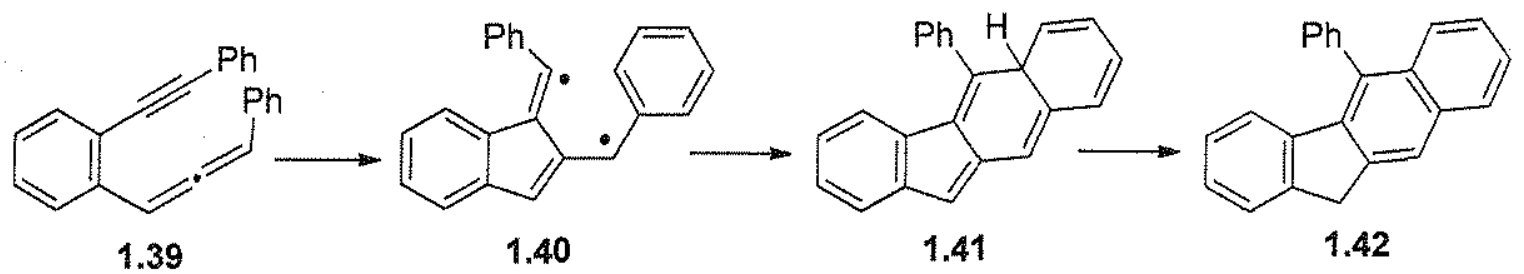

Scheme 10. Schmittel cyclization reaction

Several highly twisted polycyclic aromatic compounds were synthesized via benzannulated enyne-allene. For instance, treatment of propargylic alcohol 1.43 with thionyl chloride generated chloride 1.44. After reduction with $\mathrm{NaBH}_{4}$, the chloride 1.5 was obtained (Scheme 11). ${ }^{14}$ Similar to this example, benzannulated propargylic alcohols $1.45 \mathrm{a}$ and $1.45 \mathrm{~b}$ were again treated with 
thionyl chloride to obtain twisted polycyclic aromatic compounds $1.46 \mathrm{a}$ and $1.46 \mathrm{~b}$, respectively. ${ }^{16}$

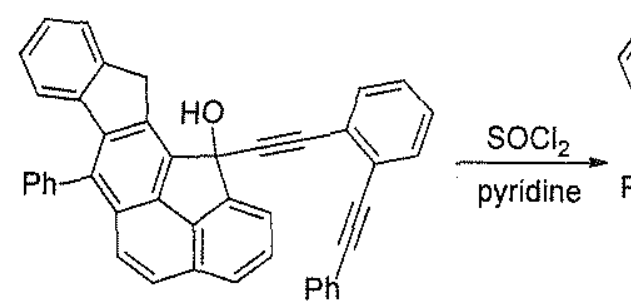

1.43

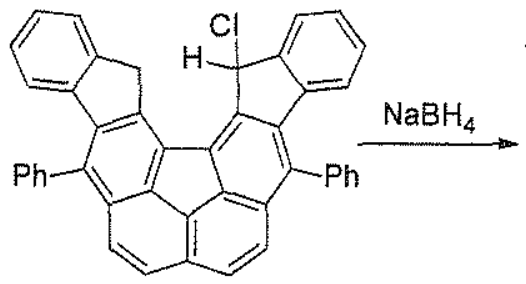

1.44

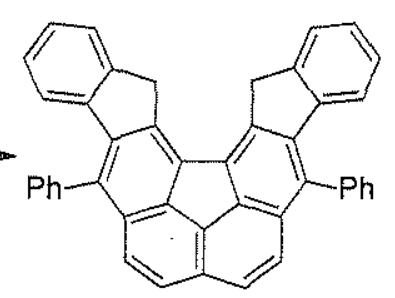

$1.5,47 \%$
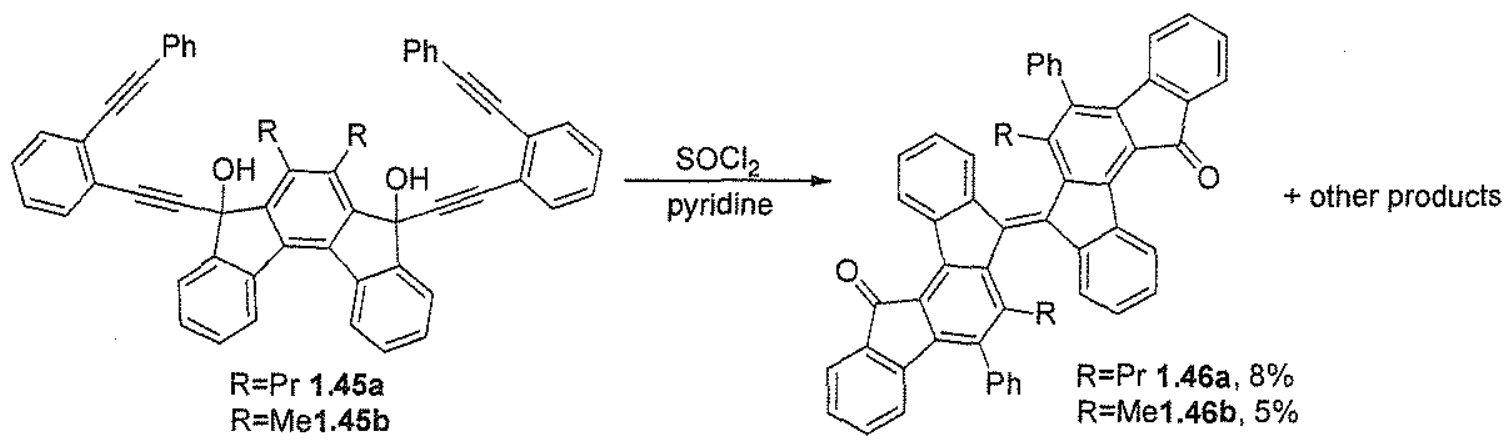

Scheme 11. Twisted polycyclic compounds synthesized via benzannulated enyene-allenes

One more example of using benzannulated enyne-allenes for the synthesis of twisted polycyclic aromatic compounds is presented below. Instead of using thionyl chloride, propargylic alcohol 1.47 was first converted to tetraacetylenic hydrocarbon 1.48 by treatment with triethylsilane in the presence of trifluoroacetic acid. The hydrocarbon 1.48 was then transformed to the 4,5-diarylphenanthrene 1.49 in the presence of potassium tert-butoxide under refluxing toluene (Scheme 12).

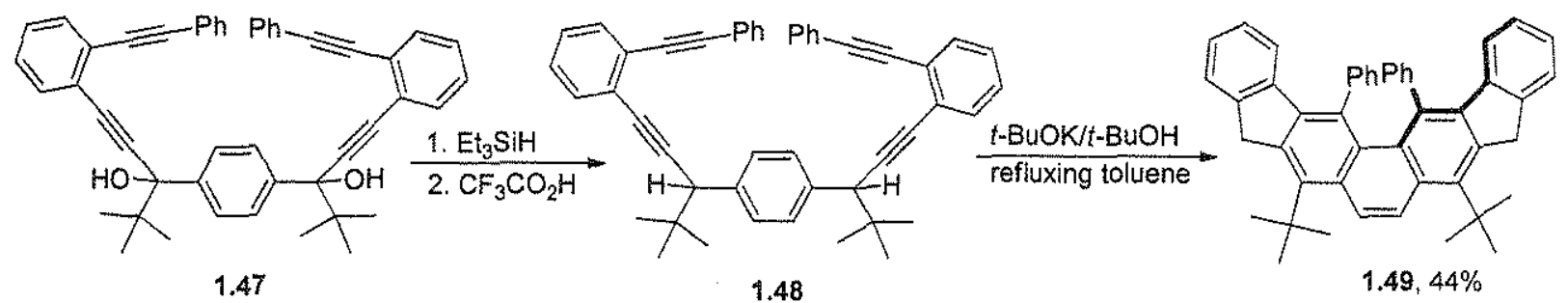

Scheme 12. An alternative synthetic pathway for twisted polycyclic aromatic hydrocarbons 
Subsequently, chrysenes $\mathbf{1 . 5 2}$ and $\mathbf{1 . 5 5}$ as nonplanar PAHs were successfully synthesized in the solution-phase via benzannulated enyne-allenes (Scheme 13). Similar to the synthetic pathway outlined in Scheme 12, treatment of benzannulated enediynes 1.50 and 1.53 with potassium tert-butoxide in refluxing toluene provided 1.51 and 1.54 , respectively. The palladium-catalyzed intramolecular arylation reactions of 1.51 and 1.54 produced buckybowls $1.52(37 \%)$ and $1.55(11 \%)$, respectively.<smiles>C[13CH](C(C#Cc1ccccc1C#Cc1c(Br)cccc1Br)c1ccccc1)C(C)(C)C</smiles><smiles>CC(C)(C)c1c2c(c(-c3c(Br)cccc3Br)c3ccccc13)-c1ccccc1C2</smiles>

$1.51,70 \%$<smiles>CC1(C)Cc2ccccc2C1C#Cc1ccccc1C#Cc1c(Br)cccc1Br</smiles><smiles>CC1(C)CC2=CC=CC3=C(c4c(Br)cccc4Br)C4=C(Cc5ccccc54)C(=C21)C3</smiles>

$1.54,62 \%$

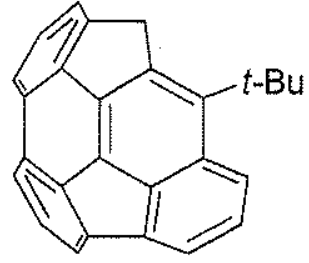

$1.52,37 \%$

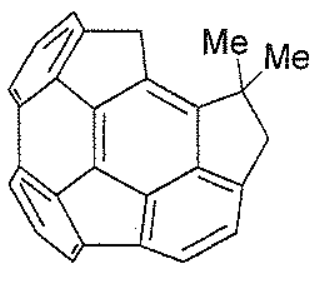

$1.55,11 \%$

Scheme 13. Synthesis of buckybowls 1.52 and 1.55 via benzannulated enyne-allenes

Both structures of 1.52 and 1.55 , confirmed by X-ray structure, indicate the presence of significant curvatures. Compared to tetrabenzopyracylene, the structure of 1.52 was less strained due to the lack of a six membered ring in the upper-right hand corner. The POAV ( $\pi$-orbital axis vector analysis) angles of tetrabenzopyracylene carbon atoms are clearly larger than those of the corresponding carbon atoms of 1.52 (Figure 4). The X-ray structure of 1.55 possessing an additional five-membered ring appears to cause its structure to be more strained among these 
structures. The POAV angles of 1.55 showed greater degree of pyramidalization. As a result, the transformation from $\mathbf{1 . 5 4}$ to $\mathbf{1 . 5 5}$ is less efficient.

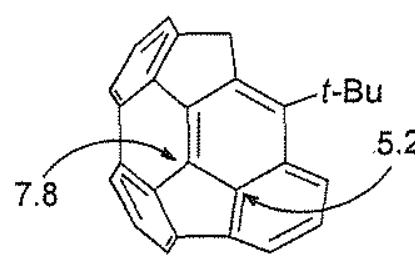

1.52

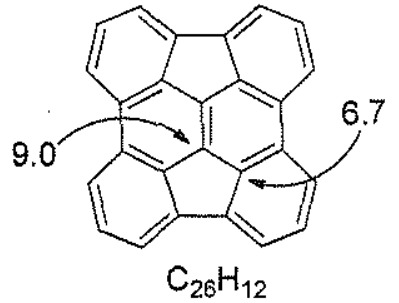

tetrabenzopyracylene

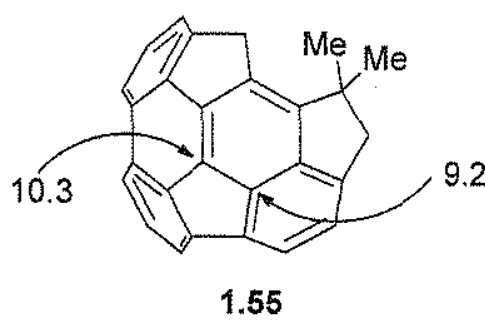

1.55

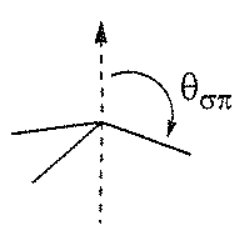

Figure 4. POAV pyramidalization angles $\left(\theta_{\sigma \pi}-90\right)$ of PAHs

Recently, our group reported the synthesis of additional fullerene fragments, including bowl-shaped $1.56\left(\mathrm{C}_{28} \mathrm{H}_{18}\right)$ and basket-shaped $1.57\left(\mathrm{C}_{56} \mathrm{H}_{40}\right)$ and $1.58\left(\mathrm{C}_{56} \mathrm{H}_{38}\right)$ (Figure 5). Specifically, these fullerene fragments were all synthesized entirely under mild solution phase via benzannulated enyne-allenes.

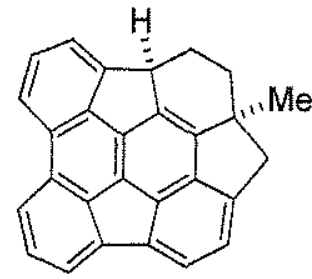

$1.56, \mathrm{C}_{28} \mathrm{H}_{18}$

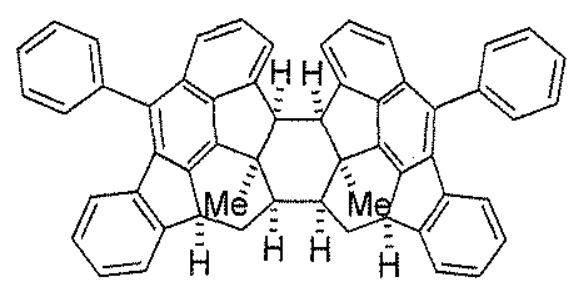

$1.57, \mathrm{C}_{56} \mathrm{H}_{40}$

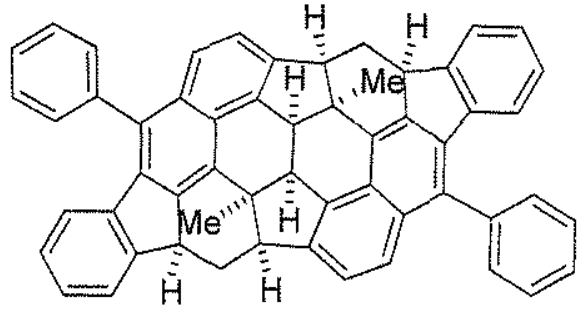

$1.58, \mathrm{C}_{56} \mathrm{H}_{38}$

Figure 5. Fullerene fragments prepared from benzannulated enyne-allenes

The bowl-shaped hydrocarbon 1.56 bearing a 27 -carbon framework that can serve as a precursor for dimerization leading to a $\mathrm{C}_{54} \mathrm{H}_{24}\left(90 \%\right.$ of $\left.\mathrm{C}_{60}\right)$ fullerene fragment. The synthetic sequence was inspired from the synthesis of chrysenes 1.52 and 1.55 . 
Drs. Yu-Hsuan Wang and Hua Yang reported the use of diketone 1.60, derived from cyclopentadienone 1.59 , as a key intermediate for the preparation of the $\mathrm{C}_{56} \mathrm{H}_{40}$ hydrocarbon 1.57 . The final intramolecular cyclization steps were carried out under mild conditions to afford hydrocarbon 1.57 (Scheme 14). The central 30 carbons of the basket-shaped 1.57 can be visualized as a $[5,5]$ circulene, a semibuckminsterfullerene.

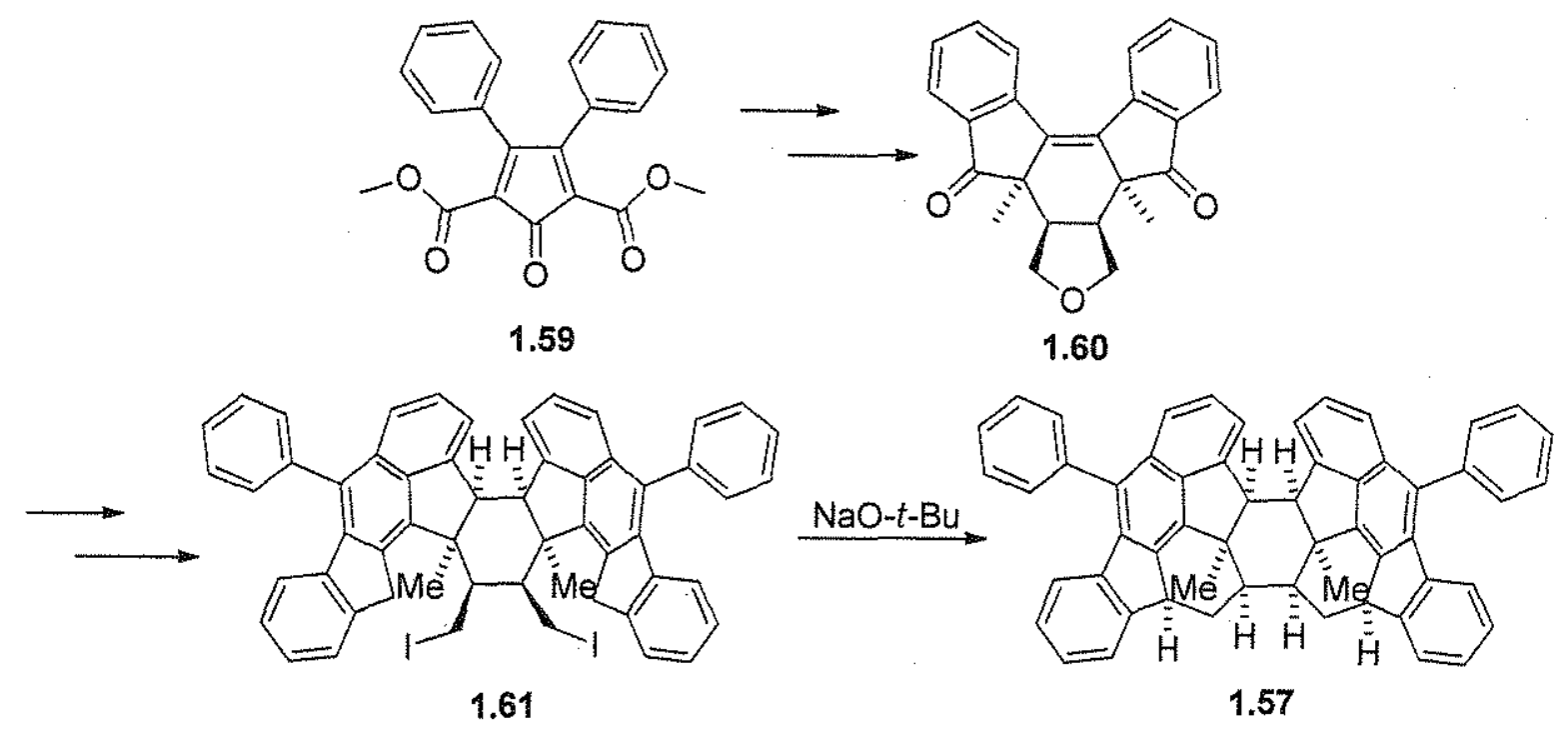

Scheme 14. Synthesis of the basket-shaped hydrocarbon 1.57

The other basket-shaped hydrocarbon 1.58 was synthesized from 4-bromo-1-indanone (1.62). Tetraketone 1.63 is a key synthetic intermediate in the 12-step synthesis and cascade cyclization reaction of benzannulated enyne-allenes 1.66 is a key step of the synthetic sequence (Scheme15). The overall yield of the process is relatively efficiency $(>10 \%)$. Compared to 1.57 , the center of the polycyclic aromatic hydrocarbon 1.58 contains a fully connected 30-carbon core. 

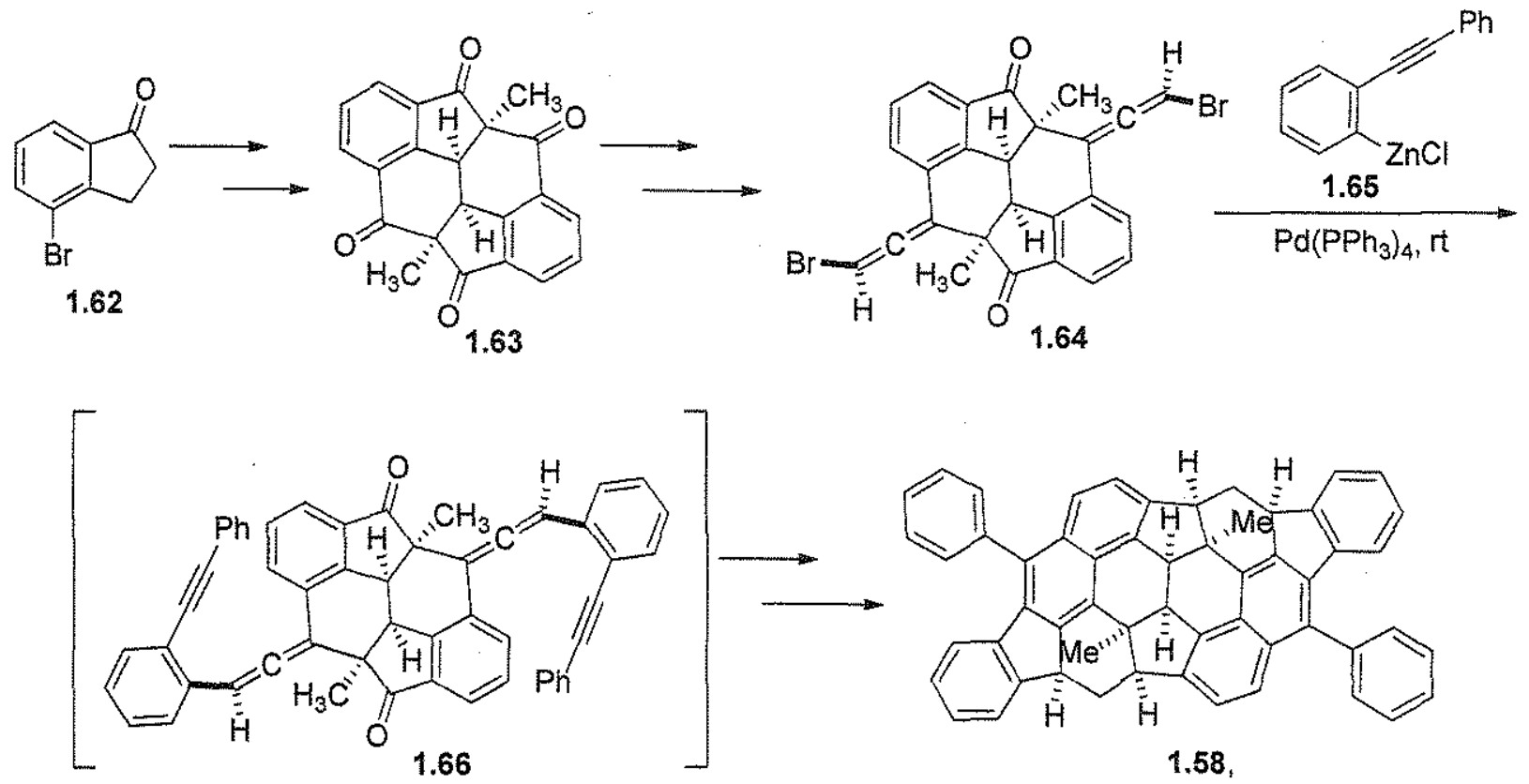

Scheme 15. Synthesis of the basket-shaped hydrocarbon 1.58

So far, our group has reported a series of simple and efficient solution-phase pathways for the synthesis of polycyclic aromatic hydrocarbons via benzannulated enyne-allenes. Although the overall yields are all below $20 \%$, it is now possible to prepare extended PAHs possessing significant curvatures using mild solution phase chemistry without the need of high temperatures.

The developments of curved PAHs synthesis using solution-phase chemistry over the last ten years have been quite substantial. Currently, it is possible to prepare buckybowls with diverse structures in greater than 30\% yield using solution-phase synthesis. Moreover, the procedures of these solution-phase studies are simple and widely used in synthetic endeavors. It is expected that in the next few years, solution-phase synthesis will be used to produce bowl-shaped or basket-shaped precursors of interest for new materials, catalysis, and pharmaceuticals. There is a need to have a better understanding of the intramolecular arylation steps. A better understanding 
of the source of strains in fullerenes structures will be useful. Hopefully, as the information accumulates, it may become possible to formulate new synthetic pathways for these nonplanar polycyclic aromatic compounds. 


\section{Research objective}

In the past few years, our group has synthesized several polycyclic aromatic compounds via the benzannulated enyne-allene route. Our next target molecule is the new bowl-shaped $\pi$ conjugated hydrocarbon 1.67 to be constructed by the benzannulated enyne-allene route as well.

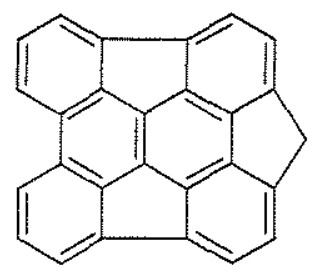

1.67

Figure 6. Bowl-shaped $\pi$-conjugated hydrocarbon 1.67

It was previously reported by Dr. Bo Wen of our group using the synthetic sequence outlined in Scheme 16 for the synthesis of $\mathbf{1 . 5 6}$, a buckybowl structurally similar to the target molecule 1.67. Transformation of 1-indanone (1.68) to the corresponding trimethylsilylenol ether 1.69 followed by alkylation with methyl iodide under mild conditions gave 2-methyl-1-indanone (1.70) in $73 \%$ yield. The methylated 1 -indanone 1.70 was then treated with $\mathrm{NaH}$ and 1 -iodo-2methoxyethane (1.71) under reflux of THF to produce the 2,2-disubtituted 1-indanone derivative 1.72 in $68 \%$ yield. Condensation of $\mathbf{1 . 7 2}$ and the lithium acetylide derived from the benzannulated enediyne 1.73 and LDA gave the enediynyl propargylic alcohol 1.74 . Subsequently, the benzannulated enediyne $\mathbf{1 . 7 5}$, serving as a precursor for the benzannulated enyne-allene 1.76, was prepared by reduction of 1.74 with triethylsilane in the presence of trifluoroacetic acid. 


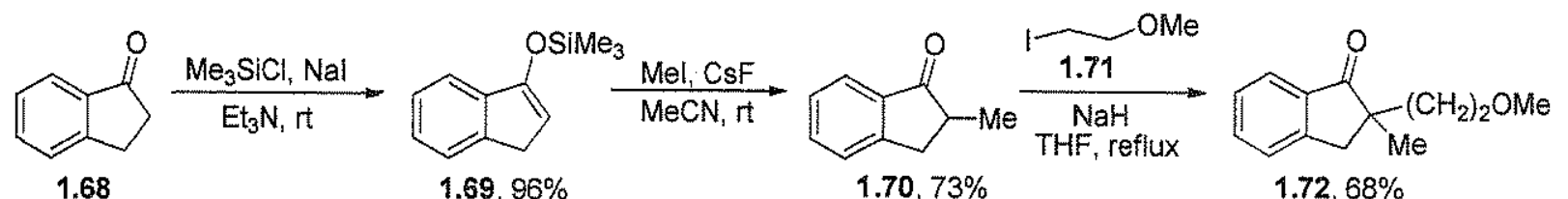

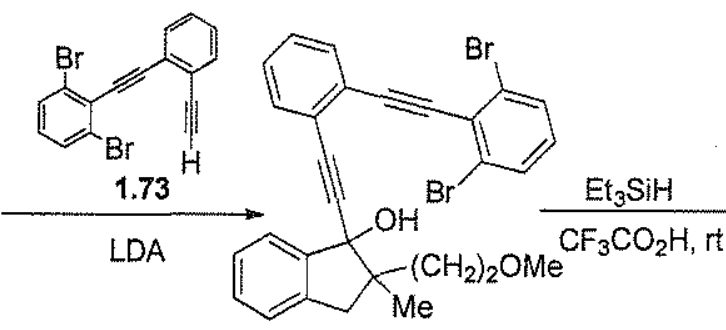

$1.74,96 \%$

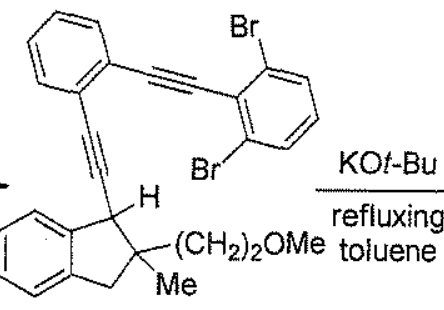

$1.75,94 \%$
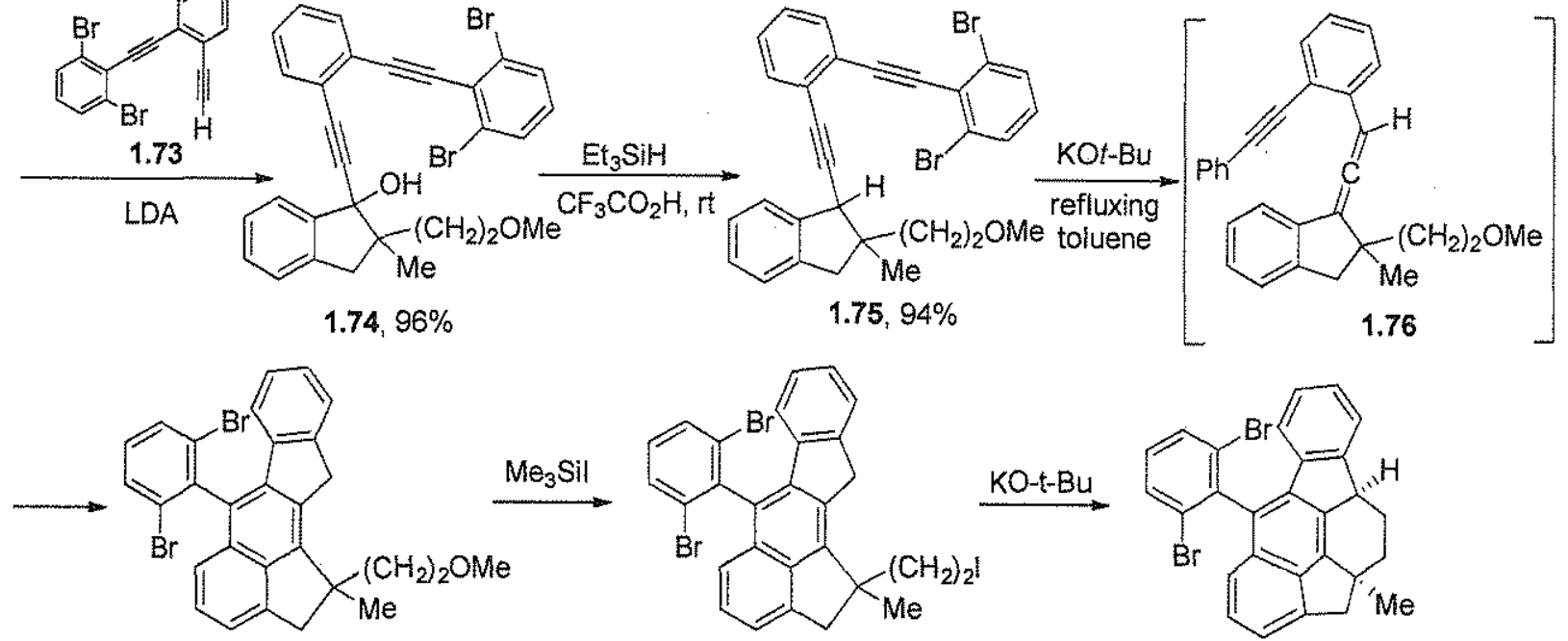

$1.77,82 \%$

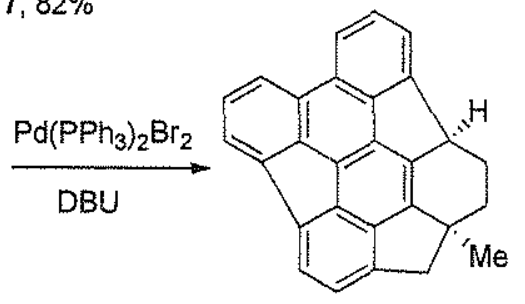

$1.56,32 \%$
$1.78,79 \%$
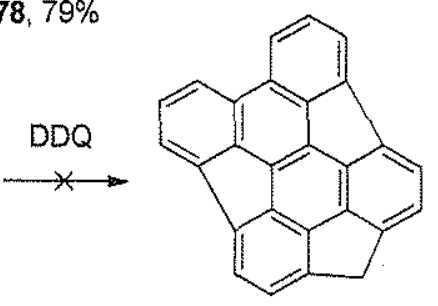

1.67

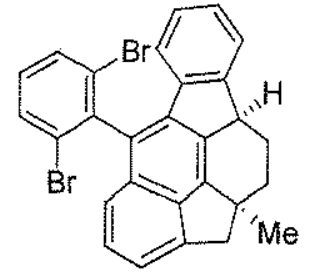

$1.79,95 \%$

Scheme 16. Synthesis of PAH 1.56

On exposure of $\mathbf{1 . 7 5}$ to potassium tert-butoxide in refluxing toluene, the benzannulated enyne-allene 1.76 was formed in situ. The subsequent Schmittel cyclization reaction then produced benzofluorene 1.77. Cleavage of the methyl ether in 1.77 with $\mathrm{Me}_{3} \mathrm{Sil}$ produced iodide 1.78. In the presence of potassium tert-butoxide, 1.78 underwent an intramolecular alkylation reaction to form 1.79. The presence of two bromo substituents in 1.79 allowed additional carboncarbon formation via the Pd-catalyzed intramolecular arylation reactions to form 1.56 in $32 \%$ yield. However, attempts to convert 1.56 to the desired buckybowl 1.67 by dichlorodicyanobenzoquinone (DDQ) were unsuccessful presumably because of the presence of 
the methyl group.

The objective of this investigation is to use a similar strategy to form 1.67 . To be successful, it was envisioned that 1 -indanone 1.80 possessing a more easily removable 2-methoxy substituent could be employed as a precursor (Scheme 17).

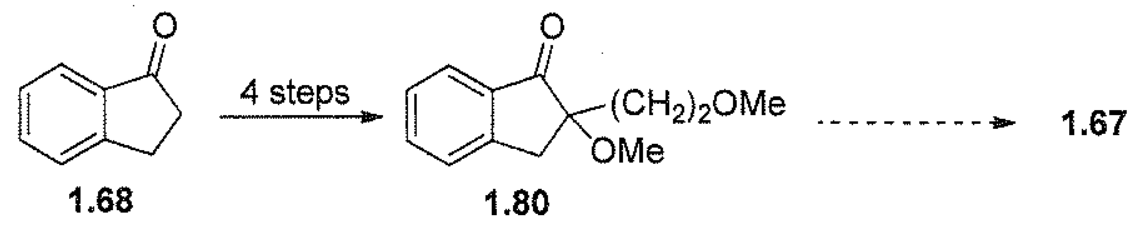

Scheme 17 Alternative synthetic pathway to the bowl-shaped PAHs 1.67

The bowl-shaped PAHs 1.67 could be further used as a building block for the construction of larger fullerene fragments. Dimerization of 1.67 could lead to $1.81 \mathrm{a}$ and/or its isomer $1.81 \mathrm{~b}$ (Figure 7). In addition, the used of a chlorinated 1.67, to be prepared from 4-chloro-1-indanone could allow the formation of two additional $\mathrm{C}-\mathrm{C}$ bonds leading to 1.82 , a basket-shaped $\mathrm{C}_{54} \mathrm{H}_{16}$ hydrocarbon bearing $90 \%$ of the $\mathrm{C} 60$ carbon framework (Figure 8 ).

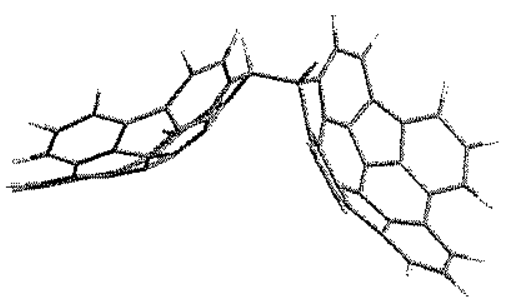

$1.81 \mathrm{a}$

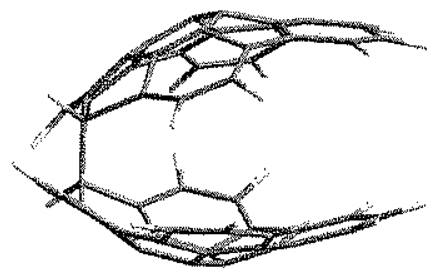

$1.81 \mathrm{~b}$

Figure 7. Dimerization products $1.81 \mathrm{a}$ and $1.81 \mathrm{~b}$ 


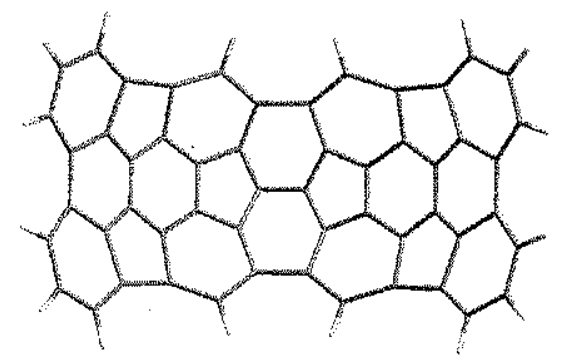

1.82

Figure 8. A basket-shaped hydrocarbon $\mathrm{C}_{54} \mathrm{H}_{16}(\mathbf{1 . 8 2})$ 


\section{Results and discussion}

As was described earlier, the synthesis of buckybowl 1.67 would rely on a strategy similar to that for 1.56 except the following modification. First we employed indanone 1.80 as a potential precursor by replacing the methyl group at the alpha position of 1.72 with a more easily removable methoxy group (Figure 9). The previous investigation outlined in Scheme 16 showed that the presence of the methyl substituent in $\mathbf{1 . 5 6}$ prevented the formation of the fully aromatized 1.67 by treatment of 1.56 with $\mathrm{DDQ}$. Second, in order to improve the Pd-catalyzed intramolecular arylation reactions, we changed the bromo substituents of benzannulated enediyne 1.73 to chloro groups in 1.83 (Figure 9).

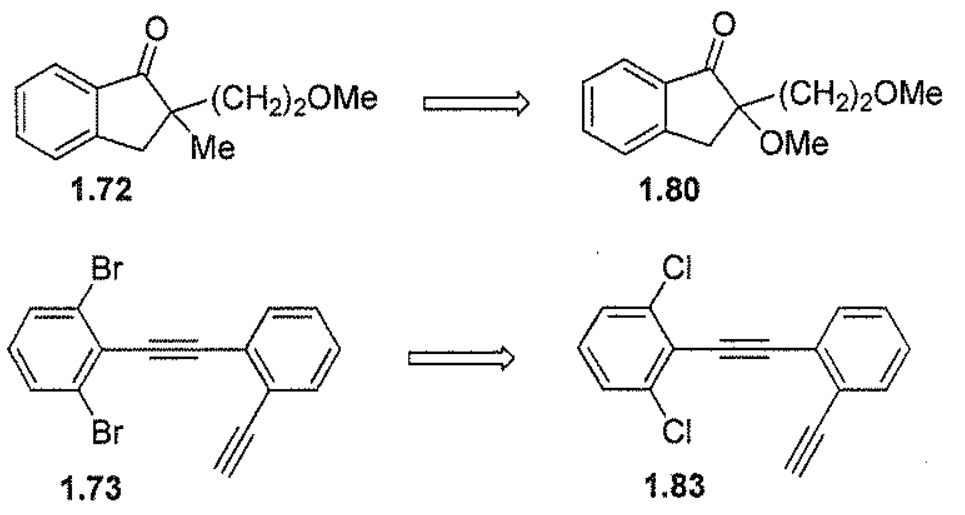

Figure 9. Modification in synthesis of buckybowl 1.67

Initially, a variety of reagents were tested to try to convert 1-indanone $(\mathbf{1 . 6 8})$ to $\mathbf{1 . 8 5}$, However, either no desired product was obtained or yields were low (Table 1). Other attempts for preparing 1.80 were also investigated by an alternative route. 1-Indanone 1.68 was first treated with hydroxy(p-nitrobenzene-sulfonyloxy)iodobenzene (HNIB) in methanol to provide 1.68a. Unfortunately, treatment of $1.68 \mathrm{a}$ with LDA or KHMDS/HMPA followed by 2 methoxyethyl triflate did not produced the desired product, and only the starting 1-indanone 1.68 was recovered (Scheme 18). 

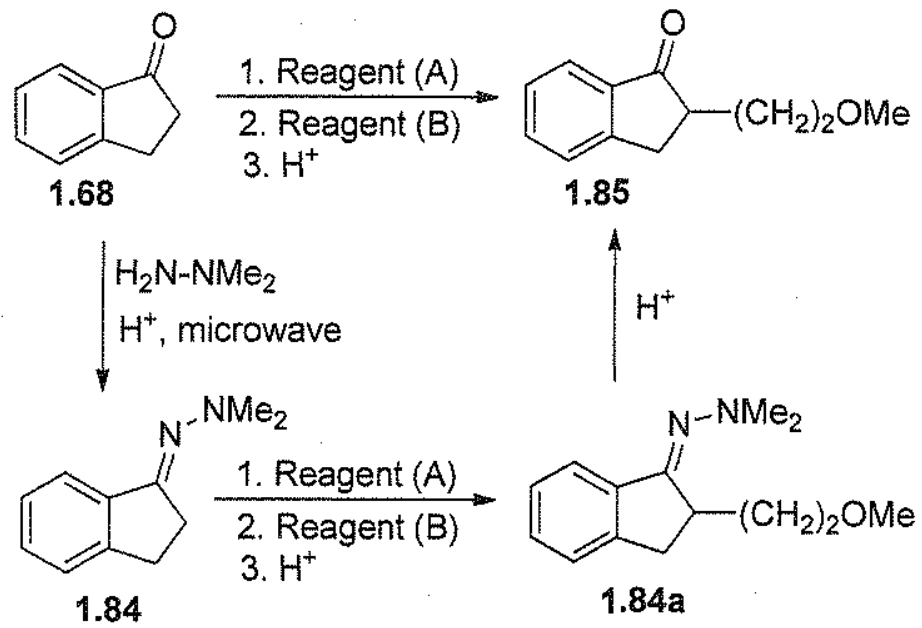

\begin{tabular}{|c|c|c|}
\hline Reagent (A) & Reagent (B) & Yield(1.85) \\
\hline LDA & $\begin{array}{l}\mathrm{MeOCH} \mathrm{CH}_{2} \mathrm{OTf} \\
\left.\mathrm{MeOCH} \mathrm{CH}_{2}\right\rfloor\end{array}$ & $\begin{array}{l}\text { Low } \\
\text { Low }\end{array}$ \\
\hline KHMDS/HMPA & $\begin{array}{l}\mathrm{MeOCH} \mathrm{CH}_{2} \mathrm{OTf} \\
\mathrm{MeOCH}_{2} \mathrm{CH}_{2} \mathrm{Br}\end{array}$ & $\begin{array}{l}\text { Low } \\
\text { Low }\end{array}$ \\
\hline LIHMDS/HMPA & $\begin{array}{l}\mathrm{MeOCH} \mathrm{CH}_{2} \mathrm{OTf} \\
\mathrm{MeOCH}_{2} \mathrm{CH}_{2} \mathrm{Br}\end{array}$ & $\begin{array}{l}\text { Low } \\
\text { Low }\end{array}$ \\
\hline$n$-BuLi & $\begin{array}{l}\mathrm{MeOCH} \mathrm{CH}_{2} \mathrm{OTf} \\
\mathrm{MeOCH} \mathrm{CH}_{2} I \\
\mathrm{MeOCH}_{2} \mathrm{CH}_{2} \mathrm{Br}\end{array}$ & $\begin{array}{l}\text { N/A } \\
\text { N/A } \\
\text { N/A }\end{array}$ \\
\hline
\end{tabular}

Table 1. Attempted synthesis of alkylated 1-indanone $\mathbf{1 . 8 5}$

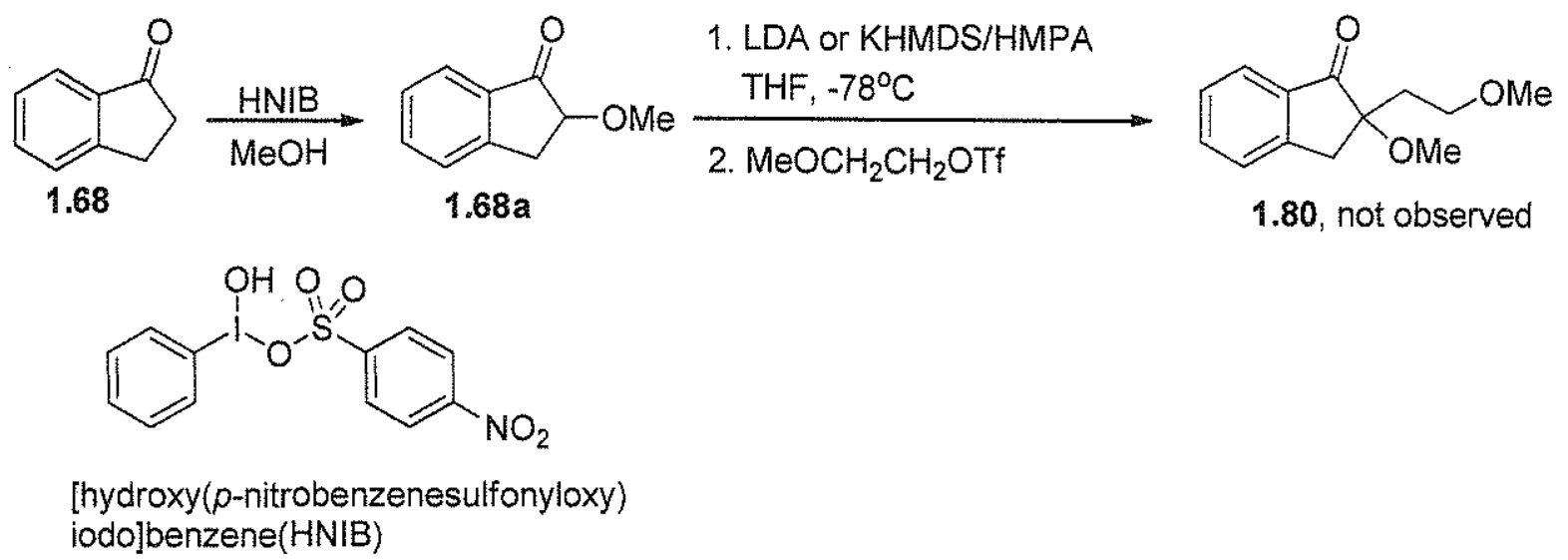

Scheme 18. Attempted synthesis of 1-indanone $\mathbf{1 . 8 0}$ 
After several attempts, we finally were able to find a feasible synthetic sequence for $\mathbf{1 . 8 5}$ depicted in Scheme 19. 1-Indanone 1.68 was first converted to the corresponding hydrazone derivative 1.84 in nearly quantitative yield by treatment with $N, N$-dimethylhydrazine in the presence of a catalytic amount of acetic acid. Alkylation of hydrazone 1.84 with the commercially available 2-bromoethyl methyl ether and LDA, followed by hydrolytic workup, then furnished the alpha alkylated indanone $\mathbf{1 . 8 5}$ in good yield (87\%).

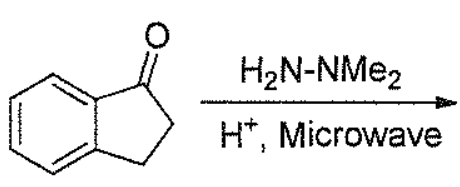

1.68<smiles>N=C1CCc2ccccc21</smiles>

$1.84,96 \%$

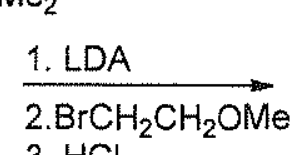
3. $\mathrm{HCl}$<smiles>COCCC1Cc2ccccc2C1=O</smiles>

Scheme 19 Synthesis of 1-indanone 1.85

Treatment of $\mathbf{1 . 8 5}$ with trimethylphosphite, tetrabutylammonium iodide, and a $50 \%$ sodium hydroxide solution under oxygen produced 2-hydroxyl-1-indanone $\mathbf{1 . 8 6}$ in $92 \%$ yield. Alkylation with methyl iodide in the presence of sodium hydride then produced the desired $\mathbf{1 . 8 0}$ in $93 \%$ yield.

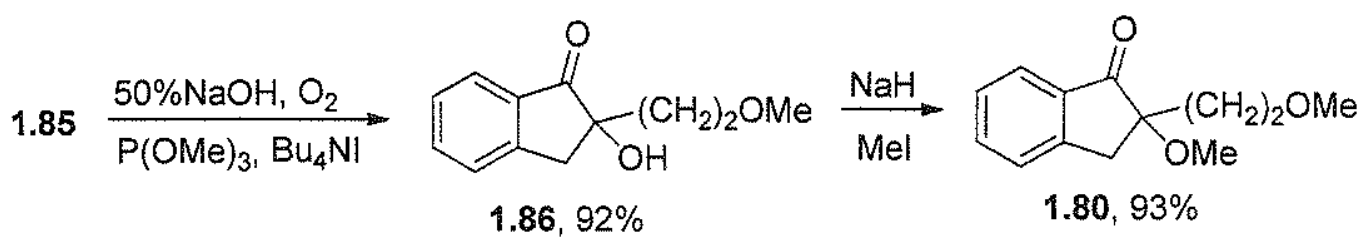

Scheme 20 Synthesis of 1 -indanone 1.80 
In an attempt to form the Schmittel cyclization product $1.85 \mathrm{e}$, a synthetic pathway outlined in Scheme 21 was pursued. Condensation of indanone $\mathbf{1 . 8 5}$ and ethynylmagnesium bromide produced propargylic alcohol $1.85 \mathrm{a}$. Treatment of $1.85 \mathrm{a}$ with thionyl bromide produced allenic bromide $1.85 \mathrm{~b}$. However, $\mathbf{1 . 8 5 b}$ was not very stable and easily decomposed and the reaction is also furnished other unexpected byproduct.
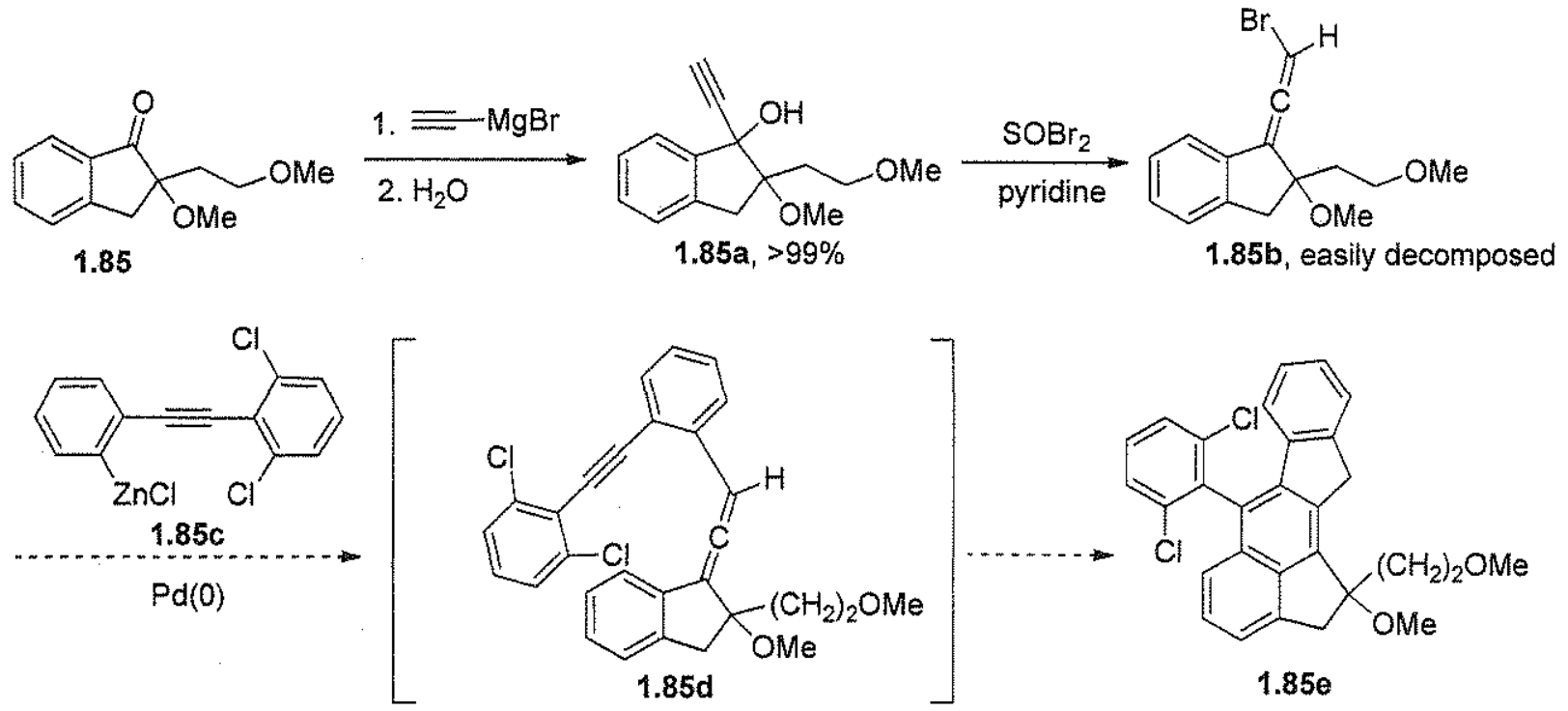

Scheme 21. Attempted synthesis of 1 -indanone $1.85 \mathrm{~b}$

With the failure of the synthetic route outlined in Scheme 21 for the Schmittel cyclization product $1.85 \mathrm{e}$, we quickly switched to an alternative approach by directly condensation of indanone 1.80 and benzannulated enediyne 1.83 .

The requisite benzannulated enediyne 1.83 was synthesized as outlined in Scheme 22 . Precursors 1.88 and 1.91 were both produced via the Sonogashira coupling reactions of (trimethylsilyl)ethyne with 1,3-dichloro-2-iodobenzene $\mathbf{1 . 8 7}$ and 2-bromo-1-iodobenzene $\mathbf{1 . 9 0 ,}$ respectively. The following desilylation reaction of $\mathbf{1 . 8 8}$ and the lithium halogen exchange 
reaction of 1.91 were successful in producing (2,6-dichloropheny)ethyne (1.89) and 1-(2iodophenyl)-2-(trimethylsilyl)ethyne (1.92), respectively. A second Sonogashira reaction between 1.89 and 1.92 then led to 1.93 , which was rapidly desilyated by $10 \% \mathrm{NaOH}$ to afford the benzannulated enediyne $\mathbf{1 . 8 3}$.

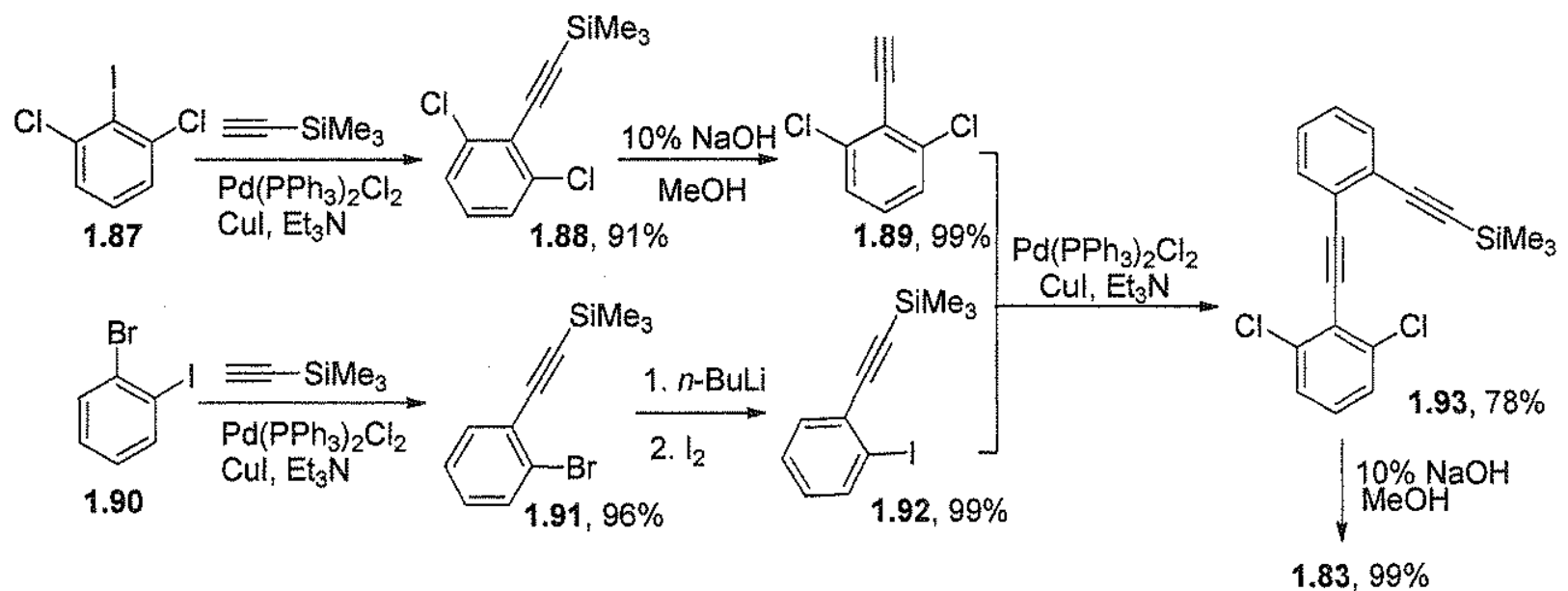

Scheme 22. Synthesis of benzannulated enediyne $\mathbf{1 . 8 3}$

Condensation between indanone 1.80 and benzannulated enediyne 1.83 in the presence of LDA furnished propargylic alcohol 1.94 (Scheme 23). Treatment of 1.94 with thionyl chloride first induced an $\mathrm{S}_{\mathrm{N}}{ }^{1}$ reaction to generate benzannulated eneyne-allene 1.95 in situ followed by cascade radical cyclization to afford 1.96a. The detailed mechanism to form $1.96 \mathrm{a}$ via benzannulated eneyne-allene 1.95 was described previously. The chloride $1.96 \mathrm{a}$ was prone to hydrolysis and further oxidation on exposure to air, water/silica gel to give a mixture of alcohol $1.96 \mathrm{~b}$ and ketone $1.96 \mathrm{c}$. The combined yield of crude $1.96 \mathrm{a} 1.96 \mathrm{~b}$ and $1.96 \mathrm{c}$ was ca. $77 \%$. 


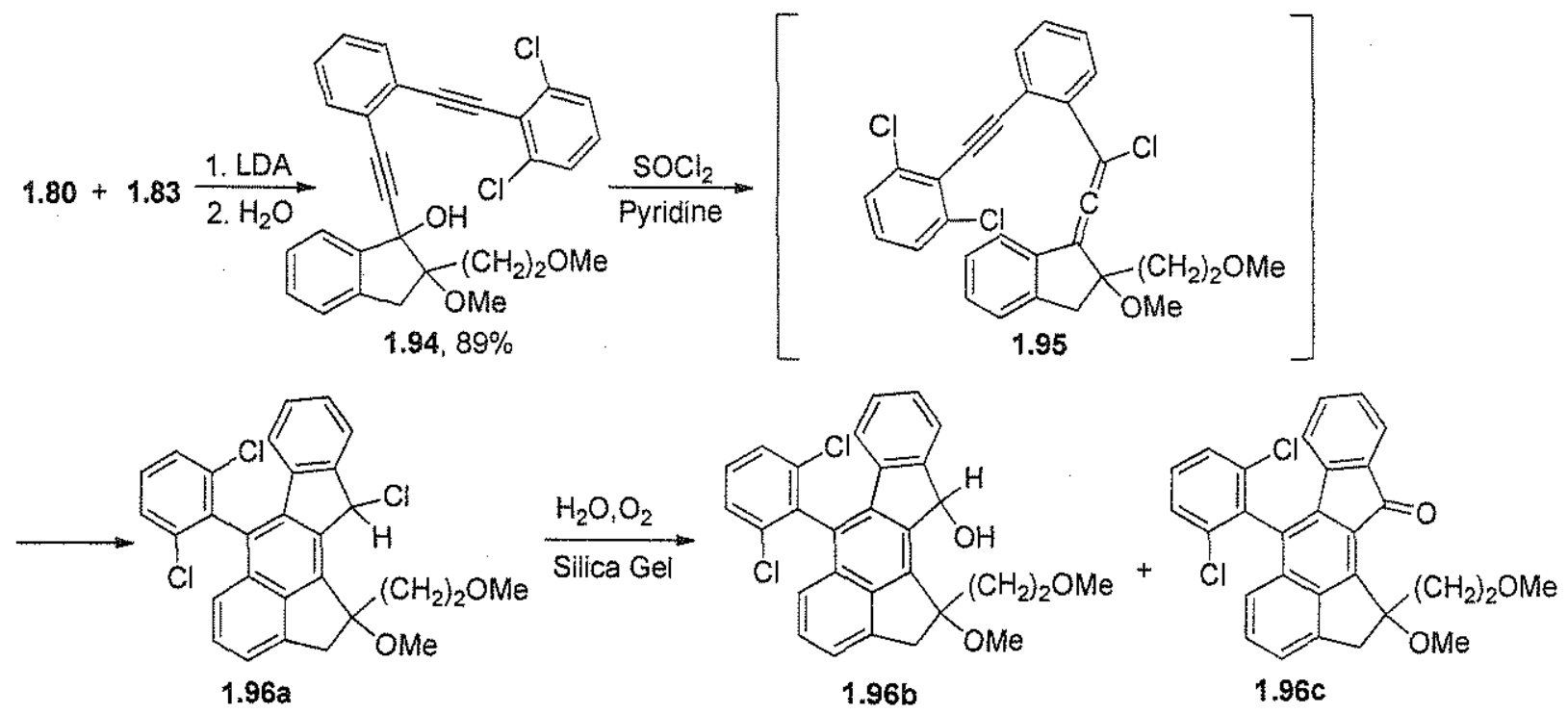

Scheme 23. Synthesis of 1.96a-c

Treatment of the crude $1.96 \mathrm{a}-\mathrm{c}$ without further purification with an excess of diiodosilane $\left(\mathrm{SiH}_{2} \mathrm{I}_{2}\right)$ converted the mixture to the desired iodide 1.97 in a very good yield (95\%) (Scheme 24). Diiodosilane is a strong Lewis acid and as good a donor of hydride and iodide ions. It was found to be very useful for cleavage and deoxygenation of ethers, alcohols, ketones and aldehydes. The use of diiodosilane to induce the transformation from 1.96a-c to 1.97 represents a new and convenient way to this desired precursor for possible transformation to 1.67 .

The aromatic hydrogen in $\mathbf{1 . 9 7}$ indicated with an arrow is shielded by the neighboring phenyl group, shifting its ${ }^{1} \mathrm{H}$ NMR signal upfield to $\delta 6.59$ (doublet). The upfield shift of aromatic hydrogen at $\delta 6.59$ is typical of a 5-phenylbenzofluorenyl structure with the phenyl substituent in essentially perpendicular orientation with respect to the benzofluorenyl group. In our previous studies, adducts derived from benzannulated eneyne-allene via cascade radical cyclization exhibited an aromatic ${ }^{1} \mathrm{H}$ NMR signal with such an upfield shift. 


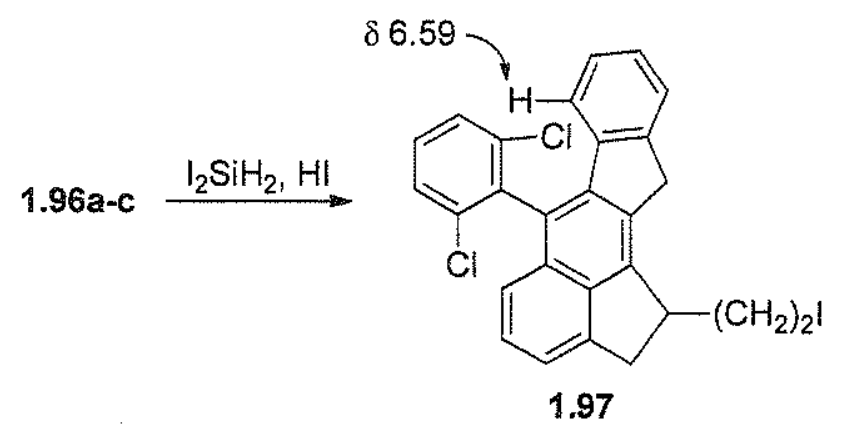

Scheme 24. Synthesis of compound 1.97

However, treatment of iodide 1.97 with potassium tert-butoxide furnished both hydrocarbon $1.98 \mathrm{a}$ and $\mathbf{1 . 9 8 \mathrm { b }}$ in nearly $1: 1$ ratio. Both structures of $\mathbf{1 . 9 8 \mathrm { a }}$ and $\mathbf{1 . 9 8 \mathrm { b }}$ were confirmed by ${ }^{1} \mathrm{H},{ }^{13} \mathrm{C}$ NMR spectroscopy and by NOESY experiments. The ${ }^{1} \mathrm{H}$ NMR spectrum indicated that the upfield shifts of aromatic hydrogens shielded by perpendicular phenyl rings are located at $\delta 6.60$ for 1.98a and $\delta 6.85$ for $\mathbf{1 . 9 8 b}$, respectively (Scheme 25).

1.96a-c $\stackrel{\left\lfloor_{2} \mathrm{SiH}_{2}, \mathrm{H}\right\}}{\longrightarrow}$

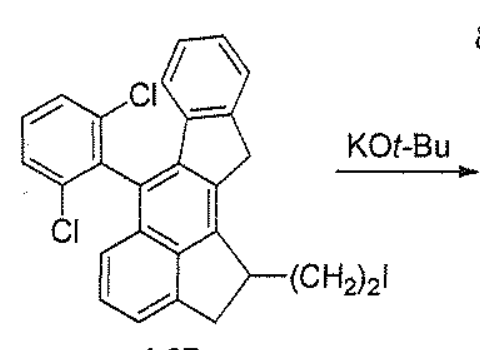

1.97

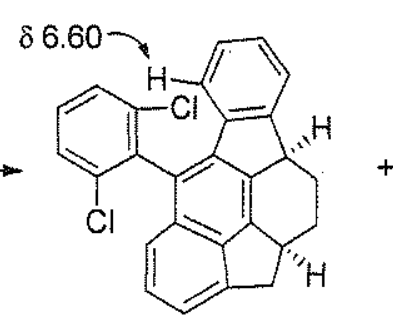

$1.98 \mathrm{a}$

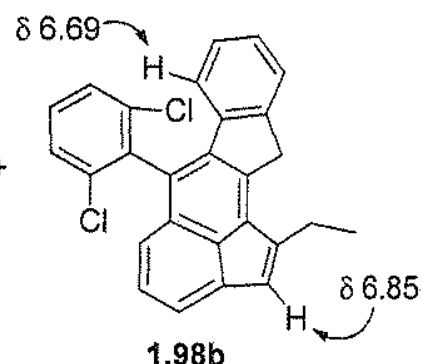

$1.98 b$

Scheme 25. Synthesis of compound 1.98a and 1.98b

Our general strategy to obtain polycyclic aromatic hydrocarbon $\mathbf{1 . 6 7}$ is given in Scheme 26 . Dichloride $1.98 \mathrm{a}$ was treated with a Pd catalyst to promote the intramolecular arylation reactions in order to produce $\mathbf{1 . 1 0 1}$ for the subsequent reaction with DDQ for aromatization to give the fully aromatized PAH 1.67. Unfortunately, the monocyclized adducts 1.99 and 1.100 were 
formed as the only identifiable products as have been observed in our earlier investigation of the intramolecular arylation step. The four upfield aromatic hydrogen signals above $\delta 9.0$ were observed in the ${ }^{1} \mathrm{H}$ NMR spectrum which indicated formation of PAHs 1.99 and 1.100 . These four hydrogens, $\mathrm{H}_{a}, \mathrm{H}_{b}, \mathrm{H}_{c}$ and $\mathrm{H}_{d}$, located in a characteristic 3-sided concave area at the periphery of non-linear PAHs 1.99 and 1.100 , are called bay region hydrogens.

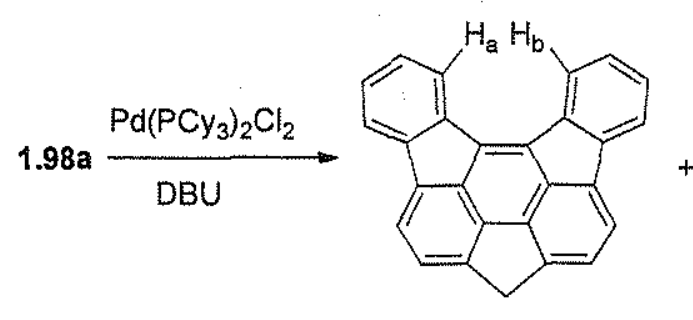

1.99

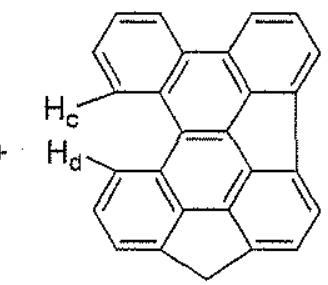

1.100

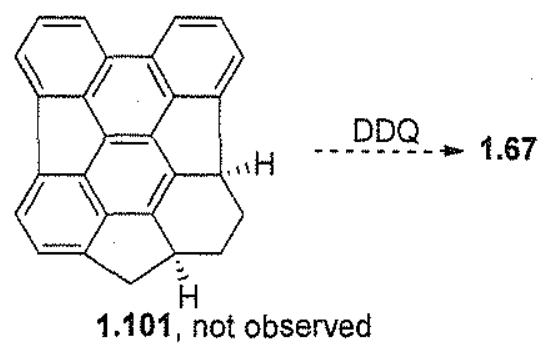

1.101, not observed

Scheme 26. Synthesis of PAHs 1.99 and 1.100

Compared to the previous results, the substructure of dichloro benzofluorene 1.98a should have similar strain and curvature as the dibromo derivative 1.78. Apparently, the reason that we were not able to obtained 1.101 might be the rigid structure of 1.99 and 1.100 . Aromatization of the lower right hand comer in $\mathbf{1 . 9 9}$ and $\mathbf{1 . 1 0 0}$ may prevent the second carbon-carbon bond formation.

Although we have not had an opportunity to perform the aromatization step, it is worth mentioning that the design of using a more easily removable methoxy group at the alpha position was successful during the transformation of $1.96 \mathrm{a}-\mathrm{c}$ to 1.97 . The tertiary methoxy group in 1.96 was successfully replaced by a hydrogen atom to form $\mathbf{1 . 9 7}$. 


\section{Conclusion}

Our synthetic approach to the bowl-shaped polycyclic aromatic hydrocarbon $\mathbf{1 . 6 7}$ was investigated. We were successful in synthesizing dichloride $1.98 \mathrm{a}$ as a potential precursor to 1.101 which could then be converted 1.67. The process involved the used of a mild and efficient route to generate benzanunulated enyne-allenes $\mathbf{1 . 9 5}$ in situ for subsequent cascade radical cyclizations. In addition, several attempts to improve the synthesis course were also made. The overall synthetic strategy is very promising and is worth further investigation. Although we have not yet reached our target PAH 1.67 yet, a suitable palladium catalyst could be developed to achieve this goal. Lastly if $\mathrm{PAH} \mathbf{1 . 6 7}$ is obtained, it could serve as a precursor to generate buckybowl 1.81a-b or 1.82 . 


\section{References}

1. Kroto, H. W.; Heath, J. R.; O'Brien, S. C.; Curl, R. F.; Smalley, R. E., Nature 1985, 318, 162.

2. Wu, Y.-T.; Siegel, J. S. Chem. Rev., 2006, 106, 4843-4867.

3. Tsefrikas, V. M.; Scott, L. T. Chem. Rev., 2006, 106, 4868-4884.

4. Mehta, G.; Rao, H. S. P., Tetrahedron 1998, 54 (44), 13325-13370.

5. Cui, H.; Akhmedov, N. G.; Petersen, J. L.; Wang, K. K., J. Org. Chem.2010, 75, 2050-2056.

6. Hill, T. J.; Hughes, R. K.; Scott, L. T., Tetrahedron 2008, 64, 11360-11369.

7. Barth, W. E.; Lawton, R. G., J. Am. Chem. Soc. 1966, 88, 380.

8. Barth, W. E.; Lawton, R. G., J. Am. Chem. Soc. 1971, 93, 1730.

9. Scott, L. T., Pure Appl. Chem. 1996, 68, 291.

10. Wang, L.; Shevlin, P. B., Org. Lett. 2000, 2, 3703.

11. Sygula, A.; Rabideau, P. W., J. Am. Chem. Soc. 1999, 121, 7800.

12. Seiders, T. J.; Elliott, E. L.; Grube, G. H.; Siegel, J. S., J. Am. Chem. Soc. 1999, 121, 7804.

13. Sygula, A.; Rabideau, P. W., J. Am. Chem. Soc. 1998, 120, 12666-12667.

14. Zhang, H.-R.; Wang, K. K., J. Org. Chem. 1999, 64, 7996-7999.

15. Yang, Y. H.; Petersen, J. L.; Wang, K. K., J. Org. Chem. 2003, 68, 8545-8549.

16. Yang, Y. H.; Petersen, J. L.; Wang, K. K., J. Org. Chem.2003, 68, 5832-5837.

17. Lawton, R. G.; Barth, W. E., J. Am. Chem. Soc. 1971, 93, 1730.

18. Scott, L. T.; Hashemi, M. M.; Meyer, D. T.; Warren, H. B., J. Am. Chem. Soc. 1991, 113, 7082.

19. Scott, L. T.; Cheng, P. C.; Hashemi, M. M.; Bratcher, M. S.; Meyer, D. T.; Warren, H. B., J. Am. Chem. Soc. 1997, 119, 10963.

20. Bronstein, H. E.; Choi, N.; Scott, L. T., J. Am. Chem. Soc. 2002, 124, 8870.

21. Rabideau, P. W.; Abdourazak, A. H.; Folsom, H. E.; Marcinow, Z.; Sygula, A.; Sygula, R., J. Am. Chem. Soc. 1994, 116, 7891.

22. Abdourazak, A. H.; Marcinow, Z.; Sygula, n.; Rabideau, P. W., J. Am. Chem. Soc. 1995, 117. 6410.

23. Scott, L. T.; Bratcher, M. S.; Hagen, S., J. Am. Chem. Soc, 1996, 118, 8743.

24. Seiders, T. J.; Baldridge, K. K.; Siegel, J. S., J. Am. Chem. Soc. 1996, 118, 2754.

25. Sygula, A.; Rabideau, P. W., J. Am. Chem. Soc. 2000, 122, 6323. 
26. Sygula, A.; Xu, G.; Marcinow, Z.; Rabideau, P. W., Tetrahedron 2001, 57, 3637.

27. Xu, G.; Sygula, A.; Marcinow, Z.; Rabideau, P. W., Tetrahedron Lett. 2000, 41, 9931.

28. Sakurai, H.; Daiko, T.; Hirao, T., Science 2003, 1878.29.

29. Higashibayashi, S.; Sakurai, H., J. Am. Chem. Soc. 2008, 130, 8592m8593.

30. Schmittel, M.; Strittmatter, M.; Vollmann, K.; Kiau, S., Tetrahedron Lett. 1996, 37, 9991002.

31. Schmittel, M.; Strittmatter, M.; Kiau, S., Angew. Chem. Int. Edit. 1996, 35 (16), 1843-1845. 


\section{Chapter 2}

\section{Experiment Section}

\section{General Experimental Methods.}

All reactions were conducted in Oven-dried $\left(110^{\circ} \mathrm{C}\right)$ glassware under a nitrogent atmosphere. Dichloromethane, diethyl ether, chloroform, ethyl acetate, hexanes, and methanol were reagent grad and used as received. Tetrahydrofuran (THF) was distilled from $\mathrm{Na}$ /benzophenone and used instantly. All other liquid reagent and solid chemicals were purchased from chemical suppliers and were used as received. Purification by column chromatography was performed using silica gel $(32-63 \mu \mathrm{m})$. Diiodosilane were prepared as reported previously ${ }^{31}$. The crude diiodosilane along with the volatile side products, including $\mathrm{HI}$, were used without further purification. ${ }^{1} \mathrm{H}$ NMR and ${ }^{13} \mathrm{C}$ NMR Spectra were recorded in $\mathrm{CDCl}_{3}$ using $\mathrm{CHCl}_{3}\left({ }^{1} \mathrm{H} \delta 7.26\right)$ and $\mathrm{CDCl}_{3}\left({ }^{13} \mathrm{C} \delta\right.$ 77.0) as internal standards on a Varian $600 \mathrm{MHz}$ NMR Spectrometer. 


\section{Hydrazone 1.84}

A mixture of $0.801 \mathrm{~g}$ of 1-indanone (6.06 mmol), 1,1-dimethylhydrazine $(0.45 \mathrm{~mL}, 6.01 \mathrm{mmol})$ and a trace amount of acetic acid was placed in a sealed reaction tube equipped with magnetic bar and heated under microwave irradiation at $140{ }^{\circ} \mathrm{C}$ for $20 \mathrm{~min}$. The reaction mixture was then concentrated under reduced pressure to remove excess 1,1-dimethylhydrazine. The residue was purified over a column of basic alumina column by using $20 \%$ of ethyl acetate in hexanes as eluent to obtain $1.02 \mathrm{~g}(5.85 \mathrm{mmol}, 96 \%) 1.84$ as a yellow oil: ${ }^{1} \mathrm{H}\left(\mathrm{CDCl}_{3}, 600 \mathrm{MHz}\right) \delta 7.76(1 \mathrm{H}$, d, $J=7.8 \mathrm{~Hz}), \delta 7.35(1 \mathrm{H}, \mathrm{t}, J=7.2 \mathrm{~Hz}), \delta 7.29(1 \mathrm{H}, \mathrm{d}, J=7.8 \mathrm{~Hz}), \delta 7.24(1 \mathrm{H}, \mathrm{t}, J=7.2 \mathrm{~Hz})$, $3.05(2 \mathrm{H}, \mathrm{t}, J=6.6 \mathrm{~Hz}), 2.92(2 \mathrm{H}, \mathrm{t}, J=6.6 \mathrm{~Hz}), 2.66(6 \mathrm{H}, \mathrm{s}) ;{ }^{13} \mathrm{C}\left(\mathrm{CDCl}_{3}, 150 \mathrm{MHz}\right) \delta 179.5$, $148.7,138.7,130.9,127.1,125.7,122.3,47.3,29.1,29.0$

\section{Indanone 1.85}

To a solution of $4.3 \mathrm{~mL}$ of a $2.0 \mathrm{M}$ solution of LDA in THF/hexanes at $-78^{\circ} \mathrm{C}$ was added a mixture of $1.052 \mathrm{~g}$ of $1.84(6.01 \mathrm{mmol})$ and $0.2 \mathrm{~g} \mathrm{LiCl}$ in $50 \mathrm{~mL}$ of THF. After $3 \mathrm{~h}$ of stirring at $78{ }^{\circ} \mathrm{C}, 0.68 \mathrm{~mL}$ of 2 -methoxyethyl bromide $(7.19 \mathrm{mmol})$ was introduced by a syringe. The reaction mixture was then allowed to warm to room temperature. After $12 \mathrm{~h}, 20 \mathrm{~mL}$ of a $2 \mathrm{M}$ solution of aqueous $\mathrm{HCl}$ was introduced. After $1 \mathrm{~h}$, the mixture was then extracted with methylene chloride and ammonium chloride solution. The organic layer was separated, and the aqueous layer was back extracted with methylene chloride. The combined organic layers were washed with brine and water, dried over $\mathrm{Na}_{2} \mathrm{SO}_{4}$, and concentrated. The residue was purified by flash chromatography (silica gel/ethyl acetate:hexane $=25: 75)$ to provide $0.984 \mathrm{~g}(5.21 \mathrm{mmol}$, $87 \%)$ of 1.85 as a dark red color oil: ${ }^{1} \mathrm{H}\left(\mathrm{CDCl}_{3}, 600 \mathrm{MHz}\right) \delta 7.75(1 \mathrm{H}, \mathrm{d}, J=7.8 \mathrm{~Hz}), \delta 7.57(1 \mathrm{H}$, t, $J=7.2 \mathrm{~Hz}), \delta 7.45(1 \mathrm{H}, \mathrm{d}, J=7.8 \mathrm{~Hz}), \delta 7.36(1 \mathrm{H}, \mathrm{t}, J=7.2 \mathrm{~Hz}), \delta 3.56(2 \mathrm{H}, \mathrm{m}), 3.36(1 \mathrm{H}, \mathrm{dd}$, 
$J=16.8 \mathrm{~Hz}, 17.4 \mathrm{~Hz}), 3.34(3 \mathrm{H}, \mathrm{s}), 2.89(1 \mathrm{H}, \mathrm{dd}, J=16.8 \mathrm{~Hz}, 16.8 \mathrm{~Hz}), 2.78(1 \mathrm{H}, \mathrm{m}), 2.26(1 \mathrm{H}$, $\mathrm{m}), 1.72(1 \mathrm{H}, \mathrm{m}) ;{ }^{13} \mathrm{C}\left(\mathrm{CDCl}_{3}, 150 \mathrm{MHz}\right) \delta 208.7,153.8,136.8,134.8,127.5,126.7,124.0,71.0$, $58.7,44.9,33.2,31.3$.

\section{2-Hydroxy-1-indanone 1.86}

To a mixture of $0.760 \mathrm{~g}$ of $1.85(4.01 \mathrm{mmol})$ and $1.480 \mathrm{~g}$ terbutyl ammonium iodide (4.02 mmol) in toluene under oxygen were added $1.04 \mathrm{~mL}$ of trimethylphosphite $(8.76 \mathrm{mmol})$ and $20 \mathrm{~mL}$ of $50 \%$ sodium hydroxide solution at room temperature for $24 \mathrm{~h}$. The reaction mixture was then extracted with dichloromethane. The combined extracts were washed with $50 \mathrm{~mL}$ of sodium bicarbonate, dried over sodium sulfate, and concentrated. The residue was purified by flash chromatography (silica gel/ethyl acetate:hexane $=25: 75)$ to afford $0.762 \mathrm{~g}(3.67 \mathrm{mmol}, 92 \%)$ of 1.86 as a brown color liquid: ${ }^{1} \mathrm{H}\left(\mathrm{CDCl}_{3}, 600 \mathrm{MHz}\right) \delta 7.77(1 \mathrm{H}, \mathrm{d}, J=7.8 \mathrm{~Hz}), \delta 7.62(1 \mathrm{H}, \mathrm{t}, J=$ $7.8 \mathrm{~Hz}), \delta 7.42(1 \mathrm{H}, \mathrm{d}, J=7.8 \mathrm{~Hz}), \delta 7.38(1 \mathrm{H}, \mathrm{t}, J=7.8 \mathrm{~Hz}), \delta 3.71(1 \mathrm{H}, \mathrm{m}), 3.54(1 \mathrm{H}, \mathrm{m}), 3.29$, $3.22(2 \mathrm{H}, \mathrm{dd}, J=16.8 \mathrm{~Hz}, 16.8 \mathrm{~Hz}), 3.31(3 \mathrm{H}, \mathrm{s}), 2.08(1 \mathrm{H}, \mathrm{m}), 1.89(1 \mathrm{H}, \mathrm{m}) ;{ }^{13} \mathrm{C}\left(\mathrm{CDCl}_{3}, 150\right.$ MHz) $\delta 207.2,150.9,135.8,134.4,128.0,126.8,124.8,79.9,69.1,59.1,41.6,37.5$.

\section{Indanone 1.80}

To a solution of $0.403 \mathrm{~g}$ of $1.86(1.93 \mathrm{mmol})$ in THF at $0{ }^{\circ} \mathrm{C}$ was added $0.093 \mathrm{~g}$ of sodium hydride $(2.30 \mathrm{mmol})$ and $0.15 \mathrm{~mL}(2.41 \mathrm{mmol})$ methyl iodide. After stirring for $1 \mathrm{~h}$ at $0{ }^{\circ} \mathrm{C}$, the reaction mixture was allowed to warm to room temperature. The reaction mixture was concentrated in vacuum and then extracted with mehylene chloride. The organic layer was washed with saturated ammonium chloride and water, dried over sodium sulfate, and concentrated. The residue was purified by flash chromatography (silica gel/ethyl acetate:hexane 
$=35: 65)$ to afford $0.402 \mathrm{~g}(1.82 \mathrm{mmol}, 93 \%)$ of 1.80 as a yellow liquid: ${ }^{1} \mathrm{H}\left(\mathrm{CDCl}_{3}, 600 \mathrm{MHz}\right) \delta$ $7.74(1 \mathrm{H}, \mathrm{d}, J=7.2 \mathrm{~Hz}), \delta 7.59(1 \mathrm{H}, \mathrm{t}, J=7.2 \mathrm{~Hz}), \delta 7.42(1 \mathrm{H}, \mathrm{d}, J=7.8 \mathrm{~Hz}), \delta 7.36(1 \mathrm{H}, \mathrm{t}, J=$ $7.2 \mathrm{~Hz}), \delta 3.51(1 \mathrm{H}, \mathrm{m}), 3.44(1 \mathrm{H}, \mathrm{m}), 3.27(2 \mathrm{H}, \mathrm{dd}, J=17.5 \mathrm{~Hz}, 17.4 \mathrm{~Hz}), 3.22(3 \mathrm{H}, \mathrm{s}), 3.17$ $(3 \mathrm{H}, \mathrm{s}), 2.10(1 \mathrm{H}, \mathrm{m}), 1.98(1 \mathrm{H}, \mathrm{m}) ;{ }^{13} \mathrm{C}\left(\mathrm{CDCl}_{3}, 150 \mathrm{MHz}\right) \delta 205.2,151.5,135.8,135.5,127.9$, $126.8,124.5,83.4,68.1,58.7,52.0,36.7,35.4$.

\section{(Trimethysilyl)ethyne 1.88}

To a flask containing $0.635 \mathrm{~g}$ of dichlorobis(triphenylphosphine) palladium $(0.55 \mathrm{mmol})$ and $0.230 \mathrm{~g}$ of $\mathrm{CuI}(1.20 \mathrm{mmol})$ was added via cannula a solution of $1.003 \mathrm{~g}$ of 1,3-dichloro-2iodobenzene $(3.66 \mathrm{mmol})$ in $45 \mathrm{~mL}$ of triethylamine followed by a solution of $0.431 \mathrm{~g}$ of trimethyl-silylacetylene $(1.20 \mathrm{mmol})$ under a nitrogen atmosphere. The resulting mixture was stirred vigorously at $80^{\circ} \mathrm{C}$ for $12 \mathrm{~h}$. The mixture was then filtered to remove solid particles, and the filtrate was concentrated. The residue was purified by flash column chromatography (silica gel/ethyl acetate:hexane $=10: 90)$ to give $0.810 \mathrm{~g}$ of $1.88(3.33 \mathrm{mmol}, 91 \%$ yield $)$ as a light yellow oil: ${ }^{1} \mathrm{H}\left(\mathrm{CDCl}_{3}, 600 \mathrm{MHz}\right) \delta 7.31(1 \mathrm{H}, \mathrm{d}, J=6 \mathrm{~Hz}), \delta 7.29(1 \mathrm{H}, \mathrm{d}, J=6 \mathrm{~Hz}), 7.15(1 \mathrm{H}, \mathrm{dd}$, $J=7.2 \mathrm{~Hz}), 0.30(9 \mathrm{H}, \mathrm{s})$.

\section{(2,6-dichloropheny)ethyne 1.89}

To a solution of $0.810 \mathrm{~g}$ of $1.88(3.33 \mathrm{mmol})$ in $50 \mathrm{ml}$ of methanol was added $10 \mathrm{~mL}$ of a $10 \%$ sodium hydroxide solution. After $10 \mathrm{~min}$ of stirring at room temperature, the reaction mixture was neutralized with a $2 \mathrm{M}$ solution of $\mathrm{HCl}$. The organic layer was separated, and the aqueous layer was back extracted with diethyl ether. The combined organic layers were treated with brine and water, dried over $\mathrm{Na}_{2} \mathrm{SO}_{4}$, and concentrated to afford, without further purification, $0.564 \mathrm{~g}$ 
(3.30 mmol, 99\%) of 1.89 as a white color solid: ${ }^{1} \mathrm{H}\left(\mathrm{CDCl}_{3}, 600 \mathrm{MHz}\right) \delta 7.34(2 \mathrm{H}, \mathrm{d}, 8.4 \mathrm{~Hz})$, $7.20(1 \mathrm{H}, \mathrm{t}, 8.4 \mathrm{~Hz}), 3.68(1 \mathrm{H}, \mathrm{s}) ;{ }^{13} \mathrm{C}\left(\mathrm{CDCl}_{3}, 150 \mathrm{MHz}\right) \delta 137.9,129.7,127.7,127.3,122.3$, 88.0

\section{(Trimethysilyl)ethyne 1.91}

To a flask containing $0.131 \mathrm{~g}$ of dichlorobis(triphenylphosphine) palladium $(0.19 \mathrm{mmol})$ and $0.060 \mathrm{~g}$ of $\mathrm{CuI}(0.32 \mathrm{mmol})$ was added via cannula a solution of $1.760 \mathrm{~g}$ of 1-bromo-2iodobenzene $(6.22 \mathrm{mmol})$ in $45 \mathrm{~mL}$ of triethylamine followed by a solution of $0.733 \mathrm{~g}$ of trimethyl -silylacetylene $(7.46 \mathrm{mmol})$ under a nitrogen atmosphere. After one hour of stirring at room temperature, the mixture was then filtered to remove solid particles, and the filtrate was concentrated. The residue was purified by flash column chromatography (silica gel/ethyl acetate:hexane $=5: 95)$ to give $1.520 \mathrm{~g}$ of $1.91(6.00 \mathrm{mmol}, 96 \%$ yield $)$ as a black color liquid: ${ }^{1} \mathrm{H}$ $\left(\mathrm{CDCl}_{3}, 600 \mathrm{MHz}\right) \delta 7.57(1 \mathrm{H}, \mathrm{d}, J=7.8 \mathrm{~Hz}), 7.49(1 \mathrm{H}, \mathrm{d}, J=7.8 \mathrm{~Hz}), 7.23(1 \mathrm{H}, \mathrm{t}, J=7.8 \mathrm{~Hz})$, $7.15(1 \mathrm{H}, \mathrm{t}, J=7.8 \mathrm{~Hz}), 0.27(9 \mathrm{H}, \mathrm{s}) ;{ }^{13} \mathrm{C}\left(\mathrm{CDCl}_{3}, 150 \mathrm{MHz}\right) \delta 133.7,132.4,129.6,127.0,125.9$, $125.3,103.1,99.7,-0.02$.

\section{1-(2-iodophenyl)-2-(trimethylsilyl)ethyne 1.92}

To a solution of $1.050 \mathrm{~g}$ of $1.91(4.20 \mathrm{mmol})$ in $50 \mathrm{~mL}$ of anhydrous diethyl ether at $-78^{\circ} \mathrm{C}$ was added dropwise $1.84 \mathrm{~mL}$ of a $2.5 \mathrm{M}$ solution of $n$-butyllithium ( $4.60 \mathrm{mmol}$ ) in hexanes. After one hour of stirring at $-78^{\circ} \mathrm{C}$, a solution of $1.070 \mathrm{~g}$ of iodine $(4.20 \mathrm{mmol})$ in $40 \mathrm{~mL}$ of anhydrous diethyl ether was added dropwise via cannula. The reaction mixture was allowed to warm to room temperature before $20 \mathrm{~mL}$ of a saturated ammonium chloride solution was introduced. The organic layer was separated, washed with water, dried over sodium sulfate, and concentrated. 
The residue was purified by flash column chromatography (silica gel/hexane) to give $1.248 \mathrm{~g}$ of 1.92 (4.16 mmol, $99 \%$ yield) as a black color liquid: ${ }^{1} \mathrm{H}\left(\mathrm{CDCl}_{3}, 600 \mathrm{MHz}\right) \delta 7.84(1 \mathrm{H}, \mathrm{d}, J=8.4$ $\mathrm{Hz}), 7.47(1 \mathrm{H}, \mathrm{d}, J=7.8 \mathrm{~Hz}), 7.28(1 \mathrm{H}, \mathrm{t}, J=7.2 \mathrm{~Hz}), 6.98(1 \mathrm{H}, \mathrm{t}, J=7.8 \mathrm{~Hz}), 0.28(9 \mathrm{H}, \mathrm{s}) ;{ }^{13} \mathrm{C}$ $\left(\mathrm{CDCl}_{3}, 150 \mathrm{MHz}\right) \delta 138.8,132.8,129.7,128.7,127.8,106.6,101.4,98.9,-0.01$.

\section{(Trimethysilyl)benzannulated enediyne 1.93}

To a mixture of $1.92(0.592 \mathrm{~g}, 1.97 \mathrm{mmol}), \mathrm{Pd}(\mathrm{PPh} 3)_{2} \mathrm{Cl}_{2}(0.041 \mathrm{~g}, 0.06 \mathrm{mmol})$, and copper(I) iodide $(0.019 \mathrm{~g}, 0.10 \mathrm{mmol})$ in $30 \mathrm{~mL}$ of triethylamine was added via cannula a solution of 0.337 $\mathrm{g}$ of $\mathbf{1 . 8 9}(1.97 \mathrm{mmol})$ in $5 \mathrm{~mL}$ of triethylamine. After two hours of stirring at room temperature, the mixture was then filtered to remove solid particles, and the filtrate was concentrated. Purification of the residue by flash column chromatography (silica gel/hexanes) afforded $0.528 \mathrm{~g}$ of $1.93(1.54 \mathrm{mmol}, 78 \%$ yield $)$ as a yellow oil: ${ }^{1} \mathrm{H}\left(\mathrm{CDCl}_{3}, 600 \mathrm{MHz}\right) \delta 7.61(1 \mathrm{H}, \mathrm{m}), 7.53(1 \mathrm{H}$, m), $7.36(2 \mathrm{H}, \mathrm{d}, J=7.8 \mathrm{~Hz}), 7.30(2 \mathrm{H}, \mathrm{m}), 7.18(1 \mathrm{H}, \mathrm{t}, J=7.8), 0.24(9 \mathrm{H}, \mathrm{s}) ;{ }^{13} \mathrm{C}\left(\mathrm{CDCl}_{3}, 150\right.$ MHz) $\delta 137.4,132.9,132.8,129.2,128.7,128.3,127.6,125.6,125.3,123.5,103.2,99.2,98.5$, $87.2,0.12$.

\section{Benzannulated enediyne $\mathbf{1 . 8 3}$}

To a solution of $0.528 \mathrm{~g}$ of $1.93(1.54 \mathrm{mmol})$ in $50 \mathrm{~mL}$ of methanol was added $20 \mathrm{~mL}$ of a $10 \%$ sodium hydroxide solution. After $10 \mathrm{~min}$ of stirring at room temperature, the reaction mixture was neutralized with a $2 \mathrm{M}$ solution of $\mathrm{HCl}$. The organic layer was separated, and the aqueous layer was back extracted with diethyl ether. The combined organic layers were treated with brine and water, dried over $\mathrm{Na}_{2} \mathrm{SO}_{4}$, and concentrated to afford, without purification, $0.413 \mathrm{~g}$ (1.52 mmol, $99 \%)$ of 1.83 as a dark brown color solid: ${ }^{1} \mathrm{H}\left(\mathrm{CDCl}_{3}, 600 \mathrm{MHz}\right) \delta 7.64(1 \mathrm{H}, \mathrm{d}, J=7.2$ 
$\mathrm{Hz}), 7.56(1 \mathrm{H}, \mathrm{d}, J=7.8 \mathrm{~Hz}), 7.34(4 \mathrm{H}, \mathrm{m}), 7.17(1 \mathrm{H}, \mathrm{t}, J=8.4), 7.18(1 \mathrm{H}, \mathrm{t}, J=8.4), 3.37(1 \mathrm{H}$, s); ${ }^{13} \mathrm{C}\left(\mathrm{CDCl}_{3}, 150 \mathrm{MHz}\right) \delta 137.5,132.8,132.6,129.3,128.8,128.6,127.6,125.9,124.7,123.3$, $98.1,87.3,82.0,81.9$.

\section{Propargylic alcohol 1.94}

To a mixture of $1.80(0.155 \mathrm{~g}, 0.70 \mathrm{mmol})$ and $1.83(0.190 \mathrm{~g}, 0.70 \mathrm{mmol})$ was in $50 \mathrm{~mL}$ of THF was added a solution of $0.43 \mathrm{~mL}$ of a $1.8 \mathrm{M}$ solution of LDA in THF/hexanes at $0{ }^{\circ} \mathrm{C}$. After $2 \mathrm{~h}$ of stirring at $0{ }^{\circ} \mathrm{C}, 20 \mathrm{~mL}$ of a saturated ammonium chloride solution and $50 \mathrm{~mL}$ of methylene chloride were-added. The organic layer was separated, and the aqueous layer was back extracted with methylene chloride. The combined organic layers were washed with brine and water, dried over sodium sulfate, and concentrated. The residue was purified by flash chromatography (silica gel)/AcOEt/hexane (30/70) to afford $0.306 \mathrm{~g}(0.62 \mathrm{mmol}, 89 \%, 1: 1$ mixture of isomers) of 1.94 as a brown color liquid. Diastereomer $1:{ }^{1} \mathrm{H}\left(\mathrm{CDCl}_{3}, 600 \mathrm{MHz}\right) \delta 7.70(1 \mathrm{H}, \mathrm{d}, J=7.2 \mathrm{~Hz}), 7.63$ $(1 \mathrm{H}, \mathrm{m}), 7.57(1 \mathrm{H}, \mathrm{m}), 7.32(4 \mathrm{H}, \mathrm{m}), 7.20(1 \mathrm{H}, \mathrm{t}, J=7.8 \mathrm{~Hz}), 7.17(1 \mathrm{H}, \mathrm{d}, J=7.8 \mathrm{~Hz}), 7.15(1 \mathrm{H}$, d, $J=7.2 \mathrm{~Hz}), 7.10(1 \mathrm{H}, \mathrm{t}, J=7.2 \mathrm{~Hz}), 4.85(1 \mathrm{H}, \mathrm{s}), 3.95(1 \mathrm{H}, \mathrm{t}, J=9 \mathrm{~Hz}), 3.49(1 \mathrm{H}, \mathrm{m}), 3.35$ $(3 \mathrm{H}, \mathrm{s}), 3.16(1 \mathrm{H}, \mathrm{d}, J=16.2 \mathrm{~Hz}), 3.15(3 \mathrm{H}, \mathrm{s}), 3.06(1 \mathrm{H}, \mathrm{d}, J=16.2 \mathrm{~Hz}), 2.27(1 \mathrm{H}, \mathrm{m}), 2.20(1 \mathrm{H}$, $\mathrm{m}) ;{ }^{13} \mathrm{C}\left(\mathrm{CDCl}_{3}, 150 \mathrm{MHz}\right) \delta 144.9,140.4,137.6,132.9,132.8,129.3,129.2,128.7,127.9,127.6$, $127.3,125.8,125.06,125.02,124.2,123.4,98.6,94.5,89.7,87.0,84.1,80.4,67.9,58.5,51.6$, 39.6, 33.5. Diastereomer 2: ${ }^{1} \mathrm{H}\left(\mathrm{CDCl}_{3}, 600 \mathrm{MHz}\right) \delta 7.61(1 \mathrm{H}, \mathrm{d}, J=7.2 \mathrm{~Hz}), 7.58(1 \mathrm{H}, \mathrm{m}), 7.51$ $(1 \mathrm{H}, \mathrm{m}), 7.34(2 \mathrm{H}, \mathrm{d}, 8.4 \mathrm{~Hz}), 7.30(2 \mathrm{H}, \mathrm{m}), 7.18(2 \mathrm{H}, \mathrm{t}, J=7.2 \mathrm{~Hz}), 7.12(1 \mathrm{H}, \mathrm{t}, J=7.8 \mathrm{~Hz})$, $7.10(1 \mathrm{H}, \mathrm{d}, J=7.2 \mathrm{~Hz}), 4.08(1 \mathrm{H}, \mathrm{s}), 3.55(1 \mathrm{H}, \mathrm{m}), 3.45(1 \mathrm{H}, \mathrm{m}), 3.36(3 \mathrm{H}, \mathrm{s}), 3.22(3 \mathrm{H}, \mathrm{s}), 3.11$ $(1 \mathrm{H}, \mathrm{d}, J=16.2 \mathrm{~Hz}), 3.08(1 \mathrm{H}, \mathrm{d}, J=16.2 \mathrm{~Hz}), 2.59(1 \mathrm{H}, \mathrm{m}), 2.04(1 \mathrm{H}, \mathrm{m}) ;{ }^{13} \mathrm{C}\left(\mathrm{CDCl}_{3}, 150\right.$ 
MHz) $\delta 144.8,139.0,137.6,132.7,132.6,129.3,128.9,128.7,128.3,127.6,127.3,125.2,124.9$,

$124.7,124.2,123.3,98.3,93.0,88.9,86.8,86.3,79.4,68.5,58.6,52.0,38.8,32.0$.

\section{Benzofluorene 1.96a-c}

To a solution of $0.101 \mathrm{~g}$ of $1.94(0.20 \mathrm{mmol})$ in methylene chloride at $0{ }^{\circ} \mathrm{C}$ was added dropwise $0.72 \mathrm{~mL}$ of thionyl chloride $(10 \mathrm{mmol})$ and $0.16 \mathrm{~mL}$ of pyridine $(10 \mathrm{mmol})$. After stirring $2 \mathrm{~h}$ at $0{ }^{\circ} \mathrm{C}, 20 \mathrm{~mL}$ of a saturated ammonium chloride solution and $20 \mathrm{~mL}$ of methylene chloride were added. The organic layer was separated, and the aqueous layer was back extracted with methylene chloride. The combined organic layers were washed with brine and water, dried over sodium sulfate, and concentrated. Purification of the residue by flash column chromatography (silica gel/ethyl acetate/hexanes (25:75) afforded $0.076 \mathrm{~g}$ of $1.96 \mathrm{a}, 1.96 \mathrm{~b}, 1.96 \mathrm{c}$ as a brown oil. 1.96a: ${ }^{1} \mathrm{H}\left(\mathrm{CDCl}_{3}, 600 \mathrm{MHz}\right) \delta 7.70(1 \mathrm{H}, \mathrm{d}), 7.63(1 \mathrm{H}, \mathrm{m}), 7.58(1 \mathrm{H}, \mathrm{m}), 7.50(1 \mathrm{H}, \mathrm{d}), 7.46(1 \mathrm{H}$, m), 7.33(2H, m), $7.14(1 \mathrm{H}, \mathrm{t}), 7.10(1 \mathrm{H}, \mathrm{t}), 6.45(1 \mathrm{H}, \mathrm{d}, J=7.8 \mathrm{~Hz}), 6.25(1 \mathrm{H}, \mathrm{d}), 3.69(2 \mathrm{H}, \mathrm{dd})$, $3.47(1 \mathrm{H}, \mathrm{m}), 3.32(1 \mathrm{H}, \mathrm{m}), 3.13(3 \mathrm{H}, \mathrm{s}), 3.06(3 \mathrm{H}, \mathrm{s}), 2.87(2 \mathrm{H}, \mathrm{m}) ; 1.96 \mathrm{~b}:{ }^{1} \mathrm{H}\left(\mathrm{CDCl}_{3}, 600 \mathrm{MHz}\right)$ $\delta 7.70(1 \mathrm{H}, \mathrm{d}), 7.59(2 \mathrm{H}, \mathrm{m}), 7.49(1 \mathrm{H}, \mathrm{d}), 7.43(1 \mathrm{H}, \mathrm{m}), 7.32(2 \mathrm{H}, \mathrm{m}), 7.12(2 \mathrm{H}, \mathrm{m}), 6.45(1 \mathrm{H}, \mathrm{d}$, $J=7.8 \mathrm{~Hz}), 5.94(1 \mathrm{H}, \mathrm{d}), 3.71(1 \mathrm{H}, \mathrm{d}), 3.53(2 \mathrm{H}, \mathrm{m}), 3.52(1 \mathrm{H}, \mathrm{d}), 3.10(3 \mathrm{H}, \mathrm{s}), 3.01(1 \mathrm{H}, \mathrm{m})$, $2.76(3 \mathrm{H}, \mathrm{s}), 2.62(1 \mathrm{H}, \mathrm{m}) ; 1.96 \mathrm{c}:{ }^{1} \mathrm{H}\left(\mathrm{CDCl}_{3}, 600 \mathrm{MHz}\right) \delta 7.74(1 \mathrm{H}, \mathrm{d}), 7.61(2 \mathrm{H}, \mathrm{d}), 7.50(2 \mathrm{H}$, m), $7.32(1 \mathrm{H}, \mathrm{d}), 7.25(2 \mathrm{H}, \mathrm{m}), 7.05(1 \mathrm{H}, \mathrm{d}), 6.36(1 \mathrm{H}, \mathrm{d}), 3.71(1 \mathrm{H}, \mathrm{d}, J=18 \mathrm{~Hz}), 3.59(2 \mathrm{H}, \mathrm{m})$, $3.44(1 \mathrm{H}, \mathrm{m}), 3.16(3 \mathrm{H}, \mathrm{s}), 3.13(3 \mathrm{H}, \mathrm{s}), 3.00(1 \mathrm{H}, \mathrm{m}), 2.65(1 \mathrm{H}, \mathrm{m})$

\section{Benzofluorene 1.97}

To a solution of $0.996 \mathrm{~g}$ of a diiodosilane* solution at room temperature was added $0.102 \mathrm{~g}$ of a mixture of $1.96 \mathrm{a}-\mathrm{c}(0.21 \mathrm{mmol})$ in $5 \mathrm{~mL}$ chloroform. After $6 \mathrm{~h}$ of stirring, $20 \mathrm{~mL}$ of a saturated 
ammonium chloride solution and $20 \mathrm{~mL}$ of methylene chloride were added. The organic layer was separated, and the aqueous layer was back extracted with methylene chloride. The combined organic layers were washed with brine and water, dried over sodium sulfate, and concentrated. Purification of the residue by flash column chromatography (silica gel/hexanes, $R f=0.90$ ) afforded $0.108 \mathrm{~g}$ of $1.97(0.20 \mathrm{mmol}, 95 \%$ yield $)$ as a white solid: ${ }^{1} \mathrm{H}\left(\mathrm{CDCl}_{3}, 600 \mathrm{MHz}\right) \delta 7.60$ $(3 \mathrm{H}, \mathrm{t}), 7.48(1 \mathrm{H}, \mathrm{t}), 7.40(1 \mathrm{H}, \mathrm{t}), 7.31(1 \mathrm{H}, \mathrm{d}), 7.28(1 \mathrm{H}, \mathrm{d}), 7.11(2 \mathrm{H}, \mathrm{t}), 6.59(1 \mathrm{H}, \mathrm{d}, J=7.8$ $\mathrm{Hz}), 4.17(1 \mathrm{H}, \mathrm{d}, J=21 \mathrm{~Hz}), 4.09(1 \mathrm{H}, \mathrm{d}, J=21.6 \mathrm{~Hz}), 4.06(1 \mathrm{H}, \mathrm{dd}), 3.75(1 \mathrm{H}, \mathrm{dd}), 3.40(1 \mathrm{H}$, $\mathrm{m}), 3.35(1 \mathrm{H}, \mathrm{dd}), 3.21(1 \mathrm{H}, \mathrm{dd}), 2.84(1 \mathrm{H}, \mathrm{m}), 2.30(1 \mathrm{H}, \mathrm{m}) ;{ }^{13} \mathrm{C}\left(\mathrm{CDCl}_{3}, 150 \mathrm{MHz}\right) \delta 144.2$, $143.7,142.6,141.0,140.3,138.1,136.5,136.4,136.3,134.2,130.0,129.5,128.6,128.0,127.5$, $127.2,125.3,124.8,122.3,120.3,119.5,44.2,38.2,36.9,34.6,4.04$

*Preparation of diiodosilane was followed exactly by the same procedure in J. Org. Chem. 1987, $52,4846-4851$

\section{Hydrocarbon 1.98a and 1.98b}

To a solution of $0.040 \mathrm{~g}$ of $1.97(0.10 \mathrm{mmol})$ in $5 \mathrm{~mL}$ THF at $40{ }^{\circ} \mathrm{C}$ was added $0.011 \mathrm{~g}$ of potassium $t$-butoxide $(0.10 \mathrm{mmole})$ in $5 \mathrm{~mL}$ of THF. After $2 \mathrm{~h}$ of stirring at $40^{\circ} \mathrm{C}, 10 \mathrm{~mL}$ of a saturated ammonium chloride solution and $10 \mathrm{~mL}$ of methylene chloride were added. The organic layer was separated, and the aqueous layer was back extracted with methylene chloride. The combined organic layers were washed with brine and water, dried over sodium sulfate, and concentrated to afford, without purification, the mixture of $0.030 \mathrm{~g}$ of $1.98 \mathrm{a}$ and $1.98 \mathrm{~b}$. All nonaromatic protons were assigned to corresponding products. 1.98a: ${ }^{1} \mathrm{H}\left(\mathrm{CDCl}_{3}, 600 \mathrm{MHz}\right) \delta 4.42-$ $4.34(1 \mathrm{H}, \mathrm{d}), 4.16-4.07(1 \mathrm{H}, \mathrm{d}), 3.92(1 \mathrm{H}, \mathrm{s}), 3.82(1 \mathrm{H}, \mathrm{m}), 2.60(2 \mathrm{H}, \mathrm{m}), 1.39(1 \mathrm{H}, \mathrm{m}), 1.03(1 \mathrm{H}$, 
m); 1.98b: ${ }^{1} \mathrm{H}\left(\mathrm{CDCl}_{3}, 600 \mathrm{MHz}\right) \delta 6.85(1 \mathrm{H}, \mathrm{s}), 6.69(1 \mathrm{H}, \mathrm{d}), 4.34(2 \mathrm{H}, \mathrm{s}), 3.03(2 \mathrm{H}, \mathrm{m}), 1.49$ $(3 \mathrm{H}, \mathrm{m})$.

\section{Hydrocarbon 1.99 and 1.100}

A mixture of $1.98 \mathrm{a}(0.030 \mathrm{~g}, 0.07 \mathrm{mmol}), \mathrm{Pd}\left(\mathrm{PCy}_{3}\right)_{2} \mathrm{Cl}_{2}(0.011 \mathrm{~g}, 0.015 \mathrm{mmol})$ and $\mathrm{DBU}(0.104$ $\mathrm{mL}, 0.7 \mathrm{mmol}$ ) in $5 \mathrm{~mL}$ dimethylacetamide was placed in a sealed reaction tube equipped with magnetic bar and heated under microwave irradiation at $150{ }^{\circ} \mathrm{C}$ for $90 \mathrm{~min}$. The mixture was then filtered to remove solid particles, and the filtrate was concentrated. The residue was washed with brine and water, dried over sodium sulfate, and concentrated to afford, without purification, the mixture of $0.014 \mathrm{~g}$ of 1.99 and 1.100 . Two doublet peaks above $\delta 9.0$ were observed in the crude NMR which indicated formation of PAHs 1.99 and 1.100. ${ }^{1} \mathrm{H}\left(\mathrm{CDCl}_{3}, 600 \mathrm{MHz}\right) \delta 9.14(1 \mathrm{H}, \mathrm{d})$, $9.29(2 \mathrm{H}, \mathrm{d})$. 


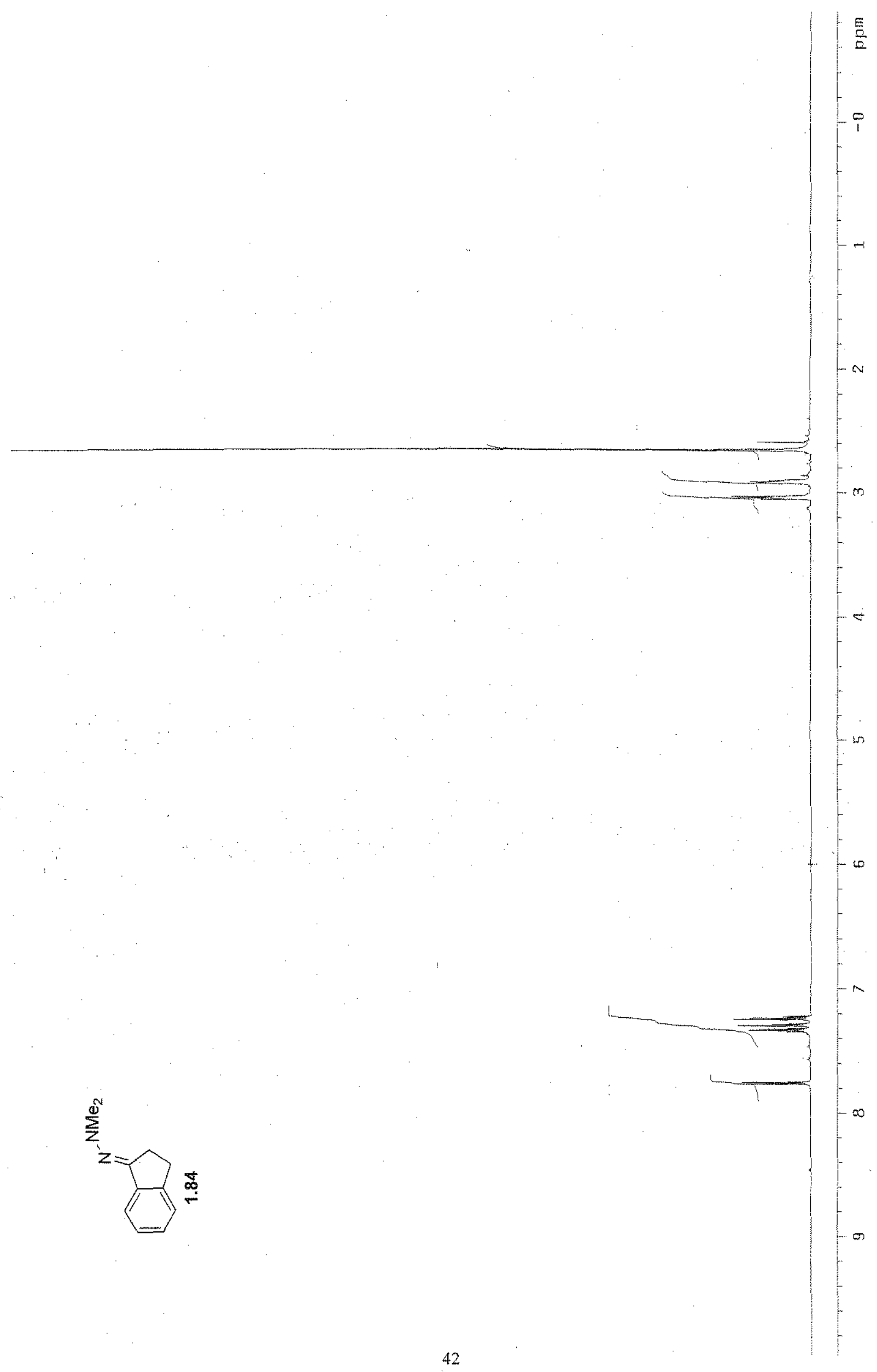




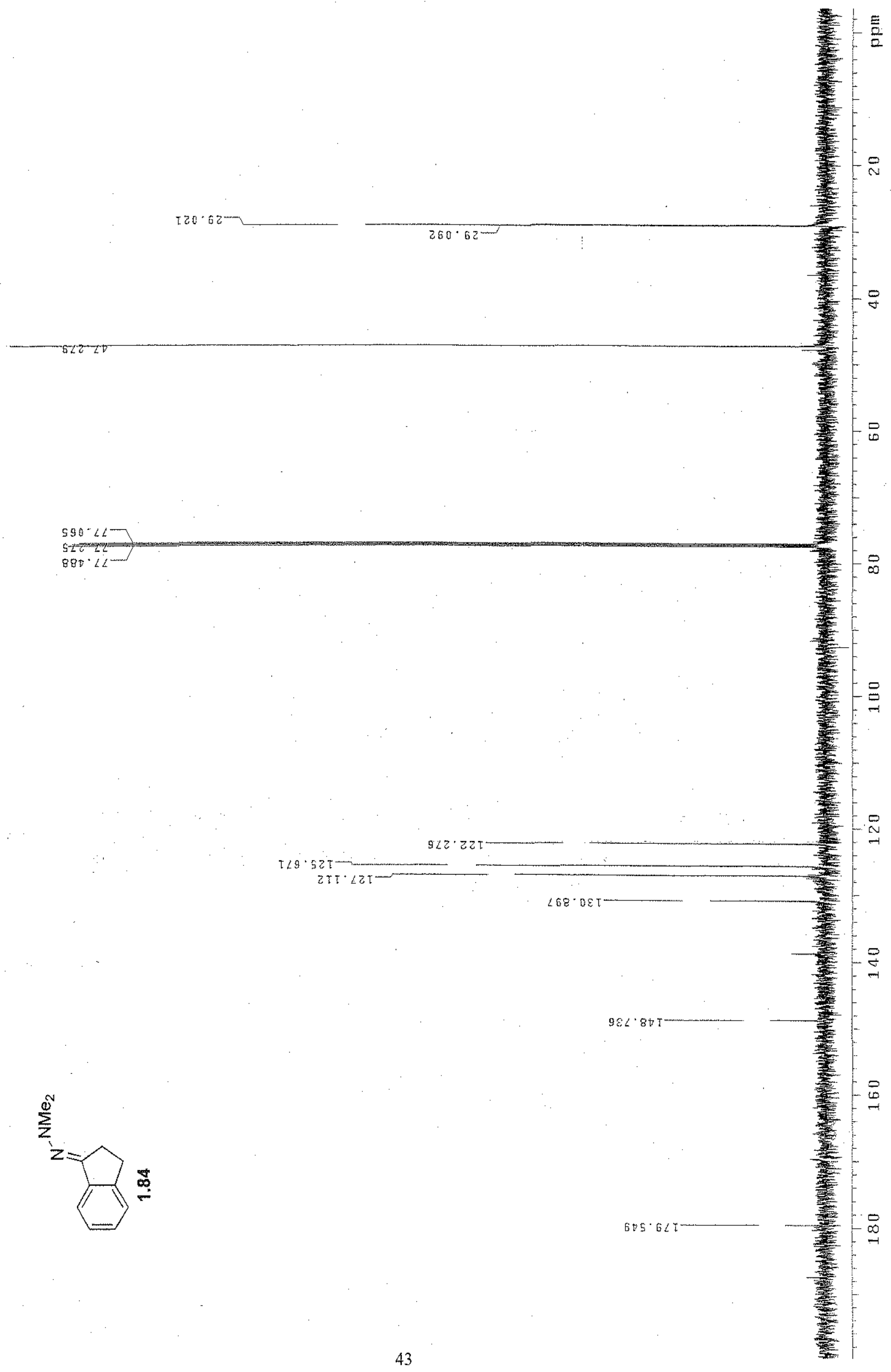




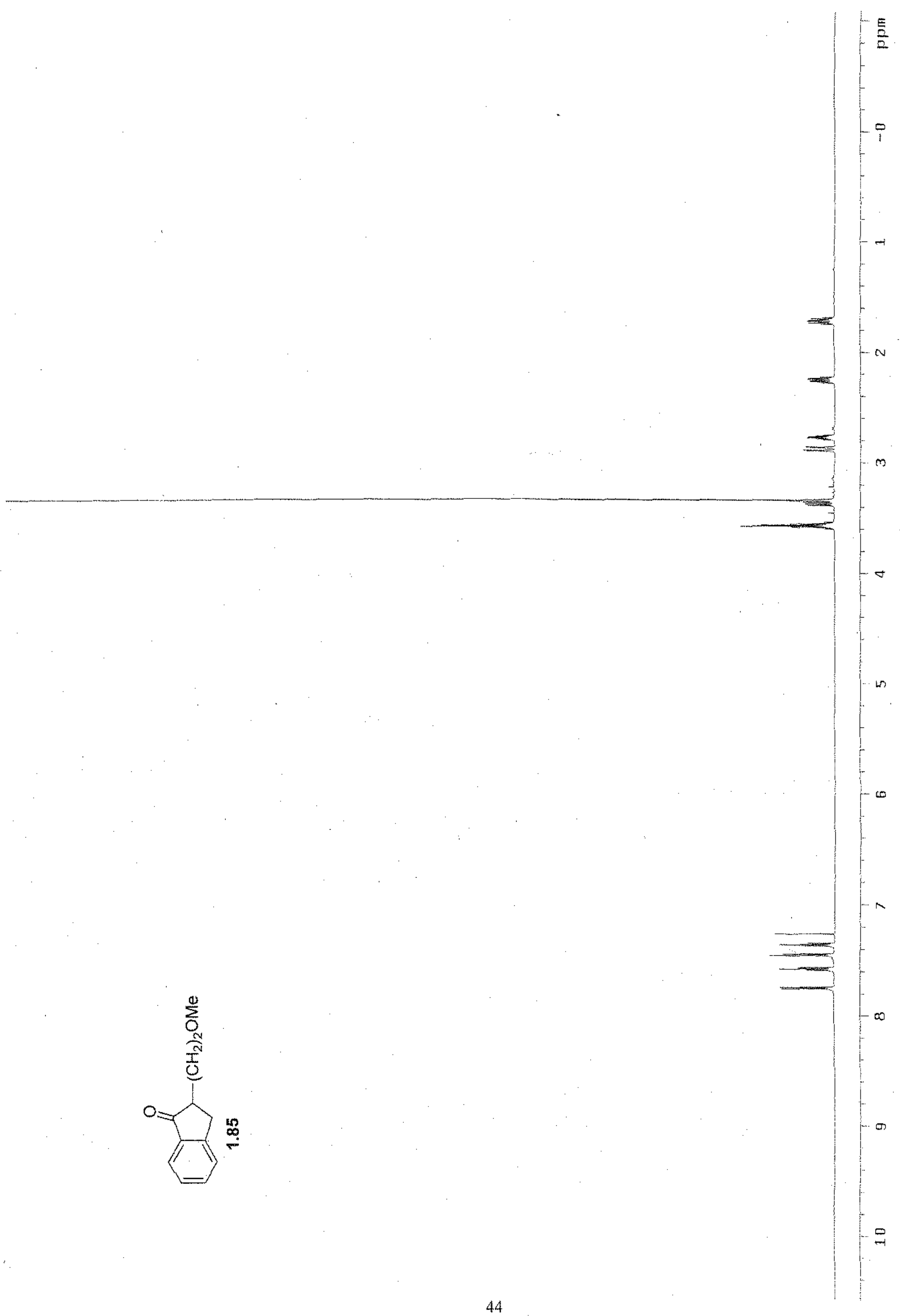




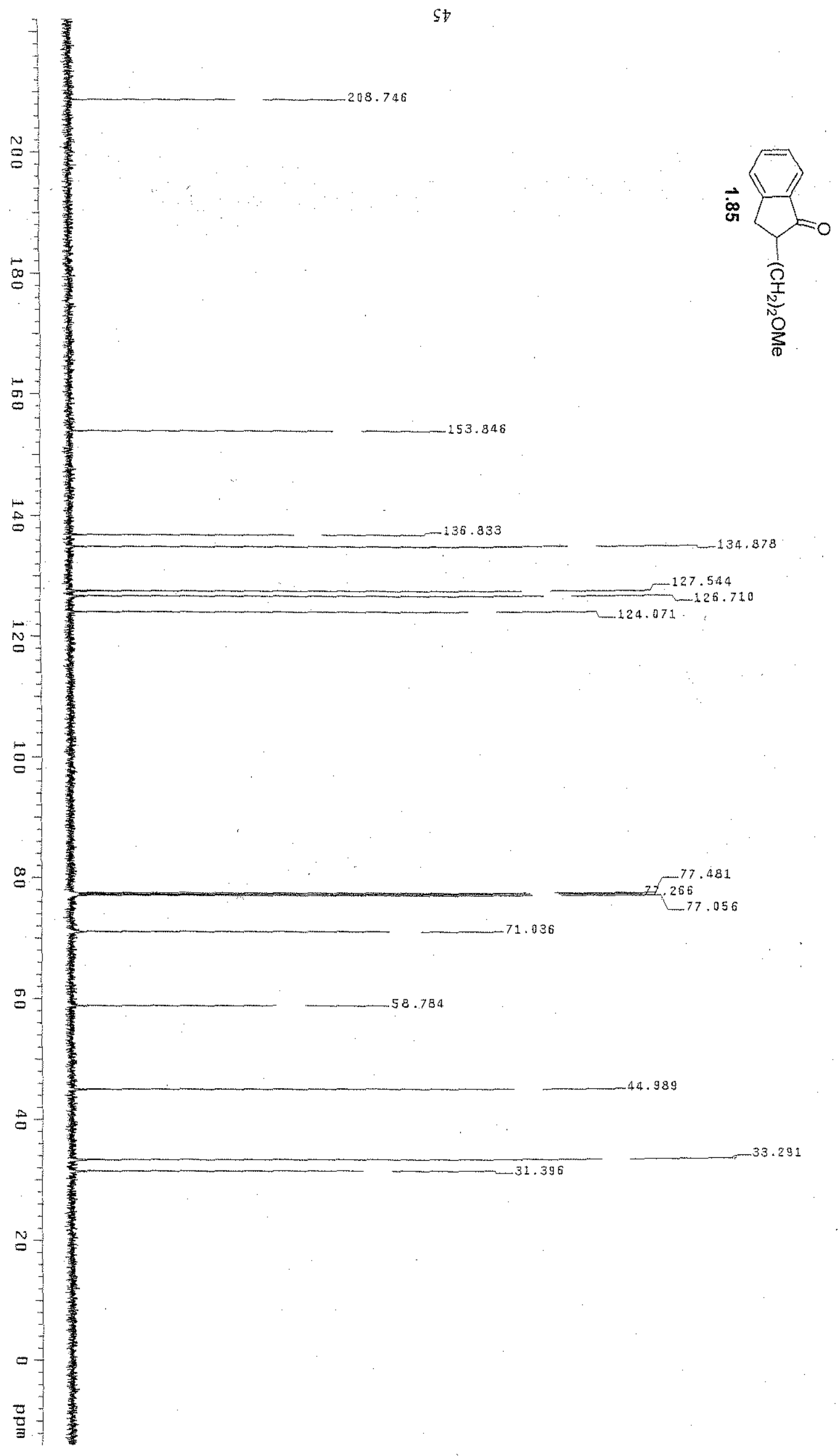




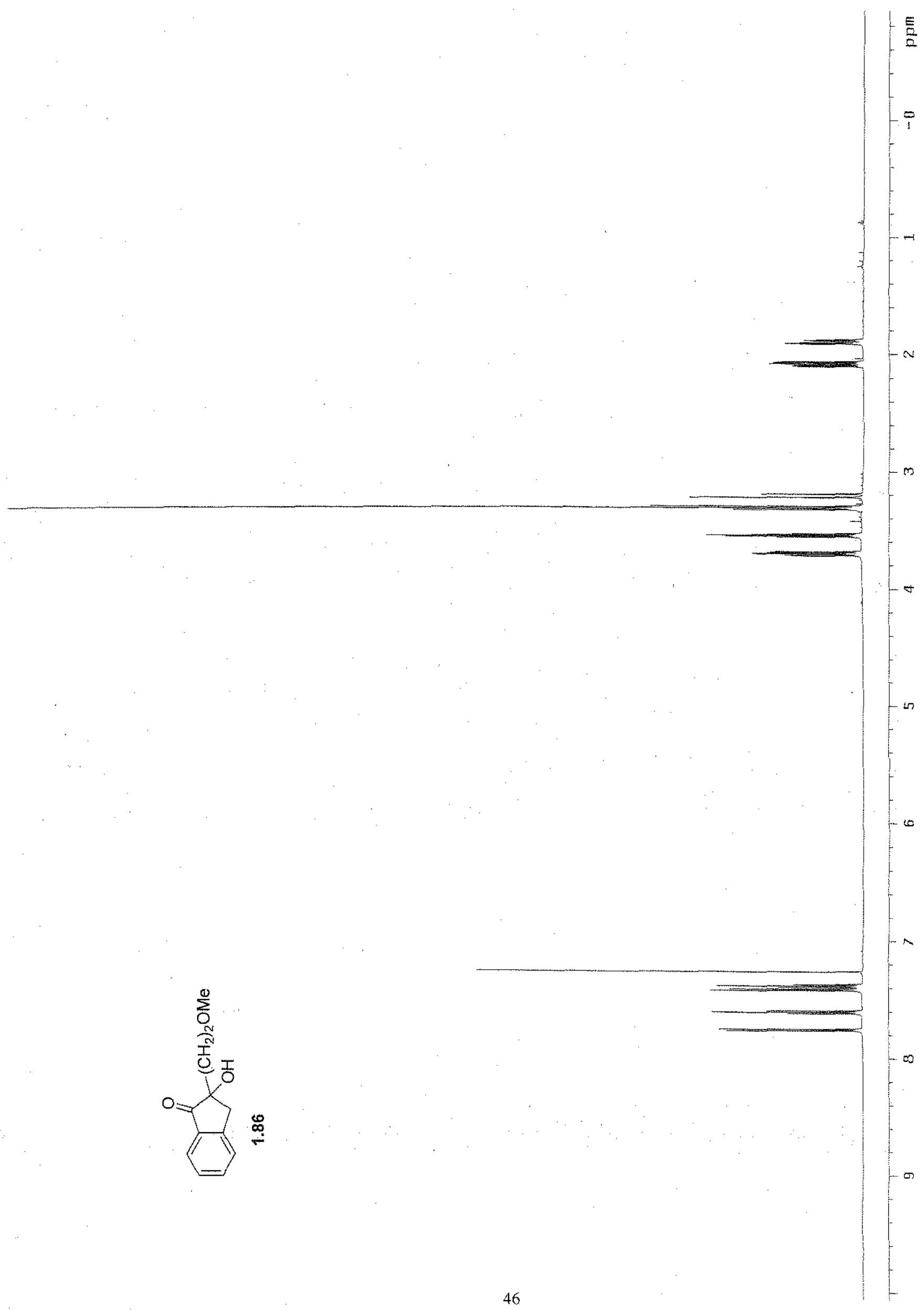




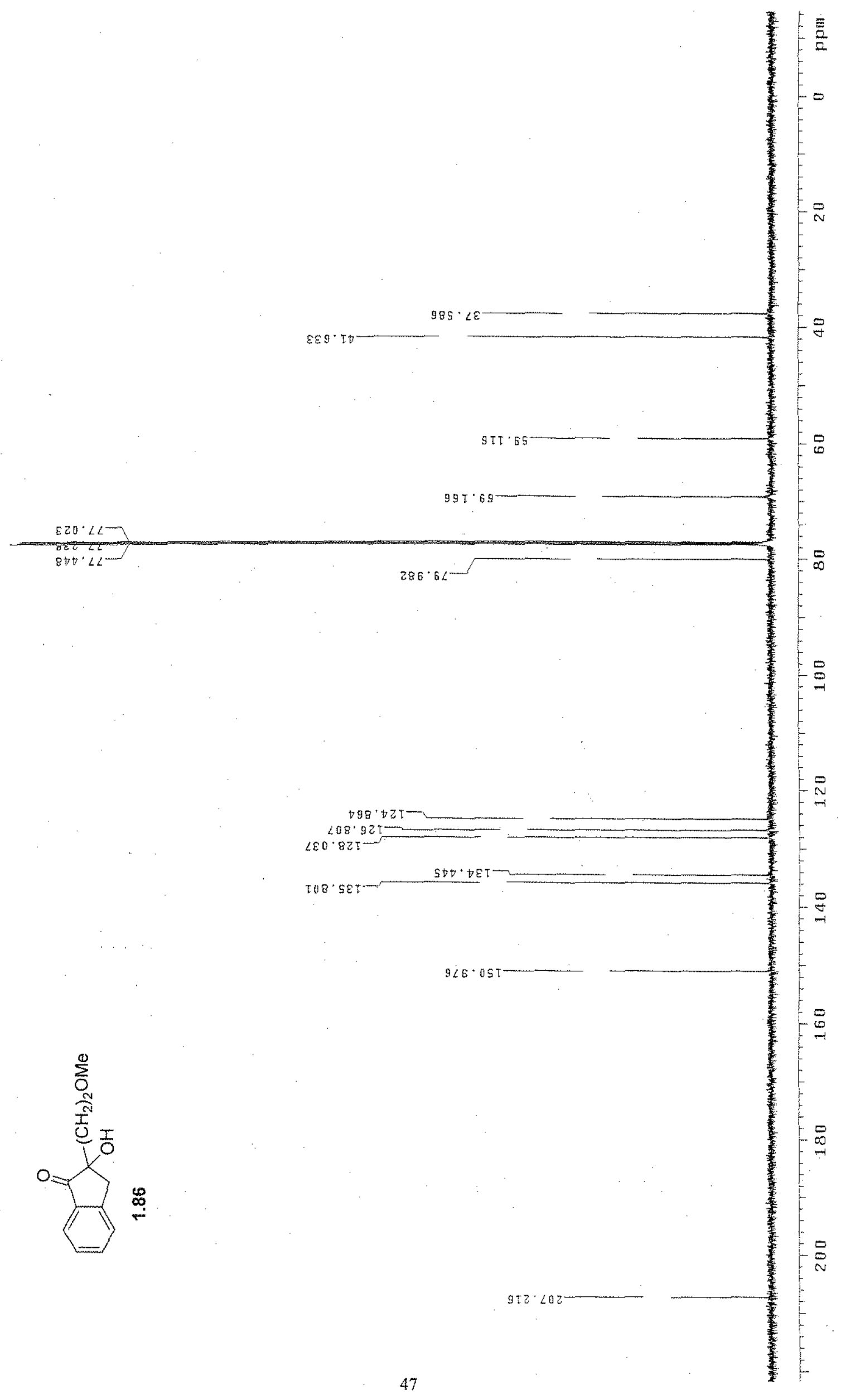




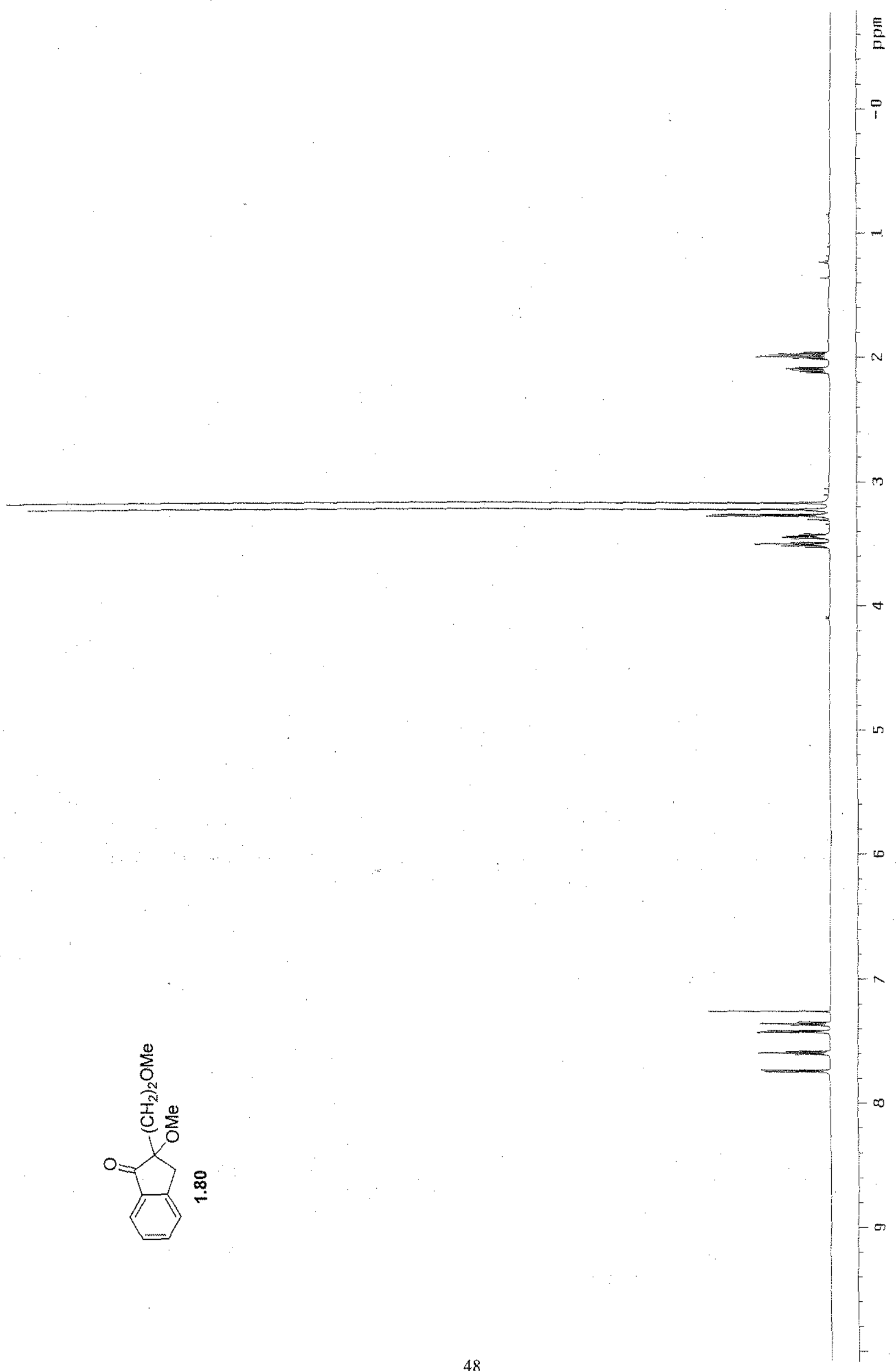




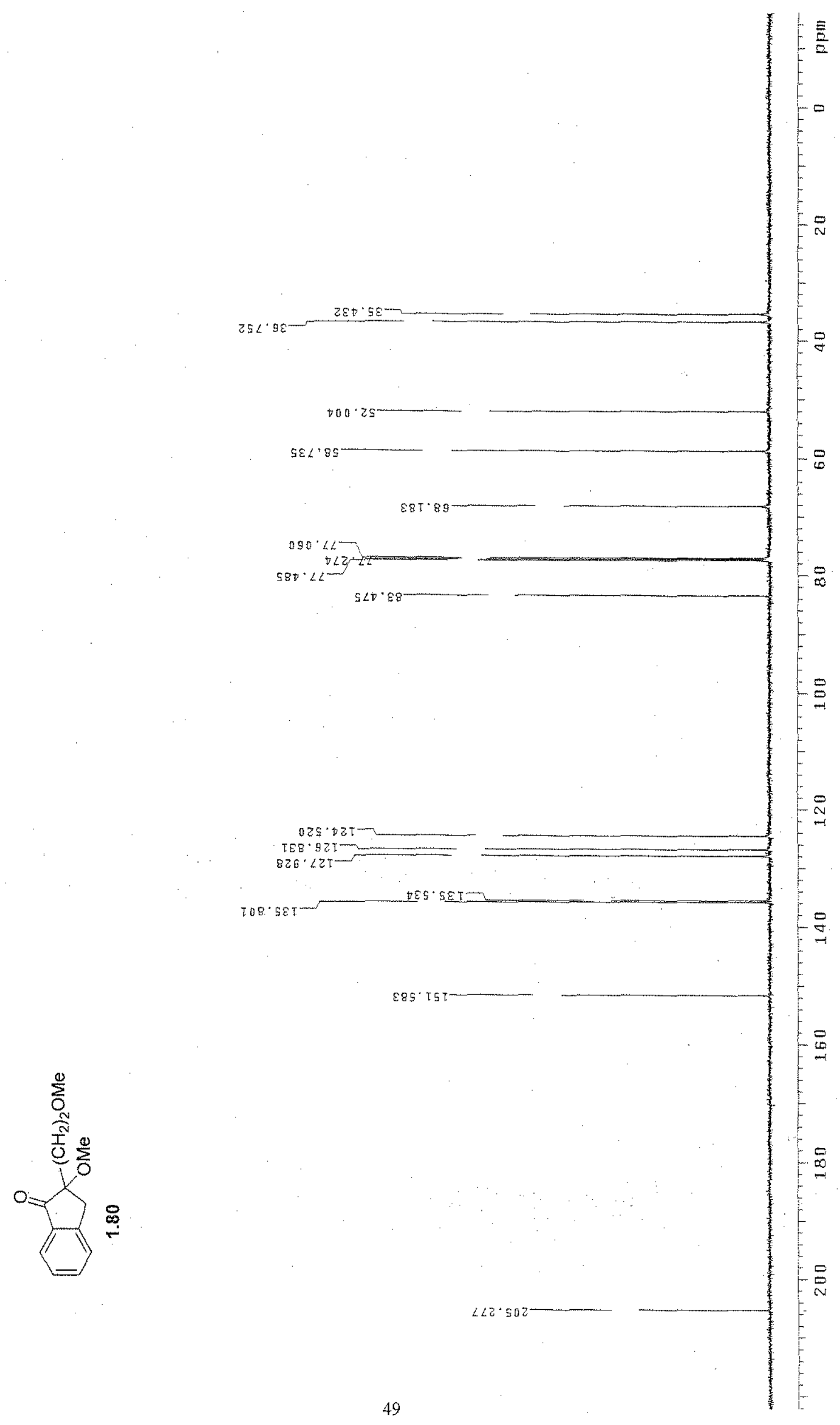




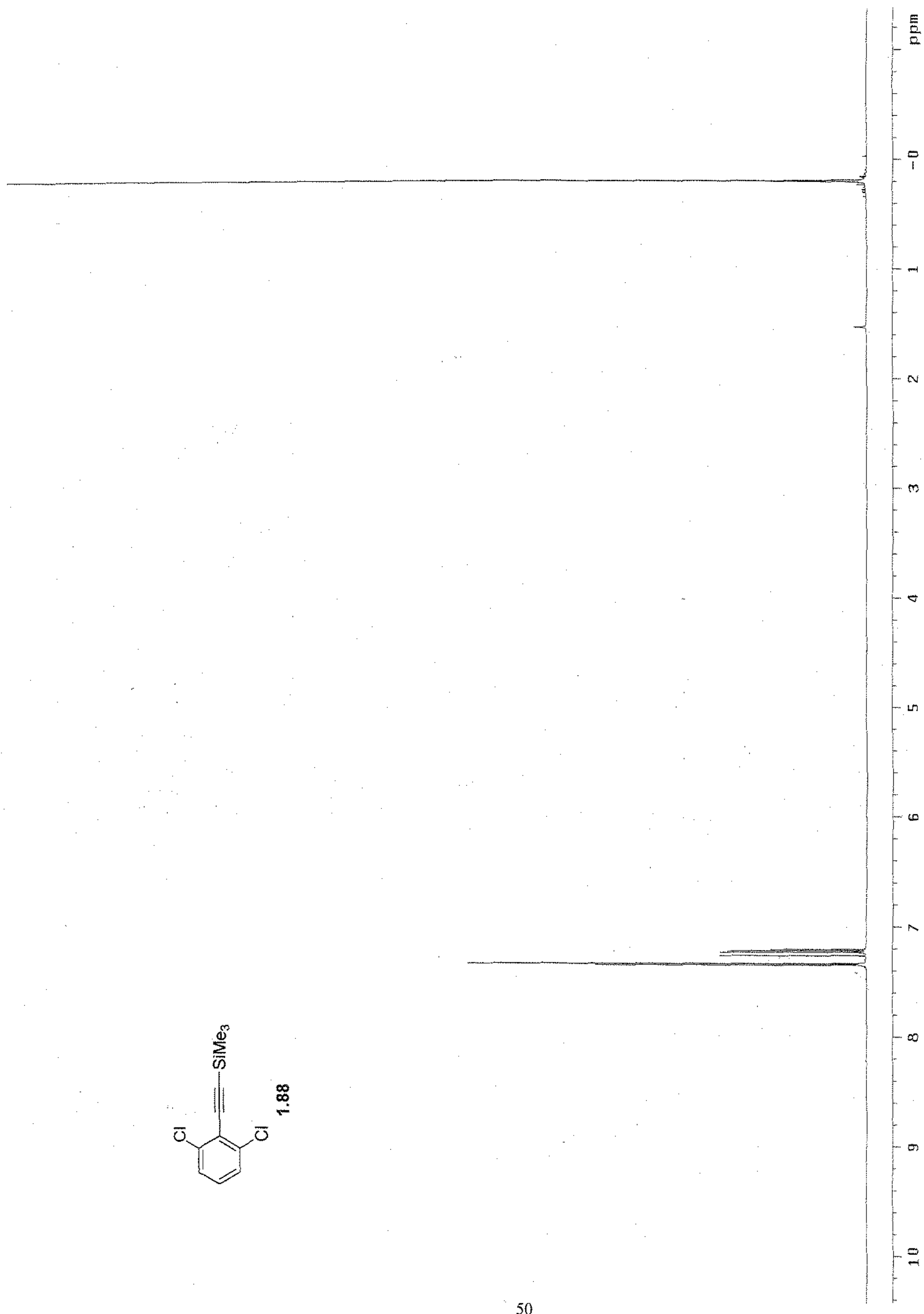




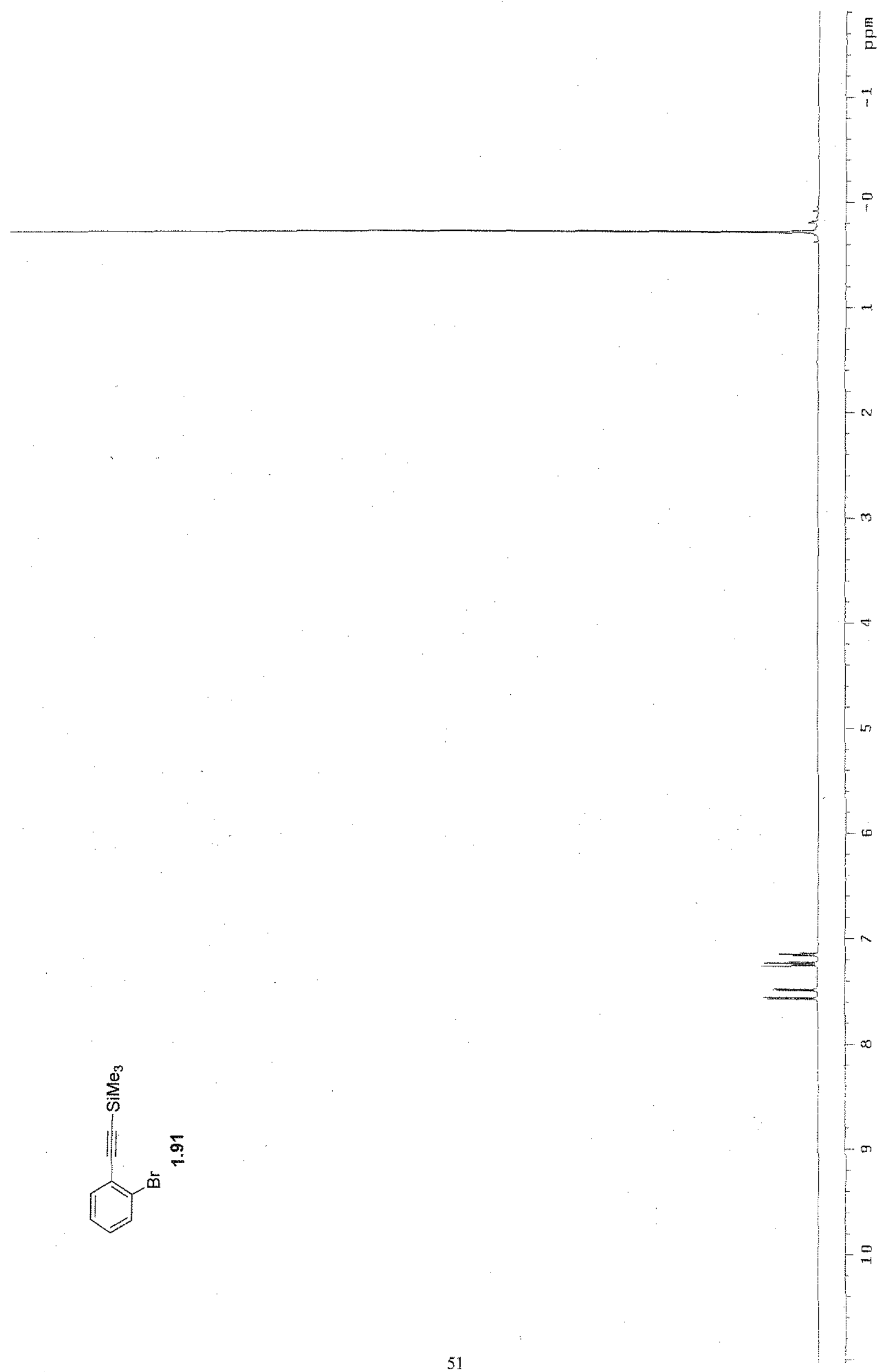




$\mid$




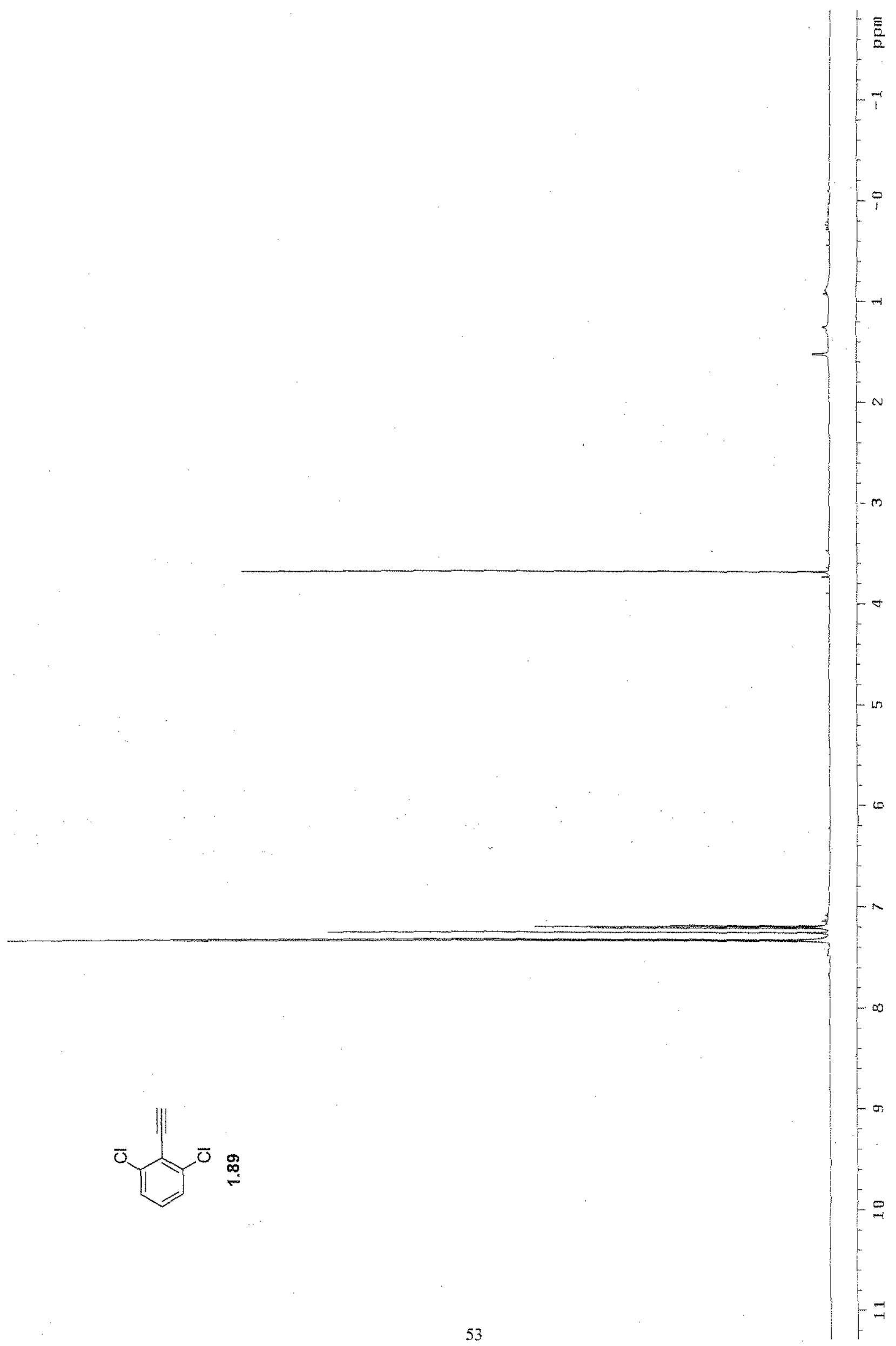




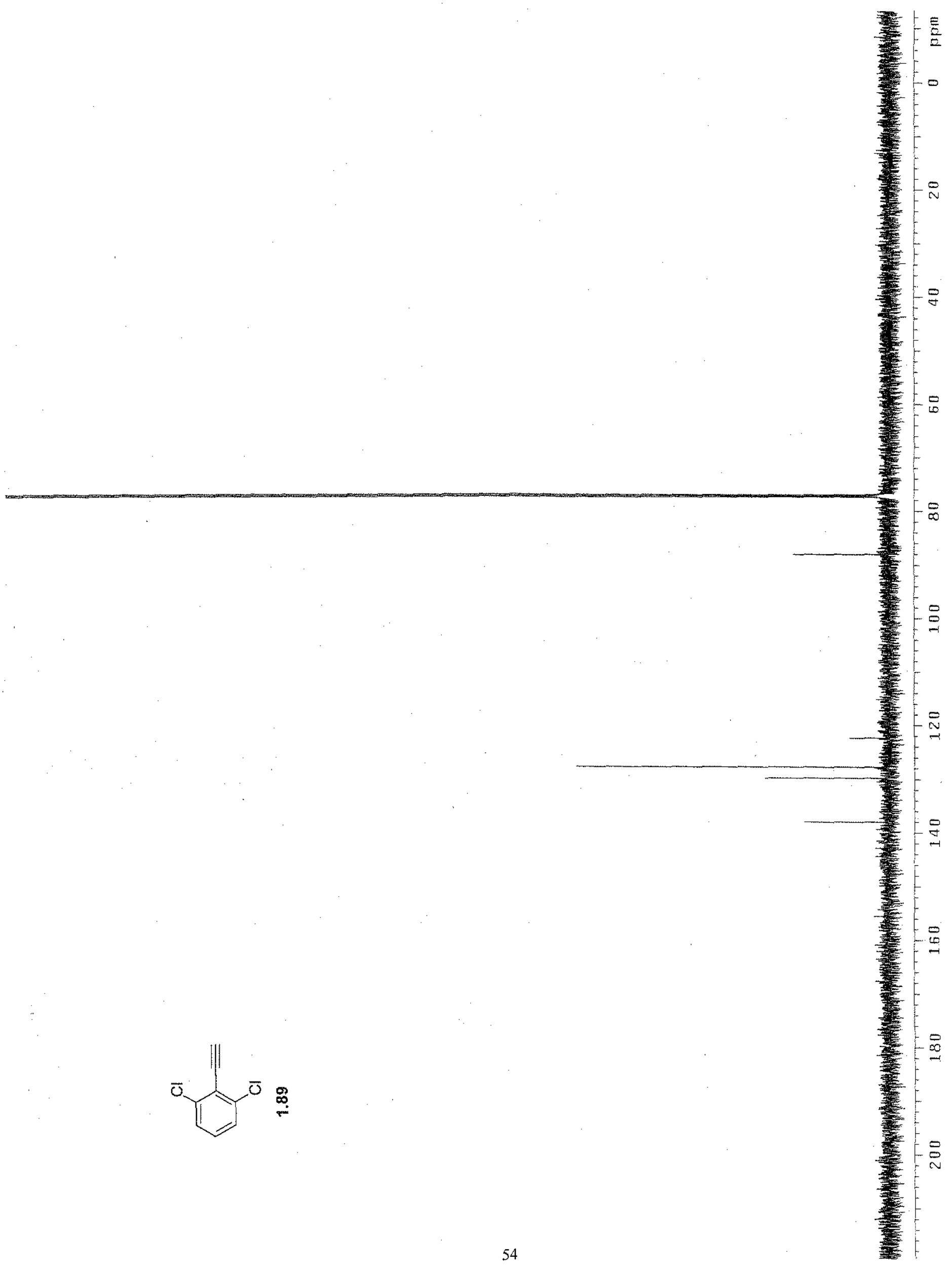




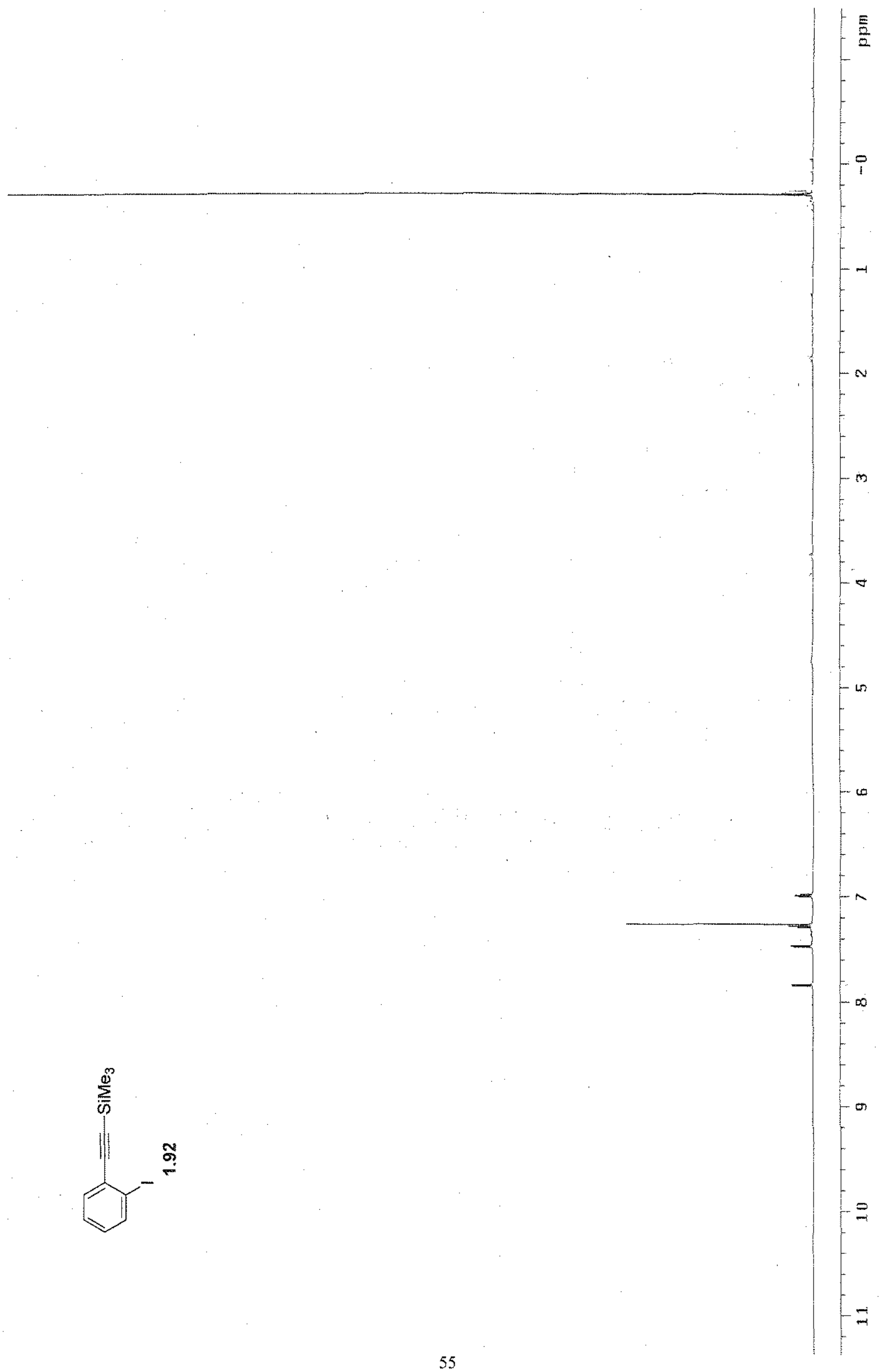




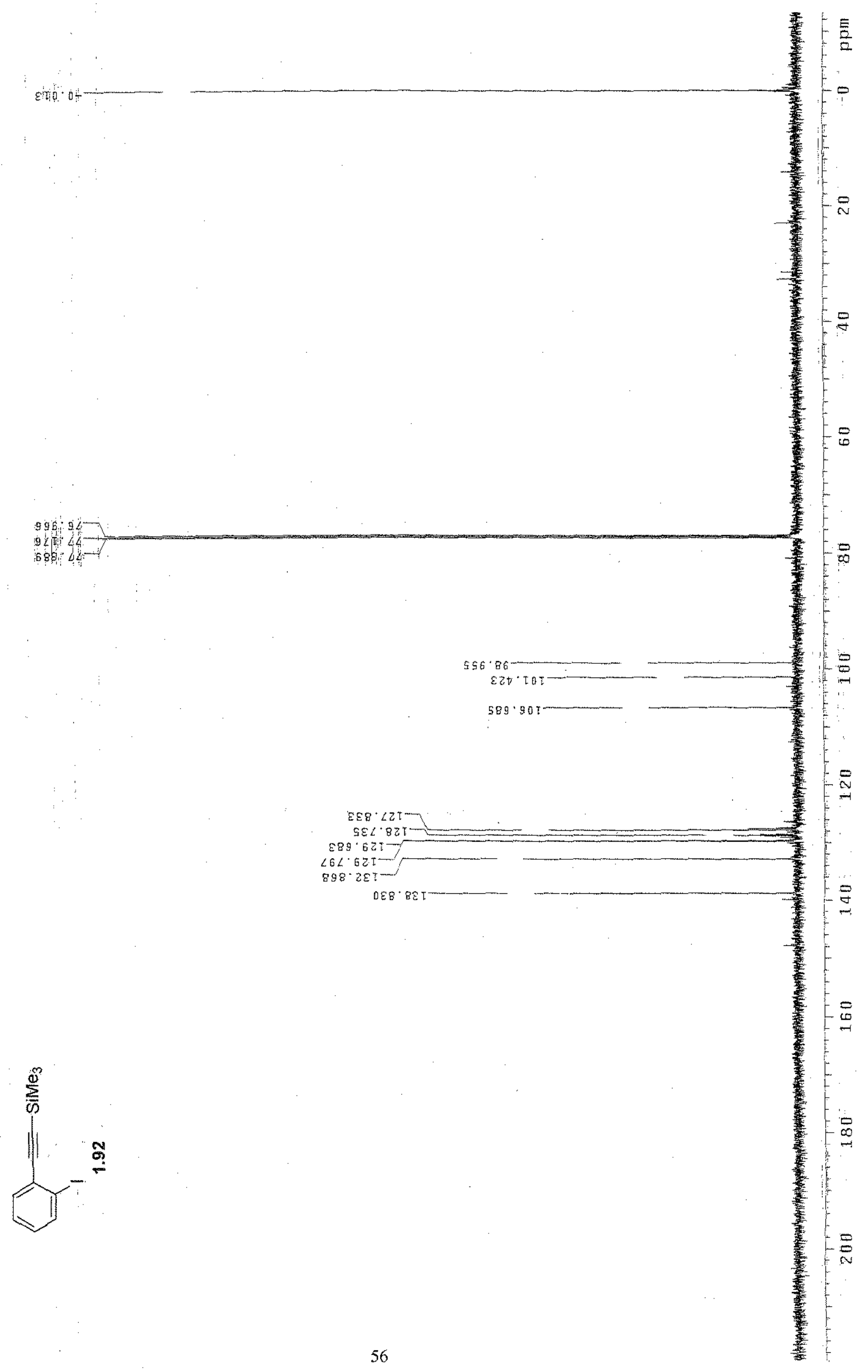




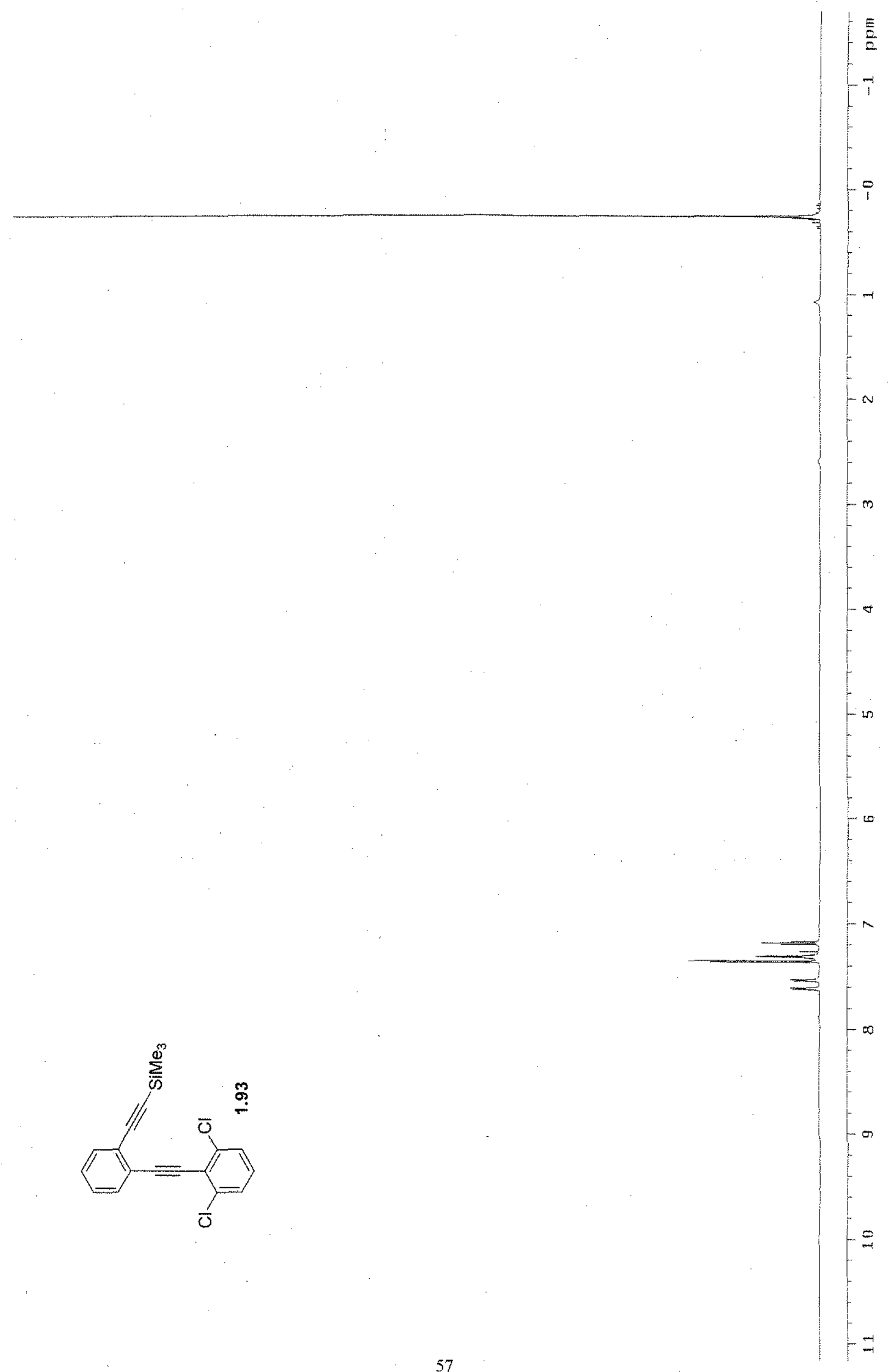




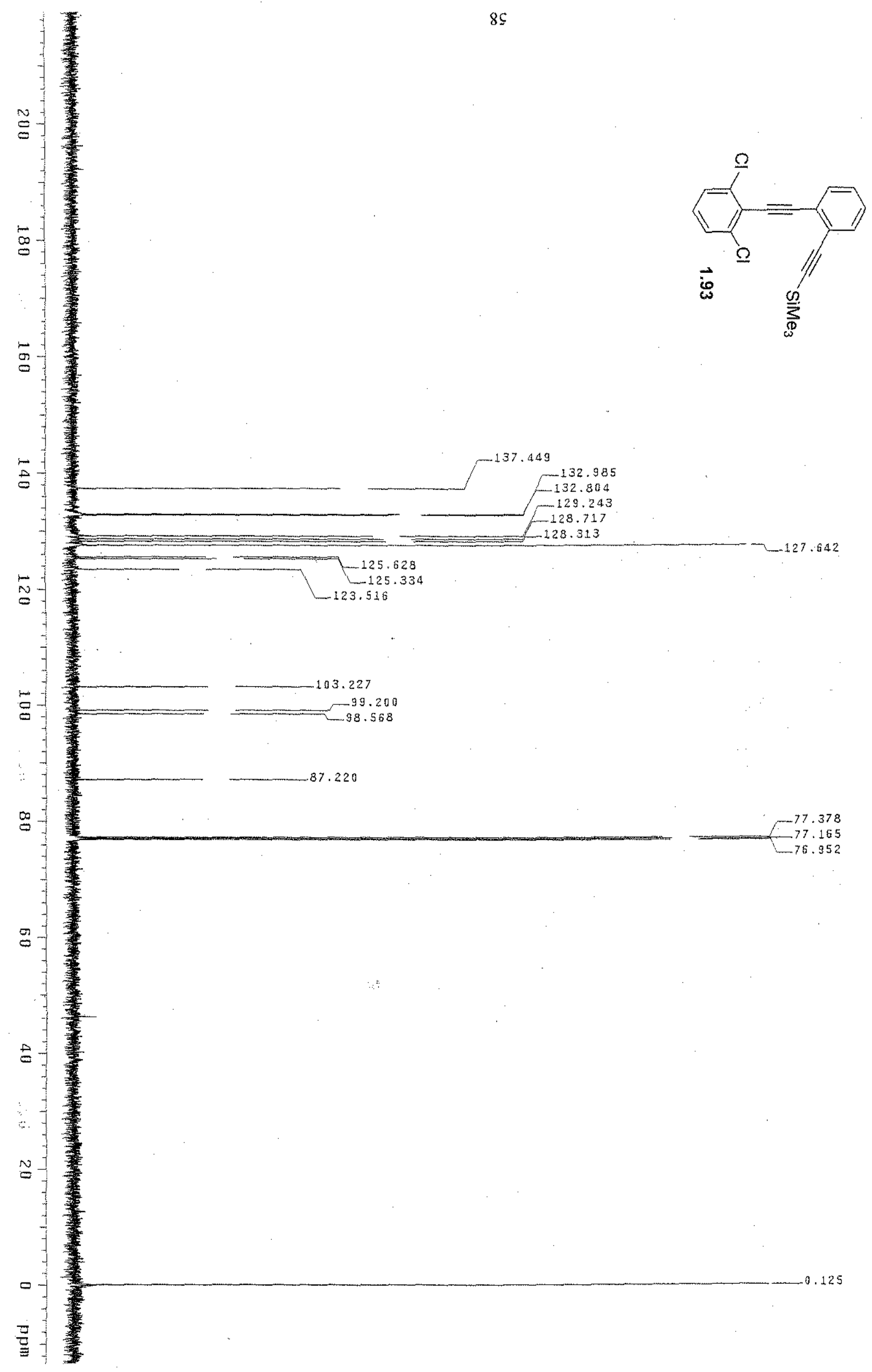




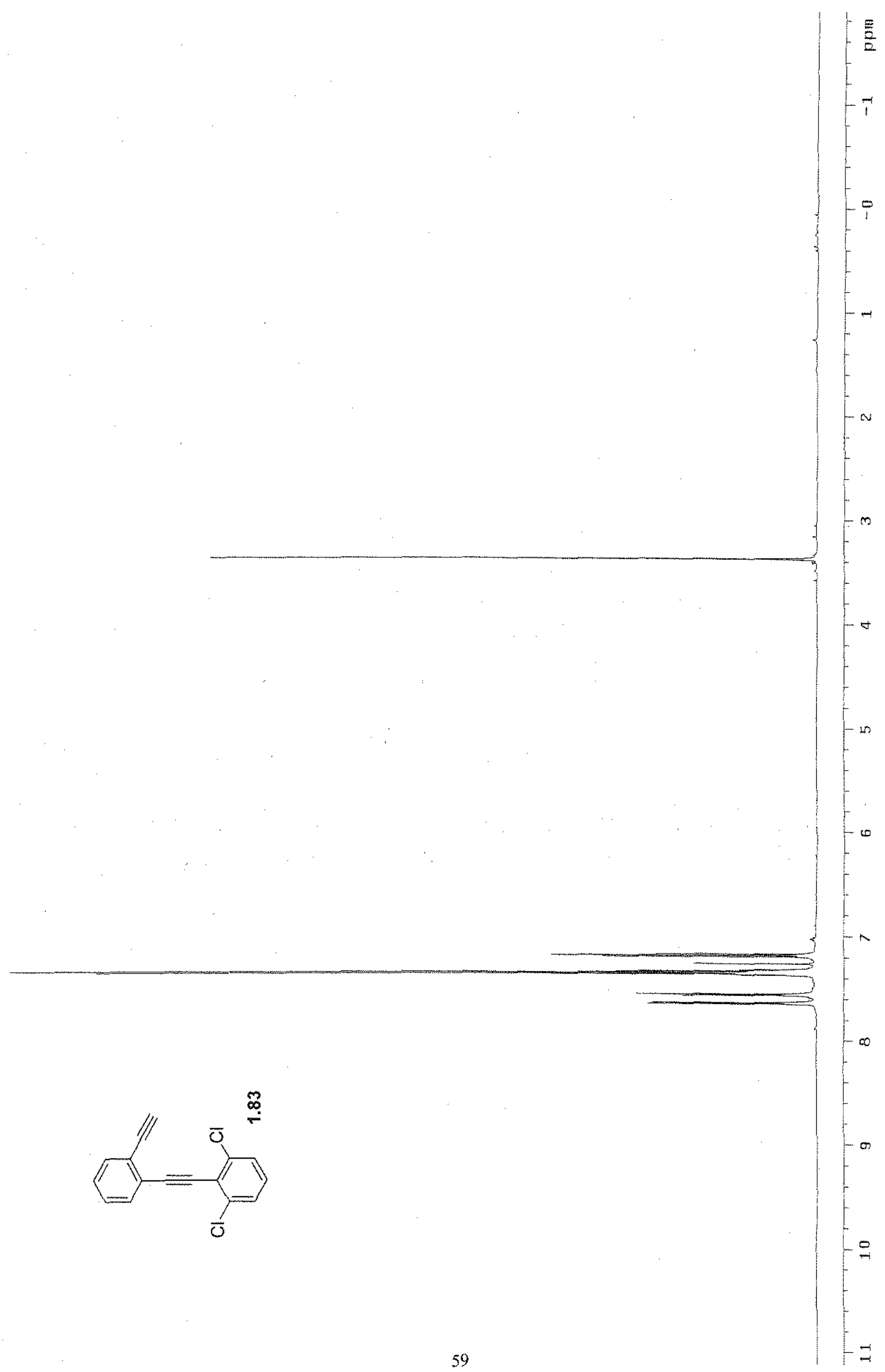




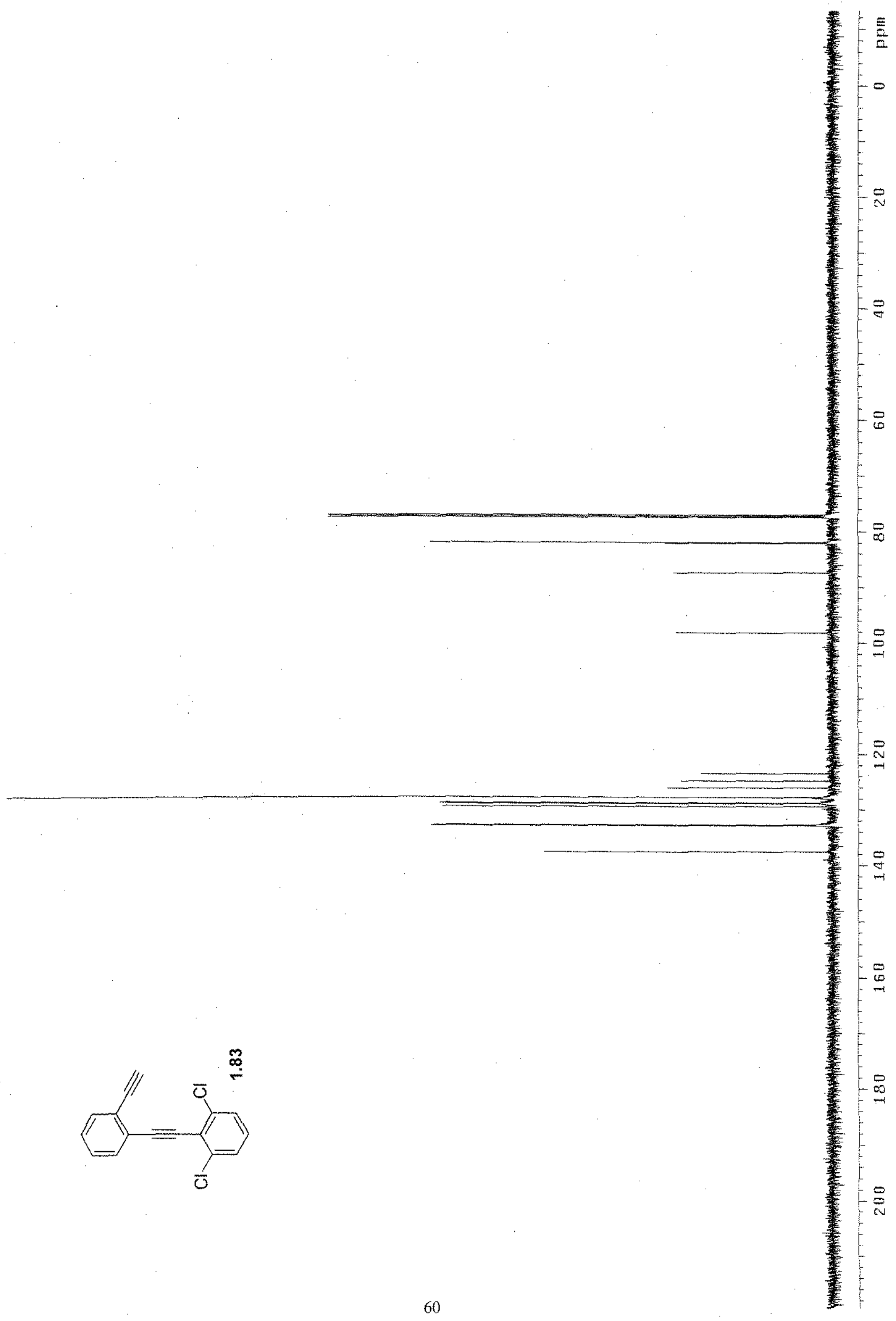




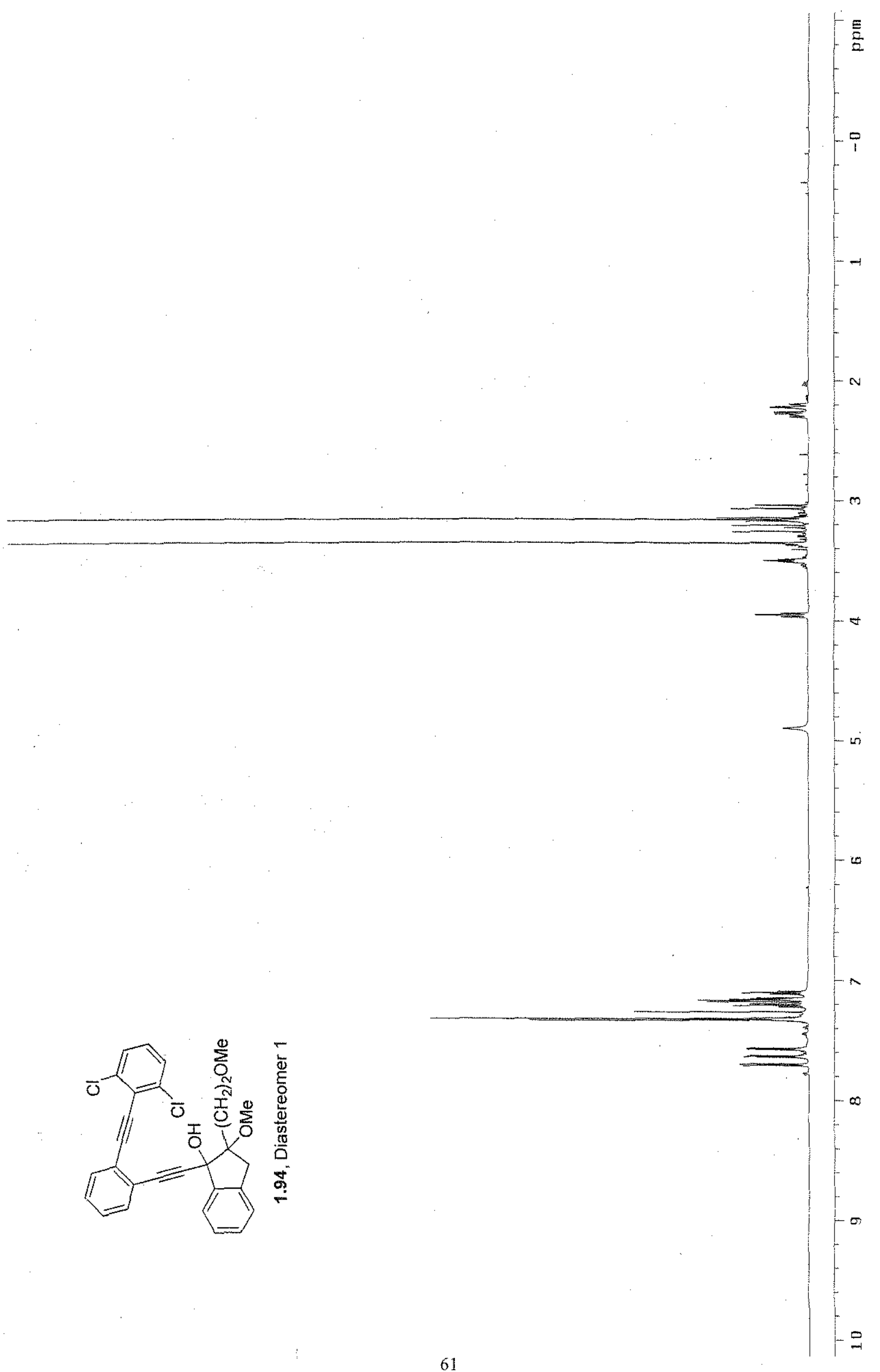




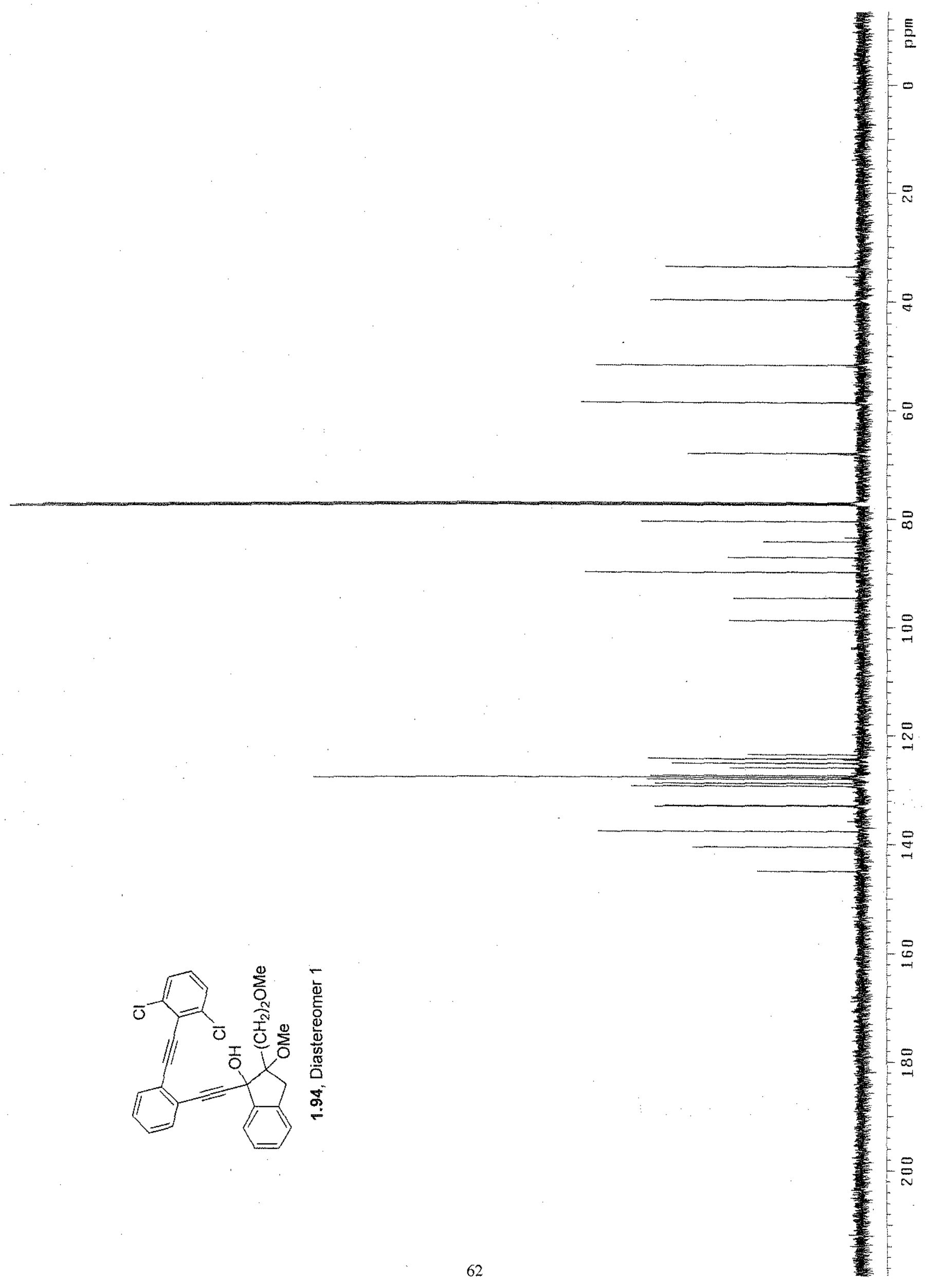




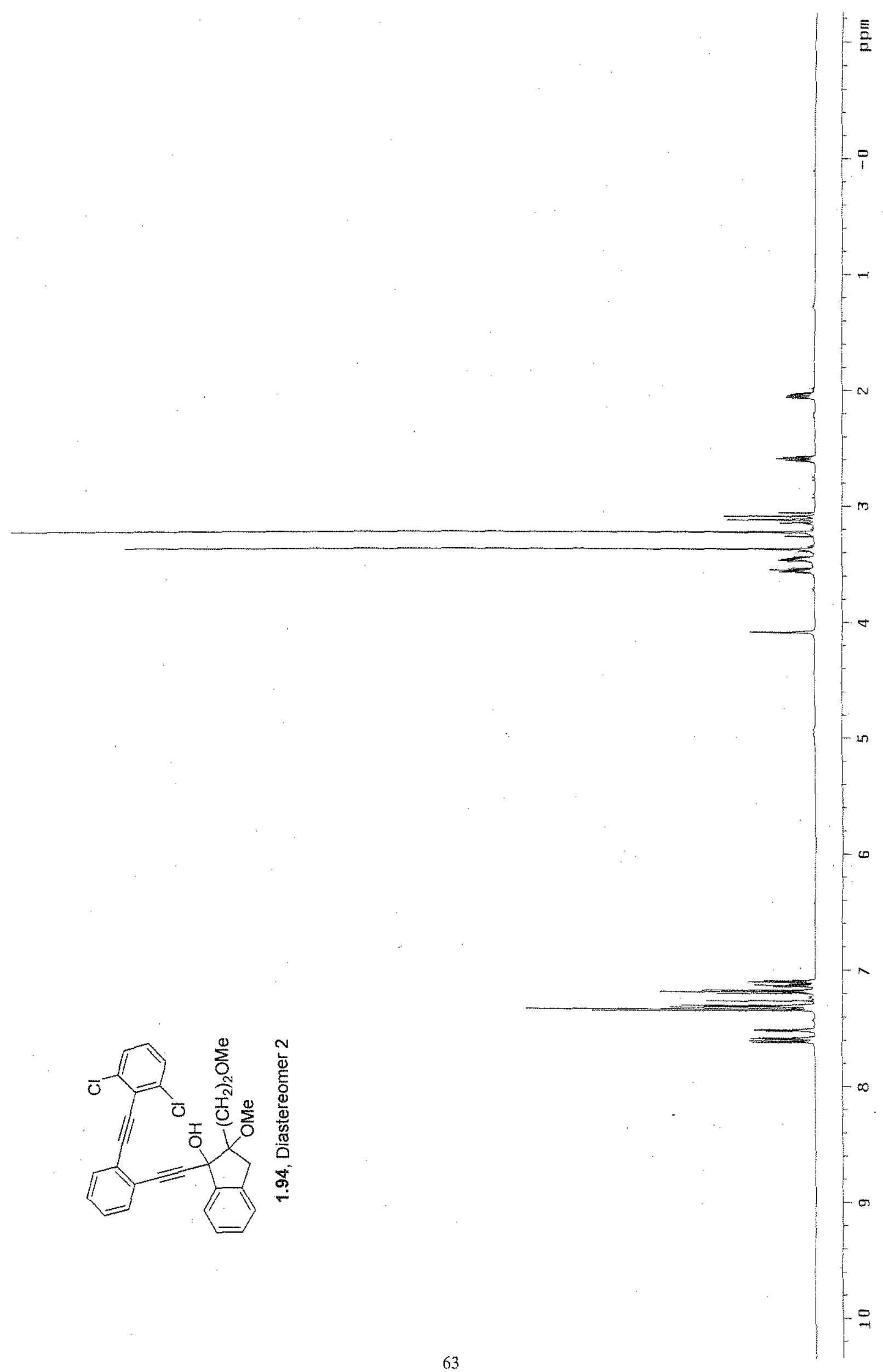




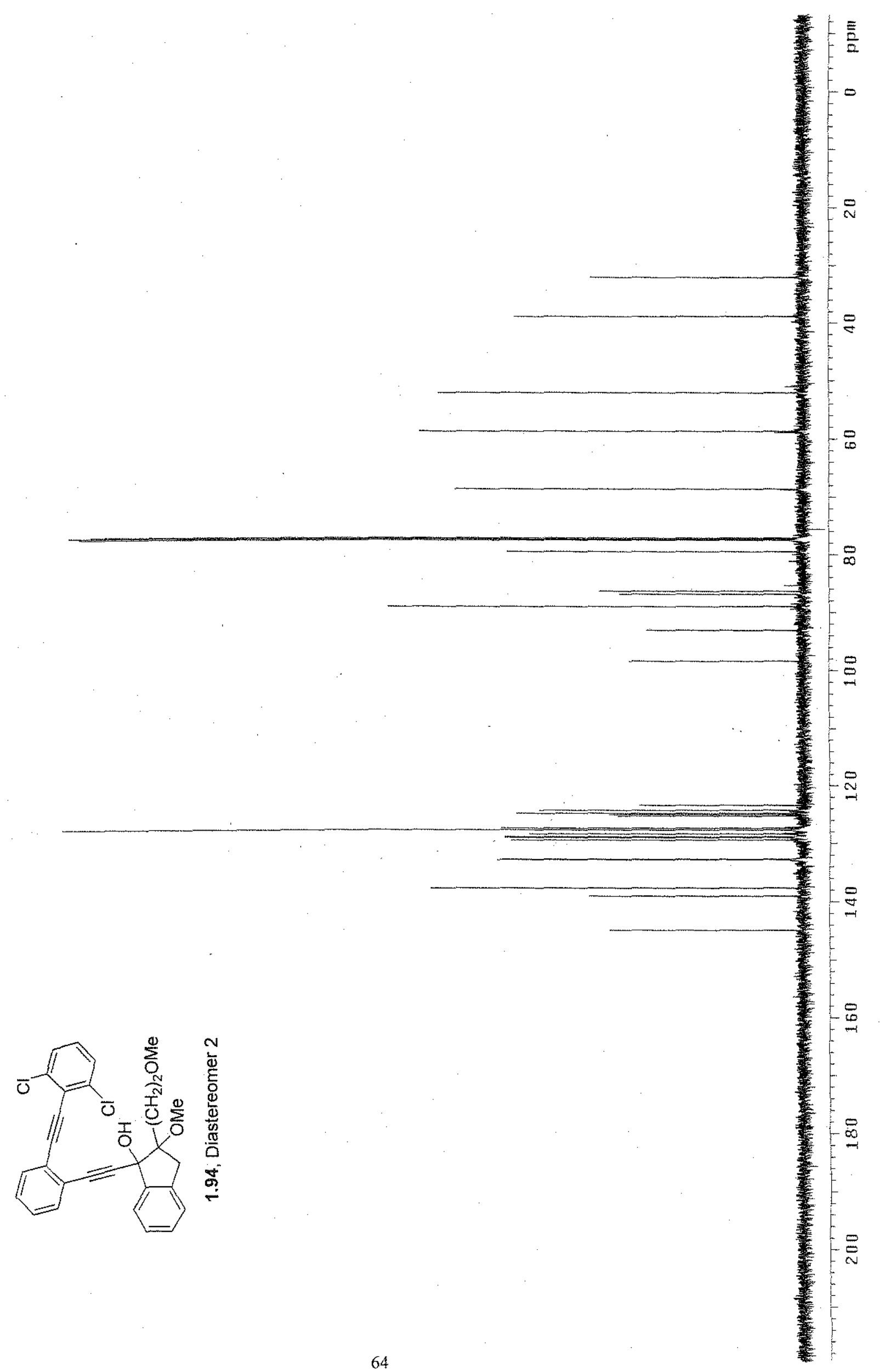




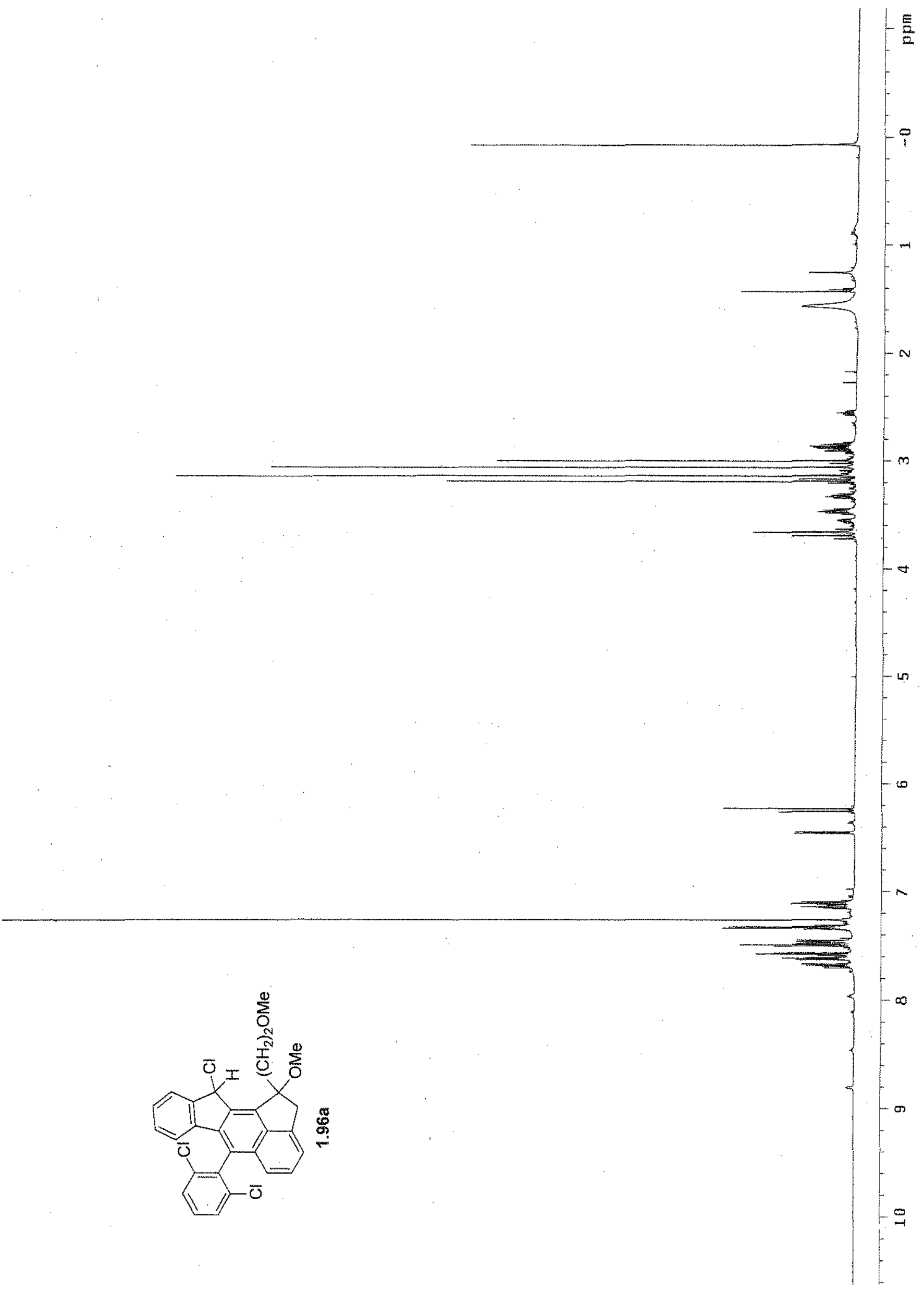




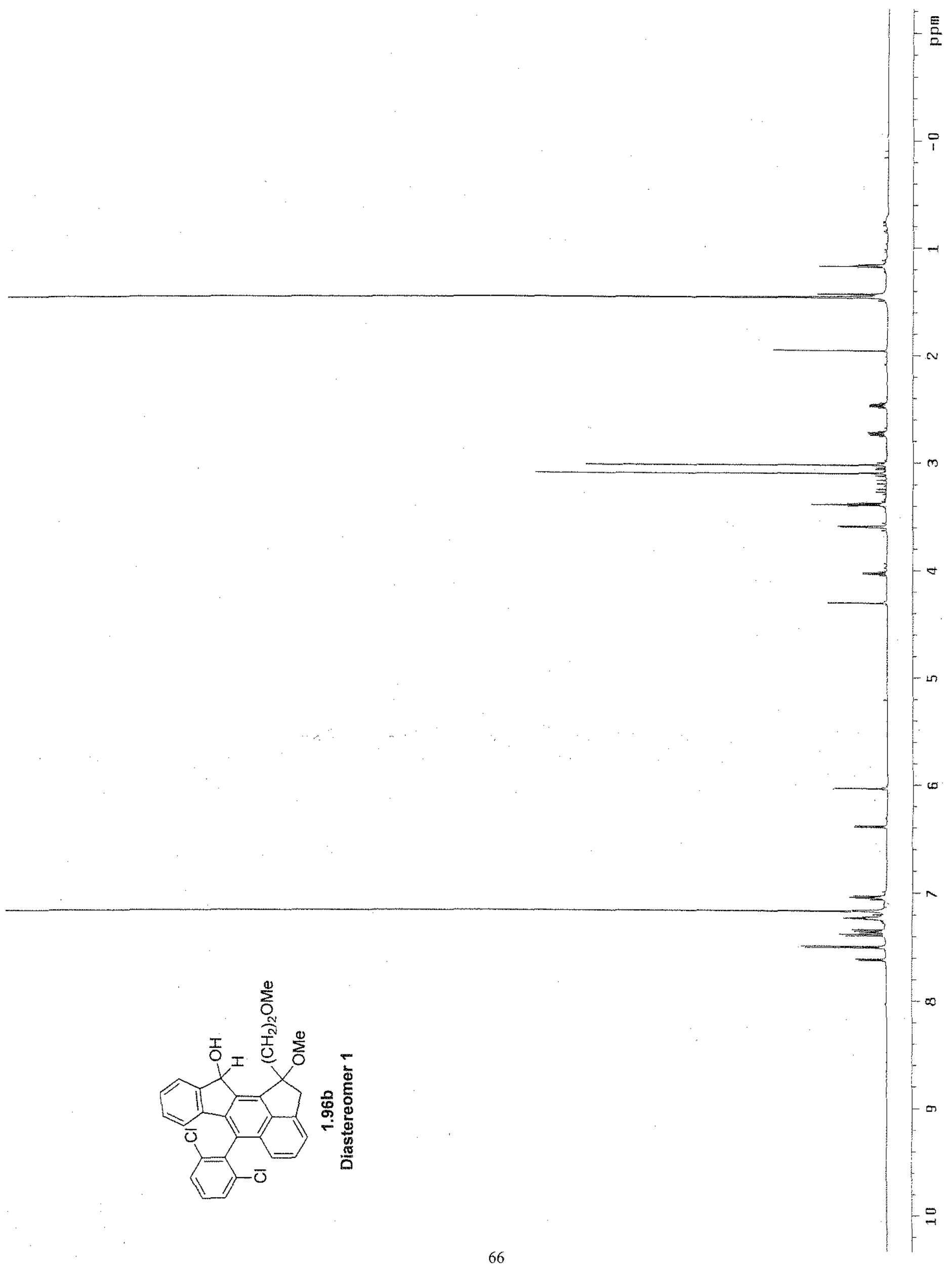




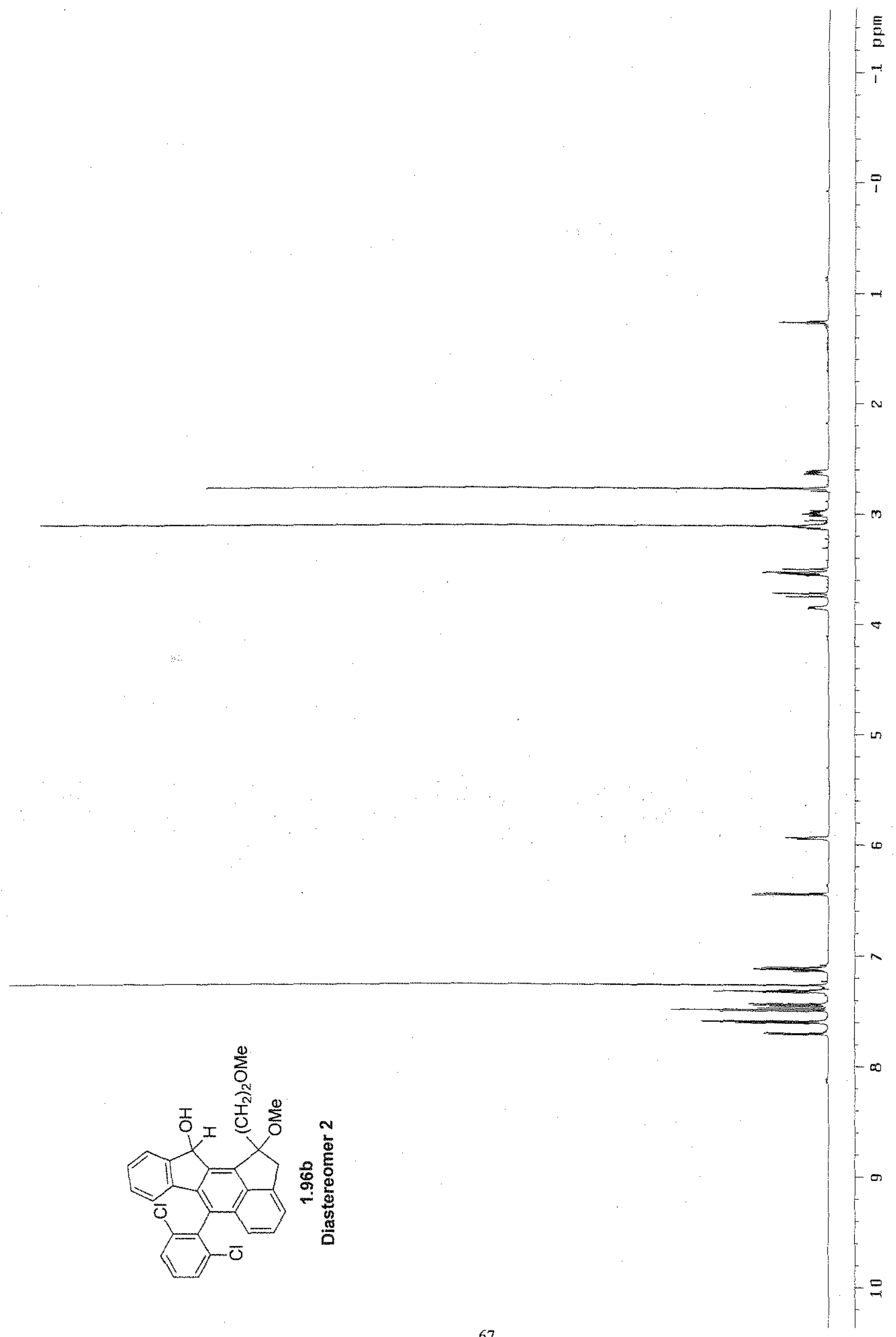




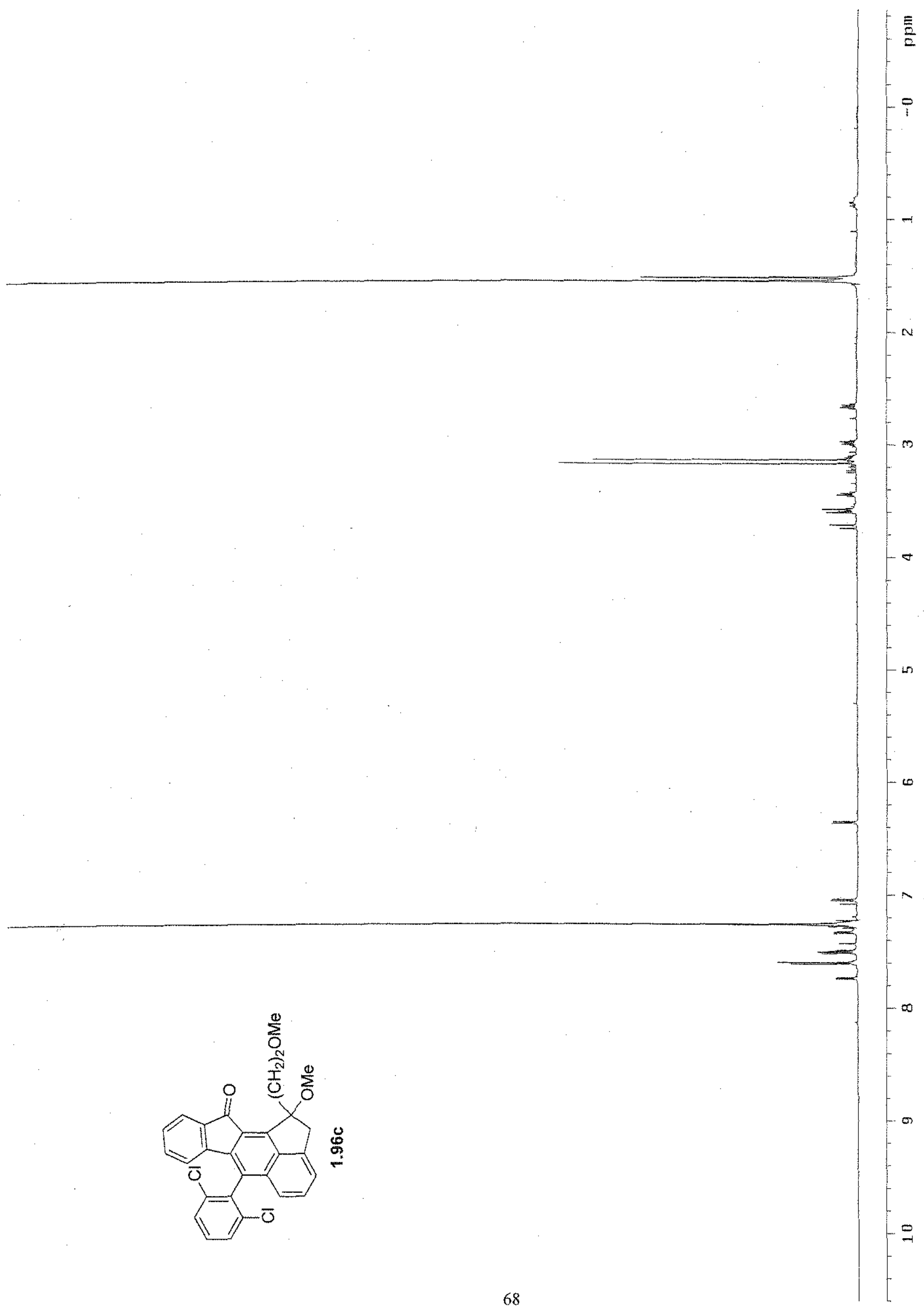




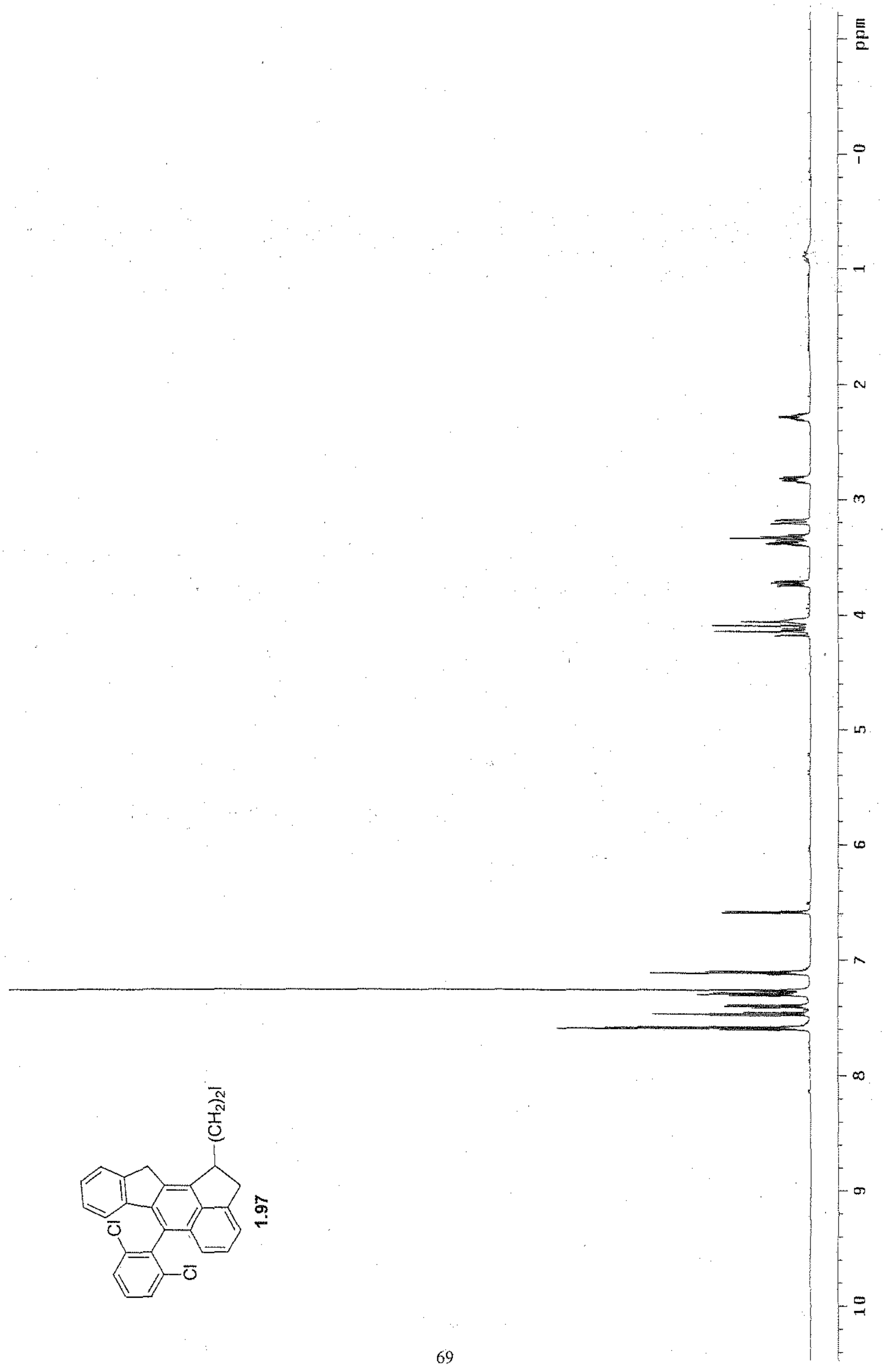




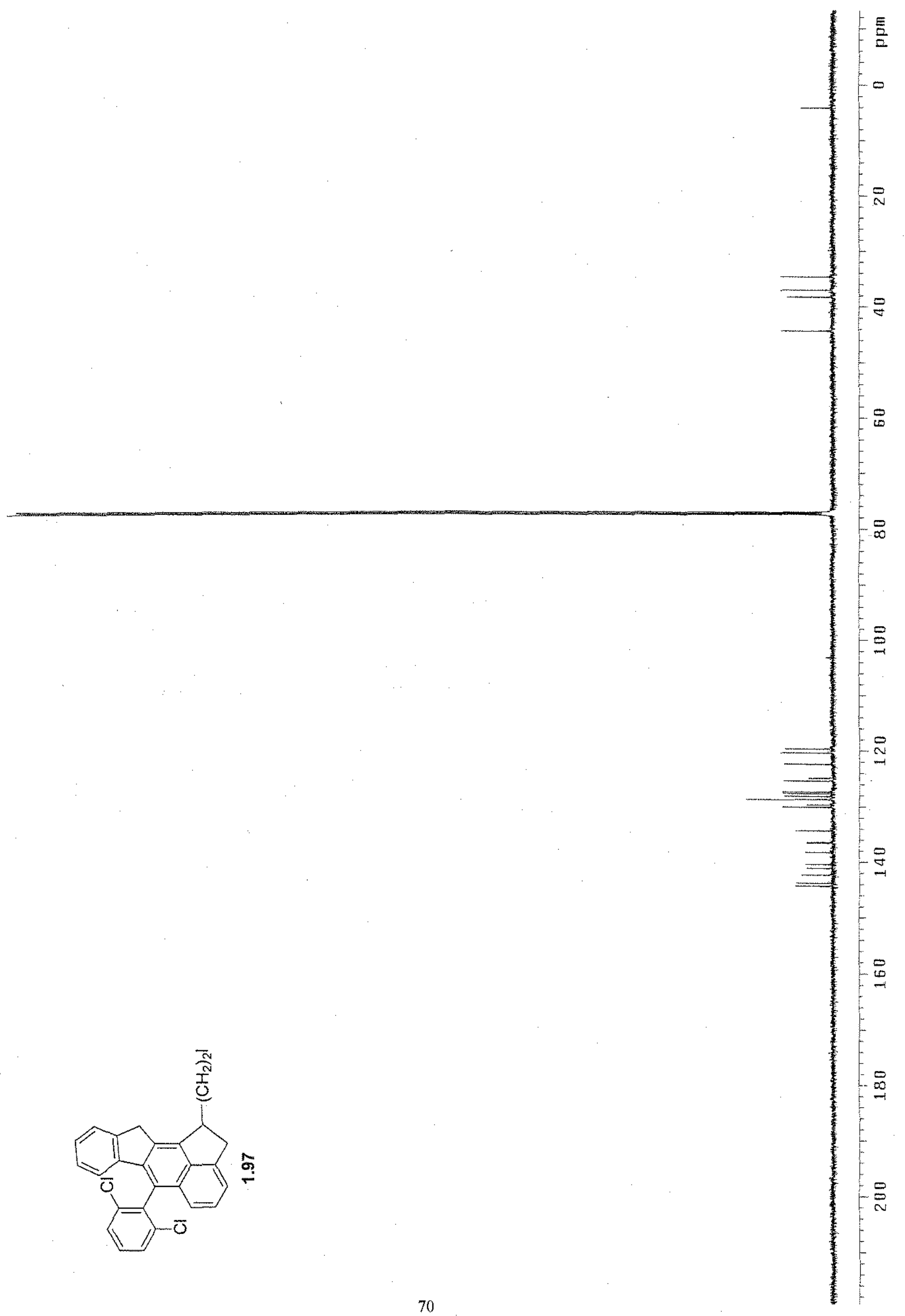




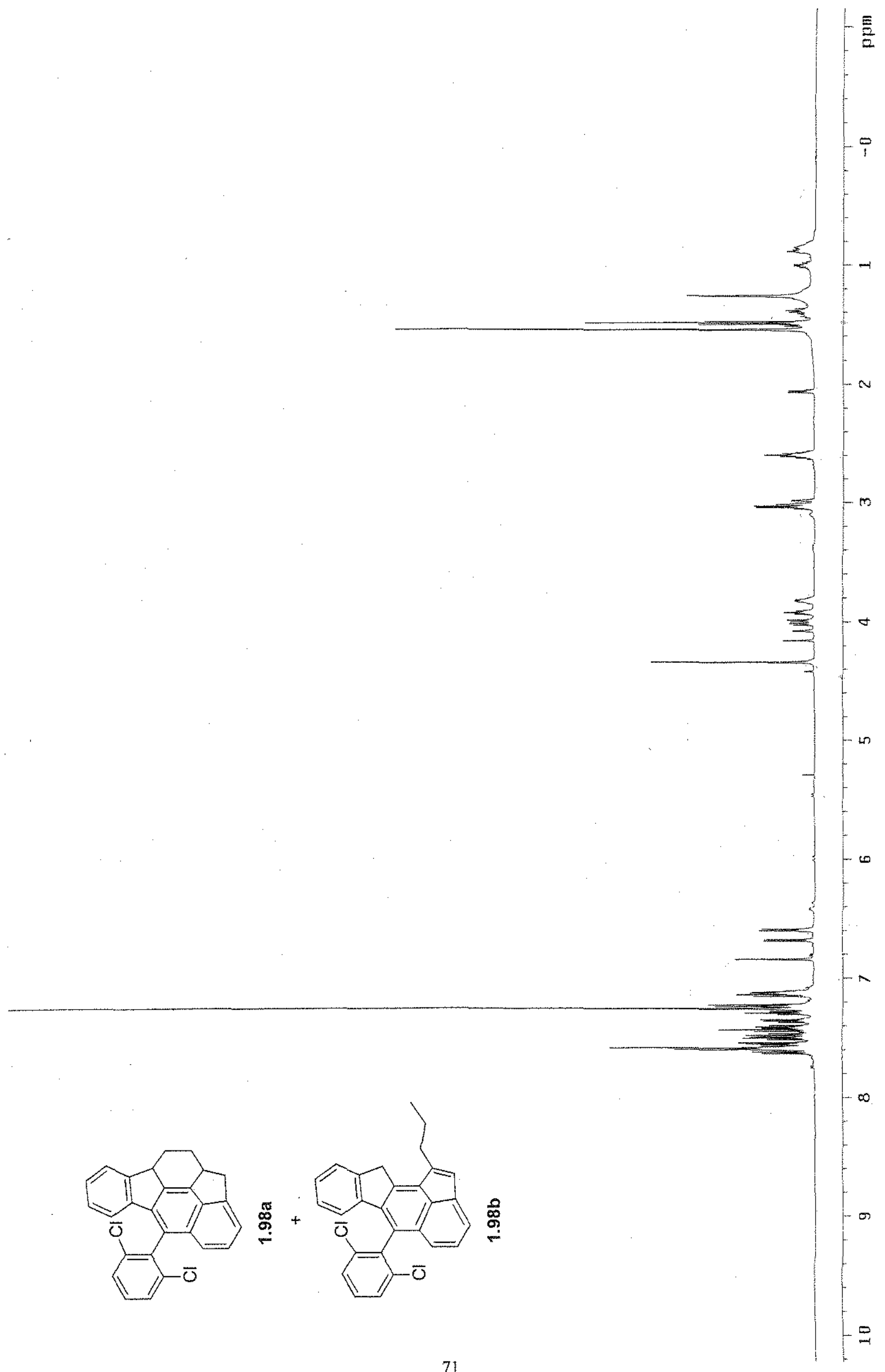




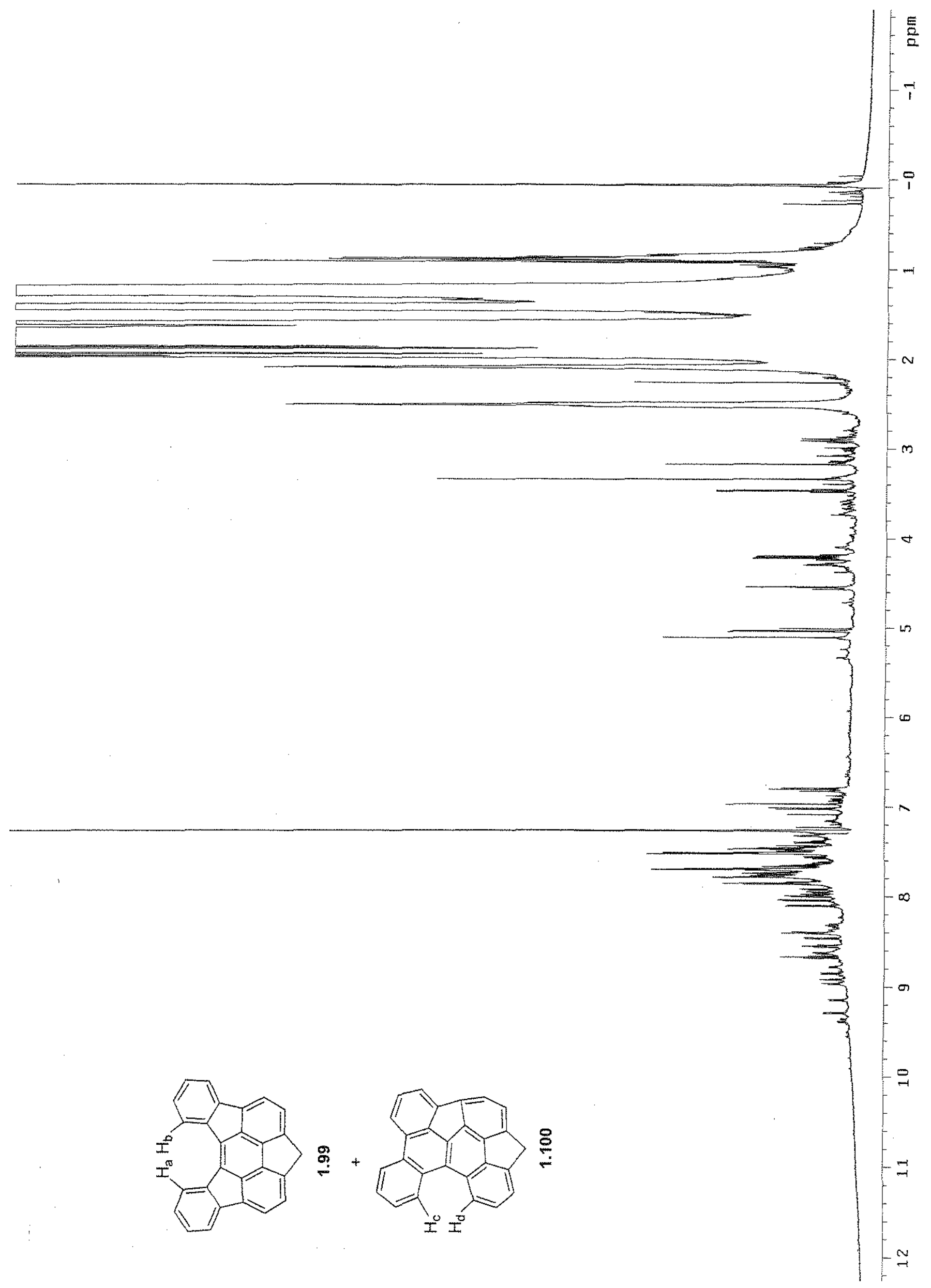




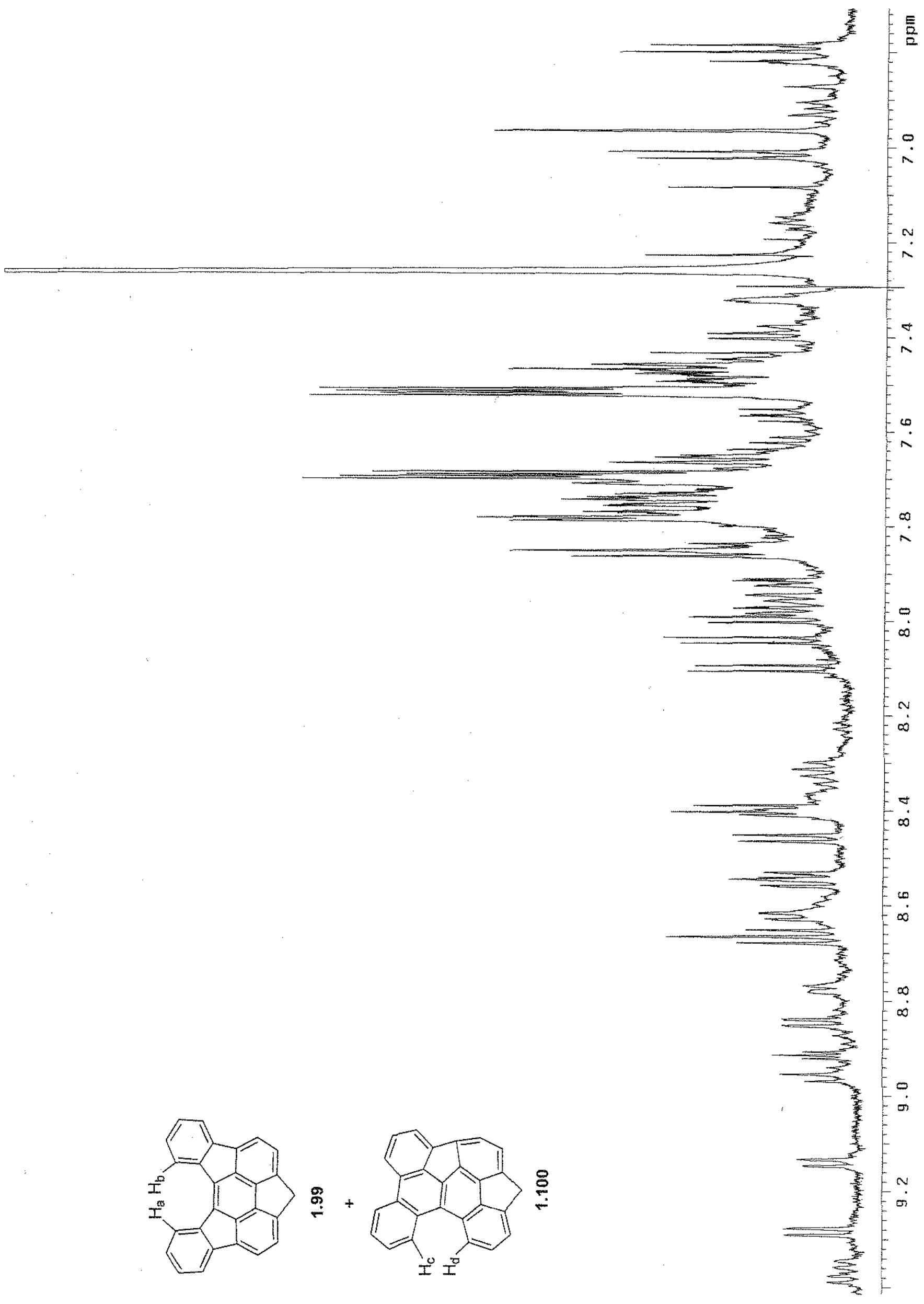


Development of a Synthetic Pathway Toward a Bowl-Shaped $\mathrm{C}_{27} \mathrm{H}_{12}$ Polycyclic Aromatic Hydrocarbon

Yang-Sheng Sun

Thesis submitted to the Eberly College of Arts and Sciences at West Virginia University in partial fulfillment of the requirements

for the degree of

Master of Science

in

Organic Chemistry

C. Eugene Bennett Department of Chemistry

APPROVAL OF THE EXAMINING COMMITTEE

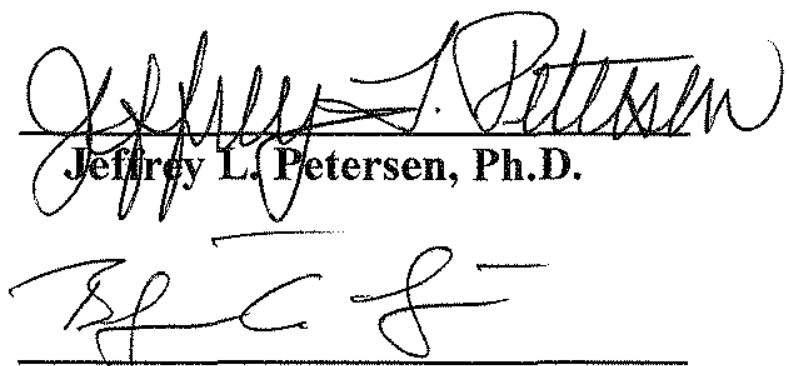

Bjôrn C. Söderberg,Ph. D.

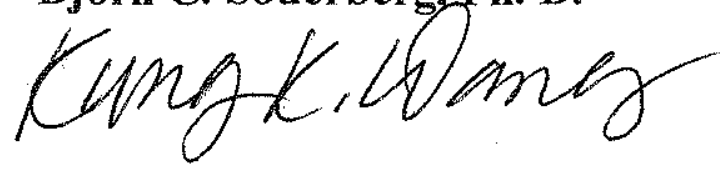

Kung K. Wang, Ph. D., Chair

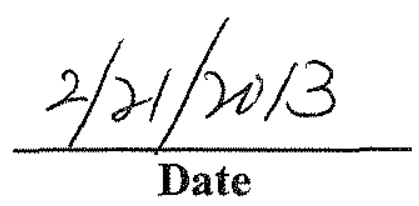

